\title{
4 Gewalt an Tyrannen
}

\subsection{Diokletian}

\subsubsection{Erste Krankheitsanzeichen. Lact. mort. pers. 17}

Nicht nur die Gewalt, die Tyrannen ausüben, korreliert mit ihrem Charakter, auch die Gewalt, die an ihnen verübt wird, steht in unmittelbarem Zusammenhang zum Charakter und Handeln der Tetrarchen. Auch die Krankheit, die Diokletian befällt, ist eine Beeinträchtigung seines körperlichen Wohlbefindens, die von Gott verhängt wird. Den Anstoß für seine Erkrankung bietet Diokletian durch sein tyrannisches Verhalten selbst. Er bringt sich selbst in die Situation, die ihn krank macht und der Auslöser ist eine seiner Tyranneneigenschaften - er erträgt das Glück seines Volkes nicht:

\begin{abstract}
Nachdem die jährlichen Feiern abgehalten worden waren, brach er, weil er die Freiheit des römischen Volkes nicht ertragen konnte, ungeduldig und übel gesinnt aus der Stadt auf, obwohl die Kalenden des Januar bevorstanden, an denen jener das neunte Konsulat erhalten sollte. Er konnte dreizehn Tage nicht aushalten, damit er eher in Rom als in Ravenna als Konsul in Erscheinung treten wollte; aber nachdem er im heftigen Winter aufgebrochen war und von Kälte und Regenschauern geschlagen worden war, zog er sich eine leichte, aber doch ewig anhaltende Krankheit $\mathrm{zu}$, und vor Qualen wurde er den gesamten Weg größtenteils in einer Sänfte getragen. ${ }^{1}$
\end{abstract}

Diokletian breche verfrüht von den jährlichen Feierlichkeiten auf, obwohl ihm kurz darauf in Rom erneut das Konsulat verliehen werden sollte. Weil er Freiheit und Freude des römischen Volkes nicht ertragen könne, reise er nach Ravenna. Die schlechten Wetterbedingungen ließen ihn erkranken bis er schließlich getragen werden müsse.

Wie bereits an anderer Stelle gezeigt werden konnte, ${ }^{2}$ ist es für Laktanz ein Zeichen von Tyrannei, dass Diokletian die Freiheit seines Volkes nicht erträgt. Er ist durch das Glück seiner Untertanen unglücklich und verlässt deshalb Rom. Laktanz erweckt den Eindruck, dass Diokletian nur wegen seines verfrühten Aufbruchs krank geworden sei und dies nicht passiert wäre, wenn er sich eines Kaisers angemessen verhalten hätte und bis zur Ernennung zum Konsul in Rom geblieben wäre. Auch wenn die Ernennung Diokletians zum Konsul nur noch der Form wegen geschah, ist eine Abreise vor der

Anmerkung zu 4.1: In diesem Kapitel behandelte Textstellen: Lact. mort. pers. 17,1; 17,2 - 3; 17,4; 17,5; 17,$9 ; 42,1-2 ; 42,2-3$.

1 Quibus sollemnibus celebratis cum libertatem populi Romani ferre non poterat, impatiens et aeger animi prorupit ex urbe impendentibus Kalendis Ianuariis, quibus ille nonus consulatus deferebatur. tredecim dies tolerare non potuit, ut Romae potius quam Ravennae procederet consul, sed profectus hieme saeviente, frigore atque imbribus verberatus morbum levem, at perpetuum contraxit, vexatusque per omne iter lectica plurimum vehebatur. Lact. mort. pers. 17,2-3 (Brandt/Laubmann 1897, 19024191,5).

2 Vgl. Seite 58 in dieser Arbeit.

Ә OpenAccess. () 2021 Gianna Zipp, publiziert von De Gruyter. (cc))BY 
Ernennung doch ein deutlicher Affront gegen das Staatswesen und das Volk. Laktanz konstatiert, dass Gott für die Bestrafung der Christenverfolger verantwortlich ist. ${ }^{3}$ Krankheit kann in der Antike oftmals als göttliche Strafe verstanden werden, sodass auch hier ohne explizite Nennung eines göttlichen Urhebers eine naheliegende Schlussfolgerung ist, dass Gott involviert sei. Dies offenbart sich in der Tatsache, dass die Krankheit unmittelbar an ein Verbrechen Diokletians anknüpft. Im vorangehenden Kapitel wird die Folter der Christen unter Diokletian beschrieben. Nach einem Lob an Donatus und einem Erzählerkommentar, beginnt das 17. Kapitel mit den Worten „Nachdem dieses Verbrechen begangen worden war, ist Diokletian also [...]“4 . Der Leser kommt nicht umhin, den kausalen Zusammenhang zu erkennen.

Die Krankheit selbst wird als levis beschrieben, also nicht tödlich, zieht sich aber über einen sehr langen Zeitraum hin. Es stellt sich die Frage, ob Diokletians Verhalten während seiner Krankheit einen Einfluss auf die Dauer der Krankheit hat. Die Reise, die ein Ausdruck seines schlimmen Charakters ist, ist Auslöser der Krankheit. Dennoch hält ihn sein Gesundheitszustand nicht davon ab, weitere Reisen zu unternehmen. Statt sich zu schonen und vollständig zu genesen, reist er weiter:

Nachdem er den Sommer damit verbrachte, das Ufer der Donau entlangzuziehen, kam er nach Nikomedien, als die Krankheit schon heftiger drängte: ${ }^{5}$

Nikomedien sei das Ziel, das Diokletian trotz seiner schlechten Verfassung erreichen wolle. Hätte er nicht seinen Regierungssitz nach Nikomedien verlegt, ${ }^{6}$ sondern wäre in

3 Qui insultaverant deo, iacent, qui templum sanctum everterant, ruina maiore ceciderunt, qui iustos excarnificaverant, caelestibus plagis et cruciatibus meritis nocentes animas profuderunt. sero id quidem, sed graviter ac digne. distulerat enim poenas eorum deus, ut ederet in eos magna et mirabilia exempla, quibus posteri discerent et deum esse unum et eundem iudicem digna videlicet supplicia impiis ac persecutoribus inrogare Lact. mort. pers. 1,5-6 (Brandt/Laubmann 1897, 172,11-173,1; Creed 1897, 4,14-20): „Die, die Gott beleidigt hatten, liegen darnieder, diejenigen, die den heiligen Tempel zerstört hatten, sind in größerem Sturz gefallen, diejenigen, die die Gerechten martervoll zerfleischten, haben unter himmlischen Schlägen und verdienten Qualen den schädlichen Lebensatem ausgehaucht. Spät geschah dies zwar, aber bedeutungsschwer und würdig. Gott hatte nämlich deren Strafen verzögert, damit er an ihnen bedeutende und wundersame Exempel statuieren konnte, durch die die Nachkommen lernen sollte, dass es sowohl nur einen einzigen Gott gibt und dass dieser als Richter offenbar angemessene Strafen über die Gottlosen und Verfolger verhängt“. Vergleiche Seite 236f. in dieser Arbeit.

4 Hoc igitur scelere perpetrato Diocletianus Lact. mort. pers. 17,1 (Brandt/Laubmann 1897, 190,21).

5 Sic aestate transacta per circuitum ripae Istricae Nicomediam venit morbo iam gravi insurgente: Lact. mort. pers. 17,4 (Brandt/Laubmann 1897, 191,5-6): „So kam er, nachdem der Sommer vergangen war, durch einen Umweg am Ufer der Donau nach Nikomedien, als sich bereits eine schlimme Krankheit anbahnte“.

6 Vgl. ita semper dementabat Nicomediam studens urbi Romae coaequare Lact. mort. pers. 7,10 (Brandt/Laubmann 1897, 110-111): „so raste er immer, bemüht, Nicomedien an Rom anzugleichen“ und nam cum ipsam imperii sedem teneret Italiam Lact. mort. pers. 8,3 (Brandt/Laubmann 1897, 182,1-2): „denn weil er Italien selbst, den Sitz der Herrschaft, hält“. Laktanz erklärt, dass Rom das 
Rom geblieben, hätte er die beschwerliche Reise nicht auf sich nehmen müssen. Der Ausbruch seiner Krankheit kann also sowohl durch sein tyrannisches Handeln als auch durch die Strafe Gottes erklärt werden. Die Verschlechterung seines Zustandes lässt sich auf ein weiteres tyrannisches Verhaltensmerkmal Diokletians zurückführen: die Baulust. Als sich Diokletian schließlich entscheidet, auch weiterhin die Strafe Gottes zu ignorieren und sein Herrscherdasein fortzuführen, indem er den von ihm gebauten Zirkus besucht, erleidet er einen Schwächeanfall:

Schließlich wurde er von einem Schwächeanfall so niedergeworfen, dass bei allen Göttern für sein Leben gebeten wurde, solange bis an den Iden des Dezember plötzlich Trauer im Palast, Traurigkeit und Tränen der Richter, Zittern und Schweigen in der gesamten Bürgerschaft entstanden. ${ }^{7}$

Ein Schwächeanfall werfe Diokletian nieder. Erst nach diesem Schwächeanfall würden Maßnahmen zur Genesung Diokletians ergriffen. Am Hof Diokletians schlussfolgern die zuständigen Ärzte, dass göttliche Hilfe für die Genesung des Kaisers notwendig sei. Die gesamte Bürgerschaft werde von Trauer ergriffen. Laktanz nennt omnes dei und meint hiermit alle paganen Götter. Er übernimmt gedanklich den Standpunkt der Ärzte des Galerius, die zu all ihren Göttern beten, nicht aber zum christlichen Gott, der eigentlich für die Krankheit verantwortlich sei und diese auch heilen könnte. Laktanz urteilt nicht explizit über die Wahl der gesuchten Hilfe, zeigt aber im Verlauf der Krankheit, dass alle paganen Götter nutzlos sind. Da in der ersten Szene des Werkes, in der pagane Gottheiten angerufen werden, deutlich verbalisiert wird, dass es sich um Dämonen handelt und nicht um Götter, weiß der Rezipient auch an dieser Stelle, dass die Ärzte sich an Dämonen wenden, die Gott weit unterlegen sind. Wenn Gott der Initiator dieser Krankheit ist, können pagane Gottheiten den Gesundheitszustand Diokletians nicht beeinflussen.

An den Iden des Dezember verändert sich plötzlich die Stimmung im Palast und im Volk, ohne dass Laktanz hierfür einen Grund nennt. Der Kaiser werde für tot gehalten, bis er an den Kalenden des März vor das Volk trete. An diese Schilderung anschließend erfährt der Leser, dass Diokletian tot gewesen sei, aber dann wieder zum Leben gekommen sei:

Und jener hatte an den Iden des März nachdem er im Tod entschlafen war, den Lebensatmen wieder aufgenommen, aber nicht vollständig. Wahnsinnig war er nämlich geworden, sodass er in manchen Stunden den Verstand verlor, in anderen aber wieder zur Besinnung kam. ${ }^{8}$

eigentliche Zentrum des Reichs sei und deutet so an, dass die Verlagerung des Zentrums nach Nikomedien unrechtmäßig gewesen sei. Siehe hierzu auch Seite 49 und Seite 51, Anm. 37 in dieser Arbeit. 7 Deinde ita languore est oppressus, ut per omnes deos pro vita eius rogaretur, donec Idibus Decembribus luctus repente in palatio, maestitia et lacrimae iudicum, trepidatio et silentium tota civitate. Lact. mort. pers. 17,5 (Brandt/Laubmann 1897, 191,9-12).

8 Et ille Idibus Decembribus morte sopitus animam receperat, nec tamen totam. demens enim factus est, ita ut certis horis insaniret, certis resipisceret. Lact. mort. pers. 17,9 (Brandt/Laubmann 1897, 191,19192,2). 
Laktanz beschreibt im unmittelbar vorangehenden Kapitel 15 die erste Welle der Christenverfolgung, bei der Diokletian seine Bediensteten und seine Familie zum Opfern zwingt, und die Auswüchse für das gesamte Reich. Er schließt die Beschreibung der Verfolgung mit einem Verweis auf die schrecklichsten Bestien, die über den Erdkreis herrschen. ${ }^{9}$ Das Lob auf Donatus verdeutlicht an einem Einzelbeispiel, wie sehr Christen unter den Verfolgungen $\mathrm{zu}$ leiden hatten ${ }^{10}$ und dürfte wohl großes Mitleid bei den Rezipienten hervorgerufen haben. Unmittelbar an die bildhafte Beschreibung der grausamen Taten des Diokletians schließt nun dessen Krankheit an, die im Wahnsinn ${ }^{11}$ gipfelt. Der Wahnsinn ist irreversibel und haftet Diokletian an wie ein Zeichen seiner Frevel. Laktanz macht mit der Formulierung morte sopitus animam receperat deutlich, dass Diokletian tatsächlich gestorben sei: Der Indikativ verhindert jede Spekulation. Würde es sich nur um ein Gerücht handeln, das Laktanz für unglaubhaft hält, würde er wie bei Nero Stellung dazu beziehen. ${ }^{12}$

9 Vgl. Vexabatur ergo universa terra et praeter Gallias ab oriente usque ad occasum tres acerbissimae bestiae saeviebant. Lact. mort. pers. 16,1 (Brandt/Laubmann 1897, 189,9-10): „Gequält wurde also die gesamte Erde und außer in Gallien wüteten die drei wildesten Untiere vom Osten bis zum Westen“. 10 Laktanz beschreibt in seiner Anrede an Donatus, dass er sprachlos sei über die Qualen, die dieser habe erleiden müssen. Er fasst die Verfolgungen der Tetrarchen zusammen und lobt die Beständigkeit des Donatus, der sich neun mal durch die vielfachen Foltermethoden nicht habe besiegen lassen. Vgl. Vexabatur ergo universa terra et praeter Gallias ab oriente usque ad occasum tres acerbissimae bestiae saviebant. non, mihi si linguae centum sint oraque centum, ferrea vox, omnes scelerum comprehendere formas, omnia poenarum percurrere nomina possim, quae iudices per provincias iustis atque innocentibus intulerunt. verum quid opus est illa narrare praecipue tibi, Donate carissime, qui praeter ceteros tempestatem turbidae persecutionis expertus es? [...] novies enim tormentis cruciatibusque variis subiectus novies adversarium gloriosa confessione vicisti, novem proeliis zabulum cum satellibus suis debellasti, novem victoriis saeculum cum suis terroribus triumphasti. [...] nihil adversus te verbera, nihil ungulae, nihil ignis, nihil ferrum, nihil varia tormentorum genera valuerunt: adimere tibi fidem ac devotionem nulla vis potuit. Lact. mort. pers. 16,1-9 (Brandt/Laubmann 1897, 189,9-190,11): „Gequält wurde also die gesamte Erde und außer in Gallien wüteten die drei wildesten Untiere vom Osten bis zum Westen. Selbst wenn ich einhundert Zungen und einhundert Münder hätte, eine eiserne Stimme, könnte ich nicht alle Arten von Verbrechen begreifen, könnte ich nicht alle Namen von Strafen aufzählen, welche Richter über die Provinzen den Gerechten und Unschuldigen auferlegten. Aber was ist es nötig, jene vor allem dir zu erzählen, geliebter Donatus, der du mehr als alle anderen den Ansturm der heftigen Verfolgung erfahren hast? [...] Neun mal nämlich warst du Foltern und verschiedenen Martern unterworfen, neunmal hast $d u$ in ruhmreichem Bekenntnis den Feind besiegt, in neun Schlachten den Teufel mit seinen Dienern bekämpft, in neun Siegen hast du das irdische Leben mit seinen Schrecken besiegt. [...] Nichts vermochten gegen dich Schläge, nichts Krallen, nichts das Feuer, nichts das Eisen, nichts die verschiedenen Arten von Folterinstrumenten auszurichten: Keine Kraft konnte dir deinen Glauben und deine Hingabe wegnehmen“.

11 Zum Wahnsinn siehe Seite 50, Anm. 30 in dieser Arbeit.

12 Vgl. Unde illum quidam deliri credunt esse translatum ac vivum reservatum, Sibylla dicente matricidam profugum a finibus terrae esse venturum, ut, quia primus persecutus est, idem etiam novissimus persequatur et antichristi praecedat adventum: Lact. mort. pers. 2,8 (Brandt/Laubmann 1897, 175,10 - 14): „Daher glauben einige, dass jener hinweggebracht worden sei und lebendig zurückgehalten worden sei, weil die Sibylle sagt, dass der Muttermörder als Flüchtling von den Grenzen der Erde 


\subsubsection{Kollaterale Damnatio und Todesqualen. Lact. mort. pers. 42}

Diokletian gesundet wieder und die Christenverfolgungen schreiten voran. Die politischen Herrschaftskonzeptionen werden durch den Rücktritt Diokletians und Maximianus' und die Nachfolge der Caesaren Maximinus Daia und Severus vorangetrieben, der nach seinem Tod durch Licinius ersetzt wird. Konstantin und Maxentius werden in der Herrschaftsfolge übergangen. Nachdem Konstantin schließlich durch Usurpation die Macht ergreift, lässt er die Statuen Maximianus’ zerstören und dessen Bilder abhängen und somit auch jene Diokletians:

Zur nämlichen Zeit wurden die Standbilder Maximians auf Konstantins Befehl umgestürzt und die Gemälde mit seinem Bilde herabgerissen. Und weil die beiden Greise zumeist mitsammen gemalt waren, so wurden auch die Bildnisse beider gemeinsam herabgenommen. So musste Diokletian lebend schauen, was keinem der früheren Kaiser je widerfahren war, und, von doppeltem Gram erfasst, beschloss er zu sterben. ${ }^{13}$

Indem Konstantin die Damnatio Memoriae gegen Maximianus richtet und Diokletian nur als Beiwerk dieselbe Strafe zukommen lässt, verstößt er nicht gegen die Sitte, dass Damnatio Memoriae nur auf Tote angewandt wird. Obwohl Diokletian noch lebt, wird mit ihm verfahren, als ob er bereits tot sei. Er wird bei vollem Bewusstsein aus der kollektiven Erinnerung getilgt und gleichsam lebendig begraben. Aus diesem Paradoxon heraus ist er so verzweifelt und leidet so vehement unter dem Verlust seiner Denkmäler, dass er sich entschließt zu sterben. Diokletian trifft diese Entscheidung aktiv und bei vollem Bewusstsein. Obwohl es sich um einen Suizid handelt, ${ }^{14}$ geht dennoch eine Todesstrafe voraus. Gott entscheidet, dass es an der Zeit ist, Diokletian zu bestrafen und lässt Konstantin die Todesstrafe verhängen. Dadurch sorgt Gott dafür, dass Diokletian zu Tode betrübt ist und sein Leben als nicht mehr lebenswert empfindet. Dennoch bleibt es Diokletian überlassen, wie er sein Leben beenden will. Laktanz macht dabei deutlich, dass trotzdem Gott die Verantwortung für den Tod des Diokletian trägt, weil Gott die Christenverfolgung rächt, die Principes einsetzt und

kommen werde, damit der, weil er ja als erster verfolgt hat, ebenso auch als letzter verfolgen werde und der Ankunft des Antichristen vorausgeht:“.

13 Eodemque tempore senis Maximiani statuae Constantini iussu revellebantur et imagines ubicumque pictus esset, detrahebantur. et quia senes ambo simul plerumque picti erant et imagines simul deponebantur amborum. Itaque Diocletianus cum videret vivus quod nulli umquam imperatorum acciderat, duplici aegritudine adfectus moriendum sibi esse decrevit. Lact. mort. pers. 42,1-2 (Brandt/Laubmann 1897, 221,16-222,3).

14 Die Diskussion zur Selbsttötung in der Antike ist weitläufig. Platon etwa vertritt im Phaidon die These, dass der Mensch keinen Selbstmord begehen dürfe, weil nur Gott das Recht habe, das Sterben eines Menschen zu befehlen (Plat. Phaid. 62c). Seneca hält die Selbsttötung für ein legitimes Mittel, um größerem Leid zu entgehen (Sen. ep. 70,10 - 14). Plinius der Jüngere folgt der Vorstellung, „,[s]einem Leben selbst ein Ende zu setzen, sollte das Resultat eines besonnenen Abwägens sein, das auch die Implikationen für die Angehörigen und Freunde einschließt“ Fögen (2015), 37. 
auch für jedes unbedeutende Leben verantwortlich ist. ${ }^{15}$ Wie bereits an mehreren Stellen gezeigt, ${ }^{16}$ legt Diokletian großen Wert auf seine Außenwirksamkeit. Die größte Strafe für Diokletian ist, dass sein Andenken zerstört werde und er nur noch unbedeutend, nur noch humilis sei. Die Damnatio Memoriae ist außerdem für die unmittelbaren Zeitgenossen das Zeichen dafür, dass Diokletian zum Staatsfeind erklärt wurde, wenn auch nur beiläufig, da Maximianus das Hauptziel war. Geht man davon aus, dass eine Handlung determiniert, wer man ist, und dass die Gegenhandlung ebenfalls die eigene Handlung beeinflusst und schärft, ${ }^{17}$ wird Diokletian auch dann durch Damnatio Memoriae zum Staatsfeind erklärt, wenn es vorher nicht das eigentliche Ziel Konstantins gewesen sein sollte. Laktanz erwähnt dies nicht explizit, macht aber deutlich, dass der Vorwurf nicht aktiv aufgehoben wurde.

Im Kontext der Damnatio Memoriae ${ }^{18}$ wird der Gesellschaft und den Herrschern ein Weg aus der Vergeltung der Tyrannei gezeigt. Der Tyrannenmord und die abschließende Damnatio machen eine weitere Auseinandersetzung mit den erfahrenen Grausamkeiten unnötig. ${ }^{19}$ Gleichzeitig fließt die Ehrenposition mit ein, die jemand innehatte, der verewigt wurde. Jemandem wurde ein Denkmal gesetzt. Oder jemand hat sich vielmehr selbst ein Denkmal setzen lassen. Dieser Anspruch auf das Erinnertwerden wird durch die Damnatio außer Kraft gesetzt. Es ist, als ob diese Person nie existiert habe. Alle Versuche, sich zu verewigen, werden revidiert. Die Damnatio Memoriae steht im scheinbaren Widerspruch zum Vorhaben des Laktanz, die Geschehnisse der Nachwelt zu überliefern. Die Damnatio Memoriae vernichtet all das, was von dieser Person geschaffen wurde - Bilder, Statuen, literarische Werke. ${ }^{20}$ Die Geschichtsschreibung erhält die Erinnerung aus Fremdperspektive inklusive der Wertung einer anderen Person oder Instanz. Laktanz ermöglicht zwar die Erinnerung an die Vorkommnisse unter den Tetrarchen, stellt sie aber als Tyrannen dar, während deren Denkmale und Bilder sie positiv dargestellt haben. Die Damnatio Memoriae hat

$15 \mathrm{Vgl}$. ita viginti annorum felicissimus imperator ad humilem vitam deiectus a deo et proculcatus iniuriis atque in odium vitae deductus postremo fame atque angore confectus est. Lact. mort. pers. 42,3 (Brandt/Laubmann 1897, 222,6 - 8): „So war der zwanzig Jahre lang der glücklichste Herrscher zu einem erniedrigten Leben herabgeschleudert worden von Gott und niedergetreten von Ungerechtigkeiten und hinweggeführt zum Hass auf das Leben starb er schließlich vor Hunger und Angst“.

16 Siehe Seiten 53 und 64 in dieser Arbeit.

17 Vgl. Butler (1991), 202. Butler erklärt mittels der Unterscheidung zwischen dem biologischen Geschlecht (sex) und der sozialen Rollenzuschreibung (gender) die komplexen gesellschaftlichen Interaktionsmechanismen, die mit Geschlechterzuschreibungen einhergehen. Für die vorliegende Arbeit ist besonders spannend, dass sie in Anlehnung an Simone de Beauvoir davon ausgeht, dass Handlungen immer in ihrem Interaktionsraum gesehen werden müssen und sich so gegenseitig bestimmen.

18 Charles Hedrick plädiert dafür, dass die Damnatio Memoriae unter verschiedenen Gesichtspunkten betrachtet werden muss: Sie sei Ausdruck politischer Machtstrukturen, der Gattung der Geschichtsschreibung und ihres Verhältnisses zum kollektiven Gedächtnis. Vgl. Hedrick (2000), 91.

19 Nach Christian Meier kann das Vergessen - und somit das aktive Tilgen der Erinnerungsorte einen Kreislauf von Gewalt unterbrechen. Vgl. Ch. Meier (2010).

20 Zu Bewältigungsstrategien in Bezug auf Erinnern und Vergessen siehe A. Assmann (2012). 
in erster Linie eine politische Tragweite: Die Erinnerungsorte an einen Staatsfeind werden getilgt. Gleichzeitig ist die Damnatio eine Form von politischer Gewalt, eine Machtdemonstration des Siegers über einen Staatsfeind. Konstantin kann als aktueller Herrscher, den Maximanus zu töten versucht hat, die Damnatio gegen Maximianus und Diokletian verhängen. Konstantin demonstriert aktiv, wie weitreichend seine politische Macht ist und tilgt seinen Feind so gut es geht aus dem Imperium. Konstantin gehört zu den Principes, die Gott geschickt hat, um den Christenverfolgern ein Ende zu machen. ${ }^{21}$ So ist die Damnatio nicht nur aus weltlicher Sicht die Bestrafung eines Staatsfeindes, sondern auch die Auslöschung eines Feindes Gottes. Das Vergessenwerden wird somit eine legitime Strafe für die Christenverfolgung.

Aleida Assmann appelliert in diesem Sinne:

In practice, „remembering“ or „forgetting“ are rarely mutually exclusive practices, which is why we should pay more attention to crossovers such as selective forgetting and partial or transitional remembering. ${ }^{22}$

Für die Damnatio Memoriae des Diokletian bedeutet dies, dass sein Andenken in unmittelbaren Begegnungsorten getilgt wird, die Christenverfolgung aber auf literarischem Weg in De mortibus persecutorum verarbeitet wird. Die Frage, ob Laktanz gegen die gegen Maximianus verhängte Strafe verstoßen habe, indem er ein Werk über die Tetrarchen geschrieben und Maximianus nicht ausgespart habe, dürfte mit dem Anliegen des Laktanz zu erklären sein, die Realität vor Fälschungen zu schützen. Den Ruhm und die Allmacht Gottes zu verkünden, ist bedeutsamer als die Erinnerung an einen Staatsfeind zu tilgen. Diokletian wird vergessen, damit das Römische Imperium die Chance auf einen Neuanfang ohne die Tetrarchen hat. Die Abnahme der Bilder hat noch einen weiteren Effekt: Die Kultbilder der Göttersöhne Herculius und Iovius werden vernichtet. Laktanz beschreibt nicht nur, wie zwei Kaiser aus der öffentlichen Geschichte getilgt werden, sondern auch, wie zwei Staatsoberhäupter, die sich auf pagane Gottheiten zurückführen, gerechterweise aus dem Stadtbild verschwinden. Wurde zu Beginn der Tetrarchie auf Befehl Diokletians nach Kultbildern der christlichen Kirchen gesucht, um diese zu verbrennen, werden nun pagane Kultbilder vernichtet.

Nachdem Diokletian noch lebend das erfahren hat, was sonst nur toten Staatsfeinden widerfährt, beginnt sein Sterben:

In glühendem Schmerz der Seele warf er sich von einer Seite zur anderen und versagte sich Schlaf und Speise. Unter Seufzen und Stöhnen, unter häufig ausbrechenden Tränen wälzte er sich ru-

21 Vgl. excitavit enim deus principes qui tyrannorum nefaria et cruenta imperia resciderunt et humano generi providerunt Lact. mort. pers. 1,3 (Brandt/Laubmann 1897, 172,4-5): „Aufgerufen hat nämlich Gott Anführer, die die Schandtaten und blutigen Befehle der Tyrannen aufheben und für das menschliche Geschlecht sorgen“.

22 A. Assmann (2012), 68. 
helos bald auf dem Lager, bald auf dem Boden. Nachdem er zwanzig Jahre lang der glücklichste Kaiser gewesen war, ist er nun von Gott zur Niedrigkeit herabgestürzt und durch seine Untaten zerstampft und zum Hass auf das Leben herabgeleitet worden und schließlich vor Hunger und Beklemmung gestorben. ${ }^{23}$

Diokletians Weg zum Tod sei von Schmerzen und Trauer geprägt. Laktanz greift zu Beginn der Beschreibung auf das Wortfeld der Fluten zurück. Iactare und aestuare „sich hin und her werfen“ und „wogen“, „branden“, aber auch „glühen“ vermitteln den Eindruck eines Schiffbrüchigen, der seine Situation nicht mehr unter Kontrolle hat. Urheber des Hin-und-her-Werfens sei Diokletian, der durch seine Willkür, respektive das Vorgehen gegen die Christen den Unmut Gottes auf sich gezogen habe. Seine Seele walle unruhig auf und sprudle über vor Sorge und Emotionen. Die Schiffbruchmetapher findet sich vielfach in der antiken Literatur. ${ }^{24}$ So erklärt beispielsweise Lukrez ${ }^{25}$, dass es „süß“ ist, einem Schiffbrüchigen zuzusehen und selbst in Sicherheit zu sein. Das Bild, das Lukrez zeichnet kann als Allegorie für das Staatswesen gesehen werden ${ }^{26}$ und auch Homer beschreibt die politischen Unruhen in der Heeresversammlung in seiner Ilias mit dem Bild des unruhigen Meeres ${ }^{27}$. Somit kann die Allegorie „wallendes Meer“ für den Staat auch auf die vorliegende Textstelle des Laktanz angewandt werden: Diokletian sei auf Grund seines Handelns zum Unglück verurteilt, weil er seine politische Macht missbraucht habe, um seine Untertanen - und vor allem Christen - zu verfolgen. Habe Diokletian in den höchsten Höhen der Macht gelebt, sei er nun umso tiefer gefallen.

Dieses epikureische Konzept instrumentalisiert Laktanz, indem er die Auf-undab-Bewegung des Tyrannen als Konsequenz des Handelns gegen die Christen mit dem christlichen Gott als Urheber postuliert. Die Schiffsbruchmetaphorik sei vor allem ein

23 Iactabat se huc atque illuc aestuante anima per dolorem nec somnum nec cibum capiens. suspiria et gemitus, crebrae lacrimae, iugis volutatio corporis, nunc in lecto, nunc humi. Ita viginti annorum felicissimus imperator ad humilem vitam deiectus a deo et proculcatus iniuriis atque in odium vitae deductus postremo fame atque angore confectus est. Lact. mort. pers. 42,2-3 (Brandt/Laubmann 1897, 222,3-8). 24 So finden sich direkte Beschreibungen des Schiffsbruches und Sturms beispielsweise in Plut. Dio 25,3; avulsit laceros, percussa puppe rudentis turbo rapax fragilemque super volitantia malum vela tulit; sonuit victis compagibus alnus. Luc. 5,594-596 (Shackelton Bailey 1988, 125,10-12): „Der unaufhaltsame Wirbelsturm reißt die zerfetzten Schiffstaue hinweg, als er das Schiff erschüttert und den zerbrechlichen Mast trägt er über die flatternden Segel; Es ächzt der Kahn durch die zum Nachgeben gebrachten Fugen“; Petron. 103,5; Petron. 114; Nicht unerwähnt bleiben dürfen Mk 4,37 und Apg

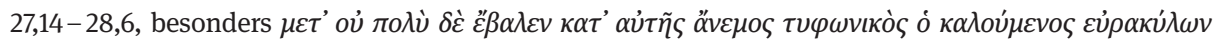
Apg 27,14: „Nicht viel später aber, kam ein Sturm von der Insel her auf, der Eurakylon genannt wird“. Ausführliche Arbeit zur Sturmfahrt und zum Schiffbruch in der Apg unter Einbeziehung literarischer Vorbilder: Börstingshaus (2010).

25 Vgl. Lucr. 2,1.

26 Vgl. hierzu unter anderem Schindler (2000), 73.

27 Vgl. Hom. Il. 2,144-149. 
Hinweis auf „signifikante Veränderungen“28. War Diokletian zuvor immer geschützt und konnte bei der Christenverfolgung und der Verfolgung seiner Bürger aus sicherer Entfernung zusehen, sei er nun selbst seinem Schicksal unterworfen und hilflos gegen die Entscheidungen des machtvollen Konstantin.

Ebenso ist aestuare im Wortfeld Feuer zu verorten, das als Auslöser der diokletianischen Christenverfolgung und bei der Folterbeschreibung in De mortibus persecutorum eine große Rolle spielt. ${ }^{29}$ Indem Laktanz bei der Folter durch Feuer dasselbe Wort benutzt wie bei der an eine Schiffsmetapher angelehnten Beschreibung des Todes des Diokletian, verknüpft er die beiden Vorgänge miteinander und spiegelt sie. So scheint es, dass Diokletian mehrfach Gewalt erfahre, die mit jenen Gewalttaten verknüpft ist, die er an seinen Untertanen ausgeübt habe: Bedingt durch seinen Charakter ertrage er die Freude der Menschen nicht und verlasse Rom. Am Ende seines Lebens werde er von Gefühlen überwältigt, die gegensätzlich zu den Feuerfoltermethoden sind, die er für die Christen bestimmt habe. Dolor als Todesursache findet sich

28 Blumenberg (1971), 173. Blumenberg stellt bei seiner Betrachtung der Schiffahrtsmetapher heraus, dass „die Metaphorik der Seefahrtsabenteuer allerdings oft nur dazu [dient], die Behaglichkeit und Ruhe, die Sicherheit und Heiterkeit des Hafens vorzustellen, in dem die Seefahrt ihr Ende finden soll“ Blumenberg (1971), 171.

29 In De mortibus persecutorum bietet Laktanz drei ausführliche Beschreibungen von Folter durch Feuer. Vgl. nam ut illum ad propositum crudelissimae persecutionis impelleret, occultis ministris palatio subiecit incendium, et cum pars quaedam conflagrasset, Christiani arguebantur velut hostes publici et [cum] ingenti invidia simul cum palatio Christianorum nomen ardebat. Lact. mort. pers. 14,2 (Brandt) Laubmann 1897, 187,15-19): „Denn um ihn zum Vorschlag der grausamsten Verfolgung anzutreiben, legte er durch seine verborgenen Diener im Palast einen Brand, und als ein gewisser Teil in Flammen stand, wurden die Christen bezichtigt wie Staatsfeinde und mit unheimlich großen Neid brannte der Name ,Christen“ zusammen mit dem Palast“; Diocletianus vero, qui semper se volebat videri astutum et intellegentem, nihil potuit suspicari, sed ira inflammatus excarnificari omnes suos protinus praecepit. sedebat ipse aque innocentes igni torquebat Lact. mort. pers. 14,3-5 (Brandt/Laubmann 1897, 187,22188,2): „Diokletian aber, der immer scharfsinnig und klug scheinen wollte, konnte nichts ahnen, sondern gab vor Zorn entflammt vor, dass sofort alle seine Hausangehörigen gefoltert werden sollten“; dignitatem non habentibus poena ignis fuit. id exitii primo adversus Christianos permiserat datis legibus, ut post tormenta damnati lentis ignibus urerentur. qui cum deligati fuissent, subdebatur primo pedibus lenis flamma tamdiu, donec callum solorum contractum igni ab ossibus revelleretur. deinde incensae faces et extinctae admovebantur singulis membris, ita ut locus nullus in corpore relinqueretur intactus.[...] quod postremo accidebat, cum per multum diem decocta omni cute vis ignis ad intima viscera penetrasset. hinc rogo facto cremabantur corpora iam cremata. Lact. mort. pers. 21,6-10 (Brandt/ Laubmann 1897, 197,10 - 21): „Für diejenigen, die keine (Standes-)Würde hatten, war Feuer die Strafe. Diese Art von Verderben hatte er zuerst gegen die Christen erlaubt, indem er gesetzlich festlegte, dass nach den Foltern die Verurteilten in Feuer langsam verbrannt werden sollten. Wenn diese angebunden waren, wurde zuerst unter ihre Füßen eine kleine Flamme gesetzt, solange bis die Haut der Solen durch das Feuer zusammengezogen sich von den Knochen löste. Dann wurden Fackeln, entzündet und gelöscht, heranbewegt an einzelne Glieder, sodass kein Ort am Körper unversehrt blieb. [...] Zuletzt kam dies hinzu, wenn schon den Großteil des Tages hindurch die Kraft des Feuers die gesamte Haut gekocht hatte, sie zu den innersten Eingeweiden hindurchdrang. Dann wurden die bereits verbrannten Körper auf einem angerichteten Scheiterhaufen verbrannt.“ und in dieser Arbeit Seite 131; 133-135 und 158162. 
ebenso wie furor und iactatio oft in Beschreibungen von Selbsttötung. ${ }^{30}$ Der Schmerz kann als Ausdruck einer vermeintlich ausweglosen Situation gesehen werden. ${ }^{31}$ Gerade bei Diokletian aber ist die Situation objektiv betrachtet nicht ausweglos. Er ist nicht das explizite Ziel der Damnatio, und er wird nicht von einer anderen politischen Macht bedroht. Er ist bereits im Ruhestand und kann auch weiterhin so leben wie bisher, nur ohne seine Bilder.

Dass die Strafe für ihn so ausweglos scheint und eng mit der Scham verbunden ist, als Herrscher, der auf seine Außenwirkung fixiert sei, nicht mehr im städtebaulichen Bild des Reiches erkennbar zu sein, zeigt, wie eng Laktanz die Charakterbeschreibung und die Gewalt, die am Tyrannen verübt wird, miteinander verknüpft. In der ersten Passage über den Tetrarchen erfährt der Leser, dass Angst das Hauptcharakteristikum Diokletians ist. Diese bestimmt sein Leben und Handeln über das gesamte Werk hinweg und kommt auch in seiner Todesszene zum Tragen. Der Tyrann fürchte sich nicht nur, sein Gesicht zu verlieren und als großartiger Herrscher, als der er sich stilisiert habe, verleumdet zu werden. Er fürchte sich noch mehr davor, in Vergessenheit zu geraten. Diokletian ist bewusst, dass die Damnatio Memoriae tatsächlich zum Vergessen führt; die Zeitgenossen kennen ihn zwar noch, aber schon ein paar Generationen später wären seine Bauten zerstört und seine Ratschlüsse vergebens, weil sein Name getilgt wurde. Sein Geltungsbedürfnis und seine Angst werden gleichermaßen genutzt, um ihn zu bestrafen.

Nach all den Qualen und der Erkenntnis, dass sein Lebenswerk nichtig sein werde, stirbt Diokletian: Er unterlasse das Essen und Trinken. Der Tod durch abstinentia cibi beziehungsweise inedia findet sich in der Antike mehrfach und wird positiv bewertet. ${ }^{32}$ Diese Todesart „was regarded as showing dignity and wisdom“33 und wird dem philosophischen Milieu zugeschrieben. ${ }^{34}$ Gleichzeitig wird ihr ein gewisses Maß an Geltungsbedürfnis attributiert, ${ }^{35}$ das für den Tod Diokletians anhand des Textes nicht nachzuweisen ist. Die oftmals nachgewiesene Verbindung zu Trauer ${ }^{36}$ findet sich in der vorliegenden Textpassage. Dagmar Hofmann stellt in ihrer Untersuchung zum Suizid in der Spätantike fest, dass

es durchaus Beispiele [gibt], wie gerade Sokrates und die „freiwilligen Märtyrer“ zeigen, in denen auch die Unterlassung einer Handlung oder eine indirekte Handlung zum freiwilligen Tod führten

30 Vgl. hierzu Hoof (1990), 83-84.

31 Vgl. Hoof (1990), 87.

32 In den Satyrica des Petron wird inedia als ein Weg aufgezeigt, sich vor einem grausamen Tod zu retten: ac mortem inedia persequentem Petron Sat. 111 (Müller 1995, 117,22): „und Tod durch Verhungern erlangte"; Modo nuntiatus est Silius Italicus in Neapolitano suo inedia finisse vitam. Causa mortis valetudo Plin. epist. 3,7,1 (Mynors 1982, 76,11-12): „Bald wurde berichtet, dass Silius Italicus in Neapel sich durch Verhungern getötet habe. Der Grund seines Todes war seine Gesundheit“.

33 Hoof (1990), 42.

34 Vgl. Hoof (1990), 42- 43.

35 Vgl. Hoof (1990), 45-46.

36 Vgl. Hoof (1990), 47. 
oder umgekehrt eine aktiv herbeigeführte Selbsttötung nicht aus eigenem Antrieb, sondern auf äußeren Druck hin erfolgte. ${ }^{37}$

Das bedeutet, dass Selbstmord zwar vordergründig die Entscheidung des sich selbst tötenden Menschen ist, bei genauerer Betrachtung aber einem fremden Urheber zugeschrieben werden kann.

Bei inedia scheint es sich um eine Grauzone der Selbsttötung zu handeln, da sie sich auf passives „Fernbleiben“ beschränkt und der Tod nicht aktiv durch ein Hilfsmittel herbeigeführt wird..$^{38}$ Laktanz postuliert in seinen Institutiones, dass es unrecht sei, sich selbst zu töten, da man keinem Menschen das Leben nehmen dürfe, weil er es auch nicht freiwillig bekommen habe. ${ }^{39}$ Seiner Argumentation in den Institutiones folgend, ist auch das Unterlassen des Weiterlebens, also auch inedia, nicht legitim, weil es die Aufgabe des Menschen sei, seinen Körper zu bewahren und das „Sichsterbenlassen“ eben diesem Auftrag widerspreche. Mit dieser Einstellung knüpft Laktanz unter anderem an die Darstellung im Phaidon an, der zufolge der Mensch sich nicht töten dürfe, da der Mensch Besitz Gottes sei und nur auf dessen Befehl hin Selbstmord begehen dürfe..$^{40}$ Da alle Todesarten in De mortibus persecutorum von Gott verhängt werden, handelt es sich um eine causa iusta, also einen legitimen Grund für Selbstmord. Pointiert zeigt Laktanz, dass letztlich auch das aktive Verhungern nur auf Gott zurückgeführt werden kann. Wäre die Todesart nicht von Gott verhängt, beginge Diokletian in seinem letzten Zug noch ein weiteres Vergehen gegen Gott. Da er aber als gebrochener Kaiser in der Hand Gottes sei und dieser seine Handlungen leite, ist sein Tod kein weiteres Vergehen gegen Gott.

Gerade in der Tatsache, dass die Selbsttötung von Gott gerechtfertigt ist, ergibt sich eine Spannung in der Machtfrage. Selbsttötung ist grundsätzlich eine machtvolle Handlung, sofern sie aus den richtigen Gründen geschieht und nicht beispielsweise aus Angst vor dem Leben. ${ }^{41}$ Der Akteur entscheidet aktiv über sein Leben und dessen

37 Hofmann (2007), 19.

38 Vgl. Hoof (1990), 47.

39 Vgl. nam si homicida nefarius est, quia hominis extinctor est, eidem sceleri obstrictus est qui se necat, quia hominem necat. immo vero maius esse id facinus existimandum est, cuius ultio soli deo subiacet. nam sicut in hanc vitam non nostra sponte venimus, ita rursus ex hoc domicilio corporis, quod tuendum nobis adsignatum est, eiusdem iussu recedendum est, qui nos in hoc corpus induxit tamdiu habitaturos, donec iubeat emitti. Lact. inst. 3,18,6-7 (Heck/Wlosok 2007, 269,5-12): „Denn wenn nämlich der Mörder gottlos ist, weil er ein Auslöscher eines Menschen ist, macht sich derjenige, der sich selbst tötet, des gleichen Verbrechens schuldig, weil er einen Menschen tötet. Aber diese muss viel eher als Schandtat eingeschätzt werden, deren Rache Gott allein unterliegt. Denn wenn wir nicht von uns aus in dieses Leben gelangt sind, darf man aus dem Wohnsitz des Körpers wiederum, der uns zum Schutz anvertraut worden ist, nur auf Befehl desjenigen herausgehen, der uns in diesen Körper hineingeführt hat, damit wir solange darin wohnen, bis er uns befiehlt, auszuziehen“.

40 Vgl. Plat. Phaid. 62c.

41 Seneca votiert dafür, dass der Freitod eine Option ist, die sorgfältig überlegt sein muss. Sie könne aber größere Qualen vermeiden und besonders in der Hand der Feinde ein Ausweg sein: manus sibi 
Ende, genau wie über die Art des Dahinscheidens. Vergleichbar ist diese Macht etwa mit der eines Tyrannen oder Christenverfolgers, der über die Todesarten seiner Gegner oder Untergebenen entscheidet. Der Wille in dieser Passage ist aber nur noch indirekt der des Diokletian, denn vorrangig ist Gott die legitimierende Instanz, die auch ,als Richter [...] verdiente Strafen über die Gottlosen und die Verfolger verhängt“"42. Gerade in seinem vermeintlich selbstbestimmten Tod wird Diokletian machtlos. Er wird von einer höheren Instanz getrieben und verliert sein Leben auf den Befehl Gottes. Der Tyrann muss jegliche Handlungsfähigkeit abgeben und wird sogar im selbstbestimmten Tod fremdbestimmt.

Seine Regierungszeit sei von Angst und Unterlassung geprägt. Er sei der Initiator der Tetrarchie und somit mitverantwortlich für die Taten der anderen Herrscher. Ebenso „stirbt er mit“ als sein Mitkaiser Maximianus stirbt und der Damnatio anheimfällt. Er sei nicht derjenige, der die Christenverfolgungen initiiert habe oder der aktiv Senatoren unter falschen Vorzeichen habe hinrichten lassen, um sein Vermögen zu vergrößern, aber er hat auch nicht eingegriffen und ist überhaupt erst dafür verantwortlich, dass solche Despoten regieren konnten. Diese indirekte Verantwortlichkeit des ersten Tetrarchen zieht eine indirekte Bestrafung dessen durch Konstantin nach sich. Auch das eigentliche Dahinscheiden ist von Passivität und Zulassen geprägt: Er unterlasse das Essen. Sogar das Prädikat confectus est nimmt die Passivität wieder auf. Die Qualen, die er durch die Damnatio Memoriae erleidet, spiegeln die

attulit, nec sine causa. Nam post diem tertium aut quartum inimici moriturus arbitrio si vivit, alienum negotium agit. Non possis itaque de re in universum pronuntiare, cum mortem vis externa denuntiat, occupanda sit an exspectanda; multa enim sunt quae in utramque partem trahere possunt. Si altera mors cum tormento, altera simplex et facilis est, quidni huic inicienda sit manus? [...] In nulla re magis quam in morte morem animo gerere debemus. Exeat qua impetum cepit: sive ferrum appetit sive laqueum sive aliquam potionem venas occupantem, pergat et vincula servitutis abrumpat. Vitam et aliis approbare quisque debet, mortem sibi: optima est quae placet. Sen. ep. 70,10-12 (Reynolds 1965, 1,205,9-24): „Hand legte er an sich, und nicht ohne Grund. Denn wer nach dem dritten Tag oder vierten sterben soll nach des Feindes Willen - wenn er lebt, besorgt er anderer Arbeit. Nicht kannst du also über das Problem eine allgemein gültige Aussage machen, ob der Tod, wenn ihn äußere Gewalt androht, vorweggenommen werden soll oder erwartet; Viele Gründe nämlich gibt es, die für die eine und die andere Seite den Ausschlag geben können. Wenn der eine Tod unter Qualen, der andere einfach und leicht sich vollzieht, warum sollte diesem nicht die Hand nachhelfen dürfen? [...] Bei nichts müssen wir uns mehr als beim Tode nach der Seele richten. Sie wähle den Ausgang, wie sie den Anstoß dazu bekommen hat: habe sie das Schwert ergriffen oder die Schlinge oder irgendeinen Trank, die Adern durchströmend, sie lasse nicht nach und zerbreche die Fesseln der Knechtschaft. Das Leben muß ein jeder auch vor anderen rechtfertigen, den Tod vor sich: Der beste Tod ist, der gefällt.“ ÜS Rosenbach 2011, 9-11. Aber auch 'itaque' inquit 'quam primum moriar'[...] Nemo te tenet: evade qua visum est; elige quamlibet rerum naturae partem, quam tibi praebere exitum iubeas. Sen. ep. 117,23 (Reynolds 1965, 2,500,14-18): „Er sagt „deshalb möchte ich möglichst bald sterben“ [...] Niemand hält dich auf: Geh den Weg, der dir richtig scheint, wähle einen beliebigen Teil der Natur, der dir entsprechend deinem Wunsch den Ausgang bietet." ÜS Rosenbach 2011, 9-11.

42 Iudicem digna videlicet supplicia impiis ac persecutoribus inrogare Lact. mort. pers. 1,6 (Brandt) Laubmann 1897, 172,17-173,1; Creed 1897, 4,20): „dass dieser als Richter offenbar angemessene Strafen über die Gottlosen und Verfolger verhängt“. 
Qualen wider, die er bei seiner aktiven Christenverfolgung den Angeklagten angetan habe. Das Bild des Schiffbruchs und des wogenden Meeres ist chiastisch zur Feuerfolter seiner Opfer. Die Fremdbestimmtheit durch eine Naturinstanz liegt der Beschreibung zu Grunde. Es scheint geradezu als hätte Gott die Feuerqualen seiner Anhänger gerächt, indem er sie mit Wasser gelöscht und Diokletian ertränkt hat.

\subsubsection{Zusammenfassung}

Diokletian wird aufgrund seines tyrannischen Verhaltens von einer schweren Krankheit geschlagen, von der er sich nur teilweise wieder erholt. Laktanz schließt die Krankheitsbeschreibung unmittelbar an die Christenverfolgung an, sodass deutlich wird, dass Gott als strafende Instanz im Hintergrund steht. Anders als in der Forschung bisher von Werner Portmann konstatiert, ${ }^{43}$ konnte gezeigt werden, dass der Tod des Diokletian sowohl der Darstellung seines Charakters als auch seiner Taten entspricht. Tyrannischer Charakter und Krankheit als Strafe werden eng miteinander verwoben. Seinen Tod findet Diokletian schließlich durch Verhungern. Als eher beiläufiges Opfer der Damnatio Memoriae gegen Maximianus muss er mit ansehen, wie er aus dem kulturellen Gedächtnis getilgt wird. Dieser Vorgang versetzt ihn in so großen Kummer, dass er das Essen einstellt, vor Trauer wahnsinnig wird und schließlich stirbt. Während Diokletian als Kaiser großen Wert auf seine Außenwirksamkeit gelegt hat, gerät er nun in Vergessenheit. Abschließend verweist Laktanz darauf, dass Gott für das Schicksal des Kaisers verantwortlich ist.

\subsection{Maximianus}

\subsubsection{Verlust aller Ehre und Tod. Lact. mort. pers. 30}

Maximianus, der zweite Augustus der ersten Generation, bleibt bis zu seinem Tod von Gewalt verschont. ${ }^{44}$ Nachdem er sich verschiedentlich auf die Seiten der Tetrarchen und Usurpatoren geschlagen habe und dabei das Ziel verfolgte, wieder an die Macht zu gelangen, versuche er schließlich, seinen Schwiegersohn Konstantin zu töten, um dessen Stellung im Staat einzunehmen. Er bemühe sich, seine Tochter Fausta, die Frau des Konstantin, auf seine Seite zu ziehen. Sie täusche Unterstützung vor und verrate seinen Plan heimlich an Konstantin. Als Maximianus nachts in das Schlafzimmer des Caesaren

Anmerkung zu 4.2: In diesem Kapitel behandelte Textabschnitte: Lact. mort. pers. 30,5; 30,6; 42,1.

43 Irrig dagegen Werner Portmann, der beim Vergleich der Todesarten Galerius' und Diokletians konstatiert: „Hilflos wirkt demgegenüber der Versuch, auch Diokletians Tod als Strafe darzustellen“ Portmann (1990), 213.

44 Lact. mort. pers. 30 (Brandt/Laubmann 1897, 207,7-208,5). 
eindringe und diesem vermeintlich den Kopf abschlage, werde er beim Versuch, diesen Triumph zu verkünden und die Herrschaft an sich zu reißen, gestellt und müsse erfahren, dass er nicht Konstantin, sondern einen Eunuchen an dessen Stelle getötet habe. Daraufhin verurteile Konstantin Maximianus zum Tode ${ }^{45}$.

Der auf frischer Tat ergriffene Mörder erstarrt und verstummt staunt er, so wie der harte Stein oder die Marpesische Klippe dasteht. ${ }^{46}$

Maximianus werde ertappt und scheint sich im selben Moment in Stein zu verwandeln. Die Verwandlung mit den Begriffen haeret, mutus und stupet erinnert an die Verwandlung der Aglauros in den Metamorphosen Ovids. ${ }^{47}$ Aglauros wird wegen ihrer Eifersucht auf ihre Schwester Herse, die von Apollo begehrt wird, durch die Invidia, die personifizierte Eifersucht, in Stein verwandelt. Auch Maximianus ist eifersüchtig auf Konstantin und das Verstummen ist in den Metamorphosen ein typisches Symbol für die beginnende Verwandlung von Menschen durch einen Gott. ${ }^{48}$

Laktanz zitiert Verg. Aen. 6,471, ${ }^{49}$ um das Bild des Versteinerns zu verstärken. Die Textstelle, die er benutzt, ist in der Aeneis im Besuch des Aeneas in der Unterwelt zu verorten. In dem Moment, als er Dido trifft, die sich seinetwegen in ein Schwert gestürzt hat, wendet sie sich von ihm ab und zeigt keine Regung wie ein harter Stein oder eine Marpesische Klippe. Laktanz rückt den erstarrenden Maximianus in die Nähe der Königin Dido in der Unterwelt. Dido ist eine fähige, erfolgreiche Königin, die Selbstmord begeht, als sie von Aeneas verlassen wird. Sie versteinert, weil sie den Schmerz nicht erträgt, mit Aeneas konfrontiert zu werden. Ebenso versteinere Maximianus, weil er die Konfrontation mit Konstantin nicht ertragen könne. Im Gegensatz zu Dido allerdings, habe Maximianus selbst versucht, Leid zuzufügen..$^{50}$ Dido ist außerdem der Inbegriff einer männlichen Königin: Vergil beschreibt Karthago wie einen Bienen-

45 Die Rolle Konstantins beim Tod des senior-Augustus wurde unter anderem von Werner Huss diskutiert. Er kommt dabei zu dem Schluss, dass Konstantin den Selbstmord des Maximianus erzwungen habe, um eine Verschwörung mit Maxentius zu unterbinden. Begründet sieht er die Handlungen des Maximianus in dessen Unwillen, seine Stellung als senior-Augustus anzuerkennen. Vgl. Huss (1978). Diese Schlussfolgerung ist sicherlich korrekt, lässt aber die Konzeption des Werkes völlig außer Acht. Indem Konstantin von Gott befähigt den Tod des Tyrannen anordnet, bietet er ihm die Möglichkeit, seinen Charakter ein weiteres Mal zu entfalten. Laktanz geht es in der Darstellung nicht darum, dass Konstantin Maximianus zum Tod verurteilt, sondern darum, welche Todesart Maximianus wählt und was er damit über sich aussagt.

46 Haeret manifestarius homicida et mutus stupet, quasi dura silex aut stet Marpesia cautes: Lact. mort. pers. 30,5 (Brandt/Laubmann 1897, 207,19-24).

47 Vgl. Ov. Met. 2,819b-832.

48 Vgl. Gauly (2009), 62-79.

49 Siehe hierzu beispielsweise Wlosok (1982b); Putnam, (1995); Freund (2003a); Heck (1990); Ogilvie (1984); Wlosok (1983), 63-86; Goulon (1978), 130.

50 Tamás Adamik sieht in dieser Szene den endgültigen Bruch zwischen Maximianus und Konstantin. Vgl. Adamik (1984), 88. 
staat. ${ }^{51}$ In einem Bienenstaat war das Oberhaupt jedoch immer männlich zu denken. Die Machtfülle, die Dido zugesprochen wird, ihr Status als Bienenkönig und schließlich der Selbstmord mit dem Schwert ordnen ihr ein männliches Gender zu. Die Ambiguität der Geschlechterfrage bei Dido wird unter anderem durch ihre Begleiterin Caeneus in der Unterwelt thematisiert. ${ }^{52}$ Indem Laktanz die Verknüpfung zu Dido herstellt, die heute vielleicht als genderfluid bezeichnet werden würde, beginnt er, die Maskulinität des Maximianus in Frage zu stellen. ${ }^{53}$

Zuletzt wird ihm die Möglichkeit gegeben, den Tod frei zu wählen, und er knüpft den Knoten eines grässlichen Todes vom hohen Balken herab. ${ }^{54}$

Maximianus wählt in De mortibus persecutorum als Todesart das Erhängen. Erneut zitiert Laktanz Vergils Aeneis, um eine Verknüpfung zwischen Maximianus und einer Persona des Werkes herzustellen. Bei Vergil heißt es: „und sie knüpft den Knoten für einen grässlichen Tod vom hohen Balken herab." ${ }^{55}$ In diesem Fall handelt es sich um Amata, die Mutter der Lavinia und Sympathisantin des Turnus. Schaut man sich die Rolle der Amata in der Aeneis genauer an, erkennt man weitere Parallelen. Amata unterstützt Turnus, dem Lavinia ursprünglich versprochen war, bis ihr Vater Latinus sich dafür entschied, sie dem Neuankömmling Aeneas zur Frau zu geben. Aeneas als Gründervater Roms wird deutlich als Held der Aeneis stilisiert und Turnus ist sein Antagonist. Amata favorisiert also den Gegner des Aeneas und so den Gegner des römischen Reichs. Maximianus habe sich auf die Seite des Galerius geschlagen und die Opposition gegen Konstantin gebildet. Somit sei auch er Feind des römischen Gründervaters, respektive des römischen Staates. Die Verwendung der Aeneis-Passage passt von ihrem originalen Kontext in De mortibus persecutorum, ohne dass die werksinterne Argumentation der Aeneis aufgehoben werden müsste. Vielmehr muss die Szene sogar im Originalkontext gekannt und verstanden werden, um die Darstellung des Maximianus als eine dem römischen Staat übelgesonnene Frau begreifen zu können. Der Prätext liegt gleich einer Schablone unter der Todesszene. Die Darstellung als Frau ist keinesfalls als Veränderung des biologischen Geschlechts an sich gedacht, sondern zielt auf die Macht und das Selbstverständnis des Kaisers ab. ${ }^{56}$ Maximianus ist in seiner Todesszene der Inbegriff von Machtlosigkeit und Hilflosigkeit. Er habe keine andere Wahl als sich Konstantin völlig zu unterwerfen. Sein Leben liege in dessen Hand, obwohl Konstantin ihm die Freiheit einräume, die Todesart zu wählen. Maximianus verlassen sein Stolz und sein Selbstverständnis als römischer Kaiser. Dieser Statusverlust zeichnet sich bereits im Verlauf seiner Versuche ab, die

51 Vgl. Berrens (2018), 231-243.

52 Vgl. Starry West (1980).

53 Vgl. hierzu auch Adamik (1984), 88.

54 Postremo datur ei potestas liberae mortis, ac nondum informis leti trabe nectit ab alta. Lact. mort. pers. 30,5 (Brandt/Laubmann 1897, 207,25-208,1).

55 Verg. Aen. 12,603.

56 Vgl. Brisson (2002), 61-71. 
Herrschaft wieder an sich zu reißen. Hierbei scheitere er aber und verliere stattdessen immer mehr Macht, bis er letztendlich genauso wenig Macht habe wie eine Frau. Besondere Schärfe bekommt diese Erkenntnis im Kontrast zu den von ihm verübten Vergewaltigungen, die ein ultimativer Beweis von Macht und nach außen gerichtete Machtdemonstration sind. Auch die Wahl des Erhängens ist eine aktive Demonstration seines Zustandes. Laktanz lässt Maximianus sich Konstantin unterordnen, er wird sinnbildlich zur Frau für Konstantin. Einer Frau, wie er sie in seiner vorigen Machtposition selbst ohne Rücksicht vergewaltigt hätte. Die Darstellung eines Mannes als, beziehungsweise die Parallelisierung mit einer Frau findet sich in mehreren Vorlagen wieder. ${ }^{57}$

Beim Erhängen handelt es sich um eine Art der Selbsttötung, die vornehmlich mit Frauen in Verbindung gebracht wird. ${ }^{58}$ Im römischen Alltag gilt das Erhängen nicht als empfehlenswerte Todesart. ${ }^{59}$ Den römischen Rezipienten wird das Erhängen als weiblich, als fern von virtus und unangemessen gezeigt. ${ }^{60}$

57 Philippo Carla-Uhink bietet eine Zusammenschau derjenigen Phänomene, die mit dem Begriff Crossdressing bezeichnet werden können. Vgl. Philippo Carla-Uhink, Crossing (2017), 17-18. Nicht unerwähnt bleiben soll auch das Epigramm des Martial, das die Entmannung mit der Bestrafung für Ehebruch in Verbindung bringt: Uxorem armati futuis, puer Hylle, tribuni, supplicium tantum dum puerile times. vae tibi, dum ludis, castrabere. Iam mihi dices, Non licet hoc.' Quid? tu quod facis, Hylle, licet? Mart. 2,60 (Lindsay 2015, 2,60): „Hyllus, Junge, du vögelst die Frau des waffenbewehrten Tribunen, wobei du nichts Schlimmeres glaubst befürchten zu müssen als die spezielle Bestrafung von Jungen. Weh dir! Noch während du schäkerst, wirst du kastriert! Gleich wirst du zu mir sagen: „Das darf der doch nicht!“ - Na und, Hyllus: Darfst du etwa, was du da tust?“ ÜS Barié/Schindler 2013, 160 - 161. Das Tragen von Frauenkleidern, also das Verkleiden als Frau lehnt beispielsweise Seneca ab: Non videntur tibi contra naturam vivere qui commutant cum feminis vestem? Non vivunt contra naturam qui spectant ut pueritia spendeat tempore alieno? Sen. Ep. 122,7 (Reynolds 1965, 2,524,24-26): „Scheinen dir nicht gegen die Natur zu leben, die ihre Kleidung vertauschen mit den Frauen? Leben nicht gegen die Natur, die darauf sehen, das Knabenalter glänze zu einer dafür nicht vorgesehenen Zeit?“. ÜS Rosenbach 2011, 820 - 821. Zur Gesetzgebung zum Ehebruch siehe auch Baltrusch (1988), 166 - 178. Einen anderen Zugang bietet Amy Richlin: Richlin (1983), 215-219.

58 Vgl. Verg. Aen. 12,603; Serv. Aen. 12,603; certe cum sub idem tempus una ex consciis, liberta Phoebe, suspendio vitam finisset, maluisse se ait Phoebes patrem fuisse. Suet. Aug. 65,2 (Kaster 2016, 114,19115,2): „Ohne Zweifel sagte er, als zur selben Zeit die freigelassene Phoebe, eine der Vertrauten, sich durch Erhängen das Leben nahm, dass er lieber Vater der Phoebe gewesen wäre“. Phyllis nennt das Erhängen neben anderen Todesarten als Ausweg aus der Trauer, die sie über die Untreue des Demophoon empfindet: Saepe venenorum sitis est mihi, saepe cruenta Traiectam gladio morte perire iuvat; Colla quoque, infidis quia se nectenda lacertis Praebuerunt, laqueis implicuisse iuvat. Ov. epist. Phylli Demophoonti, 139-141 (Kenney 1995, 12,12-15): „Häufig dürstet mich nach Gift, häufig reizt es mich, durchbohrt von einem Schwert einen blutigen Tod zu sterben. Auch den Hals, weil sie sich den ehebrecherischen Armen zur Umarmung oft hingaben, mit dem Strick zu umschlingen reizt mich“. Hierzu auch Hofmann (2007), 106 -107, Anm. 348; Loraux (1993). Zu den rechtlichen Aspekten der Selbsttötung und der Bewertung der Tötungsmethoden siehe Frantzen (2012).

59 Vgl. Liv. 42,28; Apul. Met. 6,30; Ovid wünscht seinem Feind Ibis den Tod durch Erhängen: vincula per laquei fac tibi guttur eat. Ov. Ib. 611-612 (Owen 1915): „Sorg dafür, dass dir die Kehle durch die Schlinge eines Stricks kommt“. Auch Lukan zeichnet den Selbstmord als ablehnenswert und nennt dabei sowohl den Selbstmord durch das Schwert als auch durch den „Balken“. Die beiden Todesarten 
Für christliche Leser war diese Todesart, unabhängig vom Geschlecht, beispielsweise mit Judas Iskariot verknüpft, der sich nach Matthäus erhängt habe. ${ }^{61}$ Aber auch für nicht-christliche Leser sind Reue und Schuld mit dem Erhängen verknüpft. ${ }^{62}$ Maximianus wird diese Todesart jedoch sicher nicht zugeschrieben, weil er selbst erkannt habe, dass er keine Erlösung erhalte oder den Christen Unrecht getan habe. Laktanz gibt keine innere Begründung für die Wahl an und überlässt so dem Rezipienten die Möglichkeit, Maximianus mit der Figura seiner Wahl zu verknüpfen. Für Christen können so beide Figuren mitschwingen, die pagane Leserschaft wird die abzulehnende Amata sehen. Unabhängig also von der eigentlichen Gefühlslage des Maximianus wird suggeriert, dass der Tetrarch sich schuldig fühlen musste, ob er das selbst nun erkannte oder nicht. Die Wahl der Todesart ist das (möglicherweise unbewusste) Resultat der Vergehen, die Maximianus im Laufe seines Lebens begangen habe und insbesondere der Vergehen, derer er sich gegen die Christen schuldig gemacht habe. Ausgerechnet Konstantin, dem Laktanz das Christsein bereits zuschreibt,

stehen sich als ehrenwerte und ehrlose Todesart gegenüber: numquam veniemus ad enses, aut laqueos, aut praecipites per inania iactus: turpe, mori post te solo non posse dolore'. Luc. 9,106b-108 (Shackelton Bailey 1988, 229,21-230,1): „Niemals werden wir zu den Schwertern gelangen oder den Seilen oder kopfüber einen Sturz durch die Leere: Schändlich ist es, dass du nicht ohne Schmerz ganz allein bei dir sterben kannst“. In den Amores klagt das lyrische Ich den Baum an, aus dessen Holz das Täfelchen ist, mit dem er von seiner Angebeteten die Nachricht bekommen habe, dass sie keine Zeit für ihn habe. Dieser Baum habe nicht nur das Täfelchen für die schreckliche Nachricht bereitgestellt, sondern auch zum Erhängen und die Herstellung eines Kreuzes: praebuit illa arbor misero suspendia collo, carnifici diras praebuit illa cruces; Ov. Am. 1,23,17-18 (Kenney 1995, 29,23-24): „Jener Baum hat dem elenden Hals zum Erhängen gedient, dem Henker hat jener die grässlichen Kreuze bereitgestellt;“. Auch rechtlich wurde das Erhängen abgelehnt und die Trauer verboten: Non solent autem lugeri, ut Neratius ait, hostes, vel perduellionis damnati: nec suspendiosi, nec qui manus sibi intulerunt, non taedio vitae, sed mala conscientia. dig. 3,2, 11, Ulp. lib. 6 ad edictum, 3 (CIC[B].C, 148): „Man trauert nämlich nicht, wie Neratius sagt, für Feinde oder Hochverräter: Weder für die, die sich erhängt haben, noch für diejenigen, die sich nicht aus Lebensmüdigkeit selbst getötet haben, sondern aus schlechtem Gewissen“. Siehe dazu auch Voisin (1979), 422-450. Anton van Hoof weist sogar darauf hin, dass viele griechische mythische Figuren, die sich erhängt haben, in römischen Adaptionen eine andere Todesart wählen. Vgl. Hoof (1990), 66.

60 Vgl. hierzu Tobias Arand, der bereits darauf hinweist, dass der Nutzen dieser Stelle vornehmlich in der Diskreditierung des Tyrannen liegt. Vgl. Arand (2002), 171.

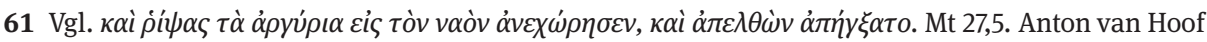
postuliert hierzu: „To the Christian, despair implied renouncing Gods mercy. Judas was the example of the man who despaired of salvation: his self-hanging is the climax of his sin. In the iconography of Christian sarcophagi his deed is pictured in the margin of the crucifixion by way of contrast. Various notorious sinners were said to have destroyed themselves in hopelessness“. Hoof (1990), 93. Weitere christliche Beispiele sind Bas. hom. II in Psalm. 14,4,58; Lib. or. 57,30; Ioh. Mosch. prat. 207.

62 So auch beispielsweise Dagmar Hofmann: „Das Erhängen befindet sich stets in der Assoziation mit Reue und Sühne für schuldiges Vorgehen. Dabei ist es unerheblich, ob die Verbindung des Motivs Schuldbewusstsein und/oder Reue mit der Todesart Erhängen lediglich ein Klischee in der literarischen Darstellung wiedergibt oder die Häufung dieser Verbindung in der Literatur auf eine historische Realität hinweist: Die Assoziation des Erhängens mit Schuld und Reue ist offenbar im antiken Denken fest verankert“ Hofmann (2007), 189-190. 
ist der Vollstrecker der von Gott angeordneten Niederlage des Tyrannen in einer öffentlichen Hinrichtung. Der Tod des Maximianus bringt auch vor dem Volk zum Ausdruck, dass er sich gegen die legitime Herrscherinstitution gestellt hat. ${ }^{63}$ Die freie Wahl der Todesart findet sich in mehreren Quellen bereits vor der Tetrarchie. ${ }^{64}$ Für Hochverrat (maiestas) scheint die Freistellung überaus milde. ${ }^{65}$

Laktanz fasst den rapiden Sturz des Maximianus zusammen und resümiert:

So beendete jener dem römischen Begriff nach größte Imperator, der nach einer langen Zeitspanne mit unglaublichem Ruhm die Zwanzigjahrfeier beging, nachdem die hochmütigste Kehle zerschmettert und gebrochen worden war, das verabscheuungswürdige Leben durch einen hässlichen und beschämenden Tod. ${ }^{66}$

Laktanz beginnt mit einem Wortspiel: Maximianus sei der größte römische Feldherr gewesen, zumindest dem Namen nach (maximus - maximianus). Da der Rezipient bereits weiß, dass Maximianus erniedrigt stirbt, bleibt die Ironie nicht verborgen. Maximianus hat einen gewissen Handlungsspielraum durch die Wahl der Todesart, sodass der Tod als eine Form von Suizid verstanden werden kann. ${ }^{67}$ Maximianus scheide nicht freiwillig aus dem Leben, aber zumindest mit der von ihm favorisierten Todesart. Der Zwang zum Tod werde von Konstantin, respektive dem Gerichtsurteil des Hochverrats ausgeübt. Der Freiwilligkeitsaspekt beim Tod des Maximianus ist das Moment seiner Erniedrigung. In dem Moment, in dem er die Macht bekomme, über sein Werden zu entscheiden, wende er sich der ultimativen Machtlosigkeit zu. Die lange Herrschaft steht in unmittelbarem Kontrast zum plötzlichen Tod durch Erhängen und der unglaubliche Ruhm während der Herrschaft zum verabscheuungswürdigen Leben und dem hässlichen und beschämenden Tod.

Auch die Strafe, die Maximianus nach seinem Tod für sein Vergehen erfahre, kann als gegen den Tyrannen gerichteter Gewaltakt verstanden werden:

Und zur selben Zeit wurden die Statuen des alten Maximianus auf Befehl Konstantins weggeschafft und die Bilder, wo auch immer sie hingemalt waren, wurden abgenommen. ${ }^{68}$

Anders als Diokletian ist Maximianus bereits tot, als er durch Damnatio Memoriae bestraft werde. Konstantin, der ihn zum Tode verurteilt habe, beschließt in De

63 Vgl. Arand (2002), 203-207. Arand zeigt auf, dass die öffentliche Hinrichtung eines Usurpators zum Repertoir der Tyrannenerzählung gehört. Sowohl christliche als auch pagane Darstellungen legitimieren die Hinrichtung eines schlechten Kaisers.

64 Vgl. Schilling (2015), 168.

65 Vgl. Harries (2007), 81-85.

66 Ita ille Romani nominis maximus imperator, qui post longum temporis invervallum cum ingenti gloria viginti annorum vota celebravit, eliso et fracto superbissimo gutture vitam detestabilem turpi et ignominosa morte finivit. Lact. mort. pers. 30,6 (Brandt/Laubmann 1897, 208,2-5).

67 Siehe in dieser Arbeit Seiten 190-193.

68 Eodemque tempore senis Maximiani statuae Constantini iussu revellebantur et imagines, ubicumque pictus esset, detrahebantur. Lact. mort. pers. 42,1 (Brandt/Laubmann 1897, 221,16-18). 
mortibus persecutorum auch seine postume Strafe. Maximianus wird durch die Damnatio Memoriae auch außerhalb der literarischen Verarbeitung offiziell als Staatsfeind gekennzeichnet. Der Akt der Damnatio Memoriae bestätigt die Charakterisierung, die Laktanz durch viele andere Eigenschaften aufgebaut hat. Das tatsächliche Tilgen des Andenkens aus dem Stadtbild hat eine besondere politische Bedeutung: Konstantin sei der siegreiche Kaiser, der die erfolgreichere Politik vertreten habe und somit die Politik des Maximianus für ungültig erklärt. Die Damnatio als klares Signal an die Bürgerschaft ermöglicht es, im gesamten Staat eine einheitliche Linie zu vertreten.

Maximianus genießt sein Leben in vollen Zügen. Ein Hauptcharakteristikum des Tetrarchen ist seine Vorliebe für das Vergewaltigen und Verführen von Männern wie Frauen. Er ist der Inbegriff eines machtvollen und gleichzeitig machthungrigen Mannes, der sich über alle Mitmenschen stellt. Durch seine Todesart und die nachfolgende Damnatio verliert er jegliche Machtposition und Ansehen, auf die er zuvor großen Wert gelegt hatte. Vielmehr noch, er wird geradezu zur Frau, also zu dem Objekt seiner Ausschweifungen. Die Parallelisierung zu gleich zwei Frauen aus der Aeneis bietet einen stufenlosen Abstieg vom Kaiser zur männlichen Frau bis hin zur schwachen Frau, die versucht, das Glück Roms zu durchkreuzen. Gott ist nur indirekt Handlungsträger in Maximianus' Untergang, die tragende Rolle kommt Konstantin zu, der als Princeps von Gott eingesetzt wurde, um die Erde von den Verfolgern zu befreien.

\subsection{Galerius}

\subsubsection{Der Machtverlust beginnt. Lact. mort. pers. 24-25}

Die erste Andeutung für den Untergang des Galerius knüpft unmittelbar an dessen grausamste Steuereintreibung an und markiert einen Wendepunkt im Geschick des Tetrarchen:

Schon eilte jenem der Richtspruch Gottes entgegen und es folgte eine Zeit, in der seine Angelegenheiten hinabzugleiten und zu zerfließen begann. ${ }^{69}$

Galerius bekomme noch keine Gewalt im eigentlichen Sinn zu spüren, werde aber bald nicht mehr genauso glücklich leben können wie bisher. Laktanz gibt dem Leser eine Deutungsvorlage für das folgende Geschehen; Constantius liege im Sterben und wolle

Anmerkung zu 4.3: In diesem Kapitel behandelte Textabschnitte: Lact. mort. pers. 24,1; 24,4-7; 25,4; 27,$8 ; 32,4 ; 33,1-4 ; 33,4-5 ; 33,6-8 ; 33,9-10 ; 35,3$.

69 Iam propinquavit illi iudicium dei secutumque tempus est quo res eius dilabi ac fluere coeperunt. Lact. mort. pers. 24,1 (Brandt/Laubmann 1897, 200,1-2). 
seinen Sohn Konstantin noch einmal sehen. ${ }^{70}$ Galerius versuche dieses Treffen zu verhindern, scheitere aber, weil Gott Konstantin schütze. ${ }^{71}$ Konnte Galerius bisher über die anderen Tetrarchen Macht gewinnen, Diokletian zur Christenverfolgung antreiben, seinen Blutdurst stillen und mit grausamster Gewalt Steuern eintreiben lassen, wird nun erstmals sein Versagen geschildert. Galerius könne Konstantin nicht davon abhalten, zu Constantius zu reisen und er sei nicht in der Lage gewesen, ihn zu töten, während er sich in seiner Obhut befand..$^{72}$ Durch eben dieses Scheitern wird Konstantin zum Tetrarchen, zum Nachfolger des Constantius ernannt. In der Ernennung Konstantins zum Tetrarchen liegt der eigentliche Wendepunkt im Schicksal des Galerius. Die erste Amtshandlung des Konstantin sei es, die Christenverfolgung zu beenden:

Nachdem er die Herrschaft angetreten hatte, beschloss der Augustus Konstantin nichts eher, als dass die Christen ihrem Kult und Gott zurückgegeben werden. Dies war dessen erste Verordnung zur Wiederherstellung der heiligen Religion. ${ }^{73}$

Im Kontrast dagegen steht die erste Amtshandlung des Galerius, namentlich sein Vorgehen gegen die Christen, indem er Diokletian zur Christenverfolgung überrede. ${ }^{74}$

70 Vgl. qui cum graviter laboraret, miserat litteras, ut filium suum Constantinum remitteret sibi vivendum, quem iam dudum frustra repetierat. Lact. mort. pers. 24,3 (Brandt/Laubmann 1897, 200,5-8): „Da er schon schwer litt, schickte er Briefe, damit er seinen Sohn Konstantin zurückschickte, solange er noch lebte, den er schon lange vergeblich zurückverlangte“.

$71 \mathrm{Vgl}$. ille vero nihil minus volebat [...] sed frustra, quoniam dei manus hominem protegebat. Lact. mort. pers. 24,4-5 (Brandt/Laubmann 1897, 200,8-13): „Jener wollte wahrlich nichts weniger, aber vergeblich, da ja die Hand Gottes den Menschen beschützte“.

72 Vgl. nam et in insidiis saepe iuvenem adpetiverat, quia palam nihil audebat, [...]. namque saepius rogatus cum iam diu negare non posset, dedit illi sigillum inclinante iam die praecepitque, ut postridie mane acceptis mandatis profisceretur, vel ipse illum occasione aliqua retentaturus vel praemissurus litteras, ut a Severo teneretur. [...] postridie imperator cum consulto ad medium diem usque dormisset, vocari eum iubet. dicitur ei post centam statim profectus. Lact. mort. pers. 24,4-7 (Brandt/Laubmann 1897, 200,8-201,1): „Denn auch mit Hinterhalten hatte er den jungen Mann oft bedroht, weil er es nicht offen wagte, [...]. Denn weil er so lange schon gebeten wurde, dass er nicht mehr länger verneinen konnte, gab er jenem ein Siegel als sich die Frist schon nahte und gab vor, dass er am nächsten Tag in der Frühe, nachdem er Aufgaben erhalten hatte, aufbrechen würde, mit dem Vorhaben ihn entweder selbst mit irgendeiner Gelegenheit aufzuhalten oder die Briefe vorauszuschicken, damit er von Severus

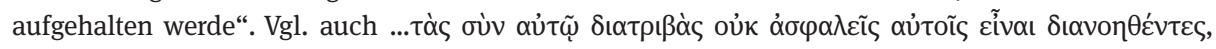

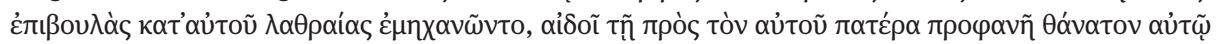

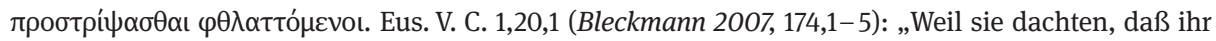
Zusammenleben mit ihm nicht sicher für sie sei, heckten sie heimlich Anschläge gegen ihn aus, wobei sie aus Schamgefühl gegenüber seinem Vater sich hüteten, ihm den Tod in aller Öffentlichkeit zuzufügen“. ÜS Schneider 2007, 175,1-5.

73 Suscepto imperio Constantinus Augustus nihil egit prius quam Christianos cultui ac deo suo reddere. haec fuit prima eius sanctio sanctae religionis restitutae. Lact. mort. pers. 24,9 (Brandt/Laubmann 1897, 201,7-9).

74 Vgl. ergo habito inter se per totam hiemem consilio cum nemo admitteretur et omnes de summo statu rei publicae tractari arbitrarentur, diu senex furori eius repugnavit ostendens quam perniciosum esset 
Indem Laktanz den Schutz des Christentums zur ersten Amtshandlung des Konstantin macht, positioniert er Konstantin und Galerius als Gegenüber, die als führende Personae der Christenverfolgung beziehungsweise -verteidigung in unmittelbaren Konflikt miteinander treten. Mit dem Auftreten des Konstantin als prochristlichem Kaiser habe Galerius erstmals einen Widersacher, der seine höchste Agenda, die Christenverfolgung, kontradiktiere. Der Untergang des Galerius vollzieht sich schrittweise. Unmittelbar nach seinem Amtsantritt schicke Konstantin eine Büste mit seinem Porträt an Galerius. ${ }^{75}$ Diese offizielle Geste verstehe Galerius als Angriff auf dessen Stellung innerhalb der Tetrarchie.

Nachdem die ersten Caesaren und Maximianus als Augustus von Diokletian ernannt worden seien, habe Galerius die Ernennung der Nachfolger übernommen. ${ }^{76}$ Konstantin ist der erste Tetrarch, dessen Ernennung Galerius nicht zugestimmt habe, der er sogar aktiv widersprochen habe, als er mit Diokletian die Nachfolgeregelungen traf. ${ }^{77}$ Laktanz fasst zusammen:

inquietari orbem terrae. [...] nec tamen deflectere potuit praecipitis hominis insaniam. [...] nec sic quidem flexus est imperator, ut accomodaret assensum, sed deos potissimum consulere statuit misitque aruspicem ad Apollinem Milesium. [...] cum Caesar vivus cremari vellet qui sacrificio repugnassent. Lact. mort. pers. 11,3-8 (Brandt/Laubmann 1897, 185,10 - 186,10): „Weil sie also untereinander den ganzen Winter über Rat gehalten hatten, und niemand zugelassen wurde, glaubten alle, dass über höchstwichtige Staatsangelegenheiten verhandelt würde, solange der alte Mann gegen dessen Raserei ankämpfe, indem er aufzeigte wie schädlich es wäre, die Erde in Unruhe zu versetzen. [...] Und dennoch konnte der Wahnsinn dieses halsstarrigen Menschen nicht abgewandt werden. [...] Und nichteinmal so konnte der Feldherr dazu bewegt werden, dass er zustimmte, sondern beschloss eher die Götter um Rat zu fragen und schickte einen Weissager zum Apollo von Milet“.

75 Vgl. Städele 2003, 158-159 Anm. 94.

76 Vgl. Lact. mort. pers. 18.

77 Während Diokletian die Söhne der anderen Tetrarchen zu Nachfolgern ernennen wollte, bestand Galerius darauf, Severus und Maximinus Daia zu Caesaren zu ernennen. Die Gründe hierfür liegen vornehmlich in der Kontrollsucht des Galerius. Vgl. Constantio quoque filius erat Constantinus, sanctissimus adulescens et illo fastigi dignissimus, qui insigni et decoro habitu corporis et industria militari et probis moribus et comitate singulari a militibus amaretur, a privatis et optaretur. eratque tunc praesens iam pridem a Diocletiano factus tribunus ordinis primi - 'quid ergo fiet?' - 'ille' inquit 'dignus non est. qui enim me privatus contempsit, quid faciet, cum imperium acceperit?' - 'hic vero et amabilis est et ita imperaturus, ut patre suo melior et clementior iudicetur'. - 'ita fiet ut ego non possim facere quae velim. Lact. mort. pers. 18,10 - 11 (Brandt/Laubmann 1897, 193,19-194,1): „Konstantius hatte auch einen Sohn: Konstantin, der ein überaus ehrwürdiger junger Mann und seinem Charakter nach der Würdigste war, der wegen seiner ausgezeichneten und anmutiger Körperhaltung und seinem Auftreten eines Militärangehörigen und wegen seiner rechtschaffenen Sitten und einzigartiger Kameradschaft von den Soldaten geliebt wurde und von der Bevölkerung gewünscht wurde. Damals war er auch anwesend, weil er am Vortag von Diokletian zum Tribun des ersten Ranges gemacht worden war. ,Was also soll geschehen?' -,Jener', sagte er ,,ist nicht würdig. Wer mich als Privatmann verachtet, was wird er tun, wenn er Amtsmacht erhält? ${ }^{*}$-,Er ist wirklich liebenswert und wird so herrschen, dass man ihn für besser und milder als seinen Vater halten wird ${ }^{\circledR}$-,So wird es dazu kommen, dass ich nicht machen kann, was ich will'“. 
Schon waren seine Pläne durchkreuzt worden und er hatte keinen anderen außer der Reihe ernennen können wie er es wollte. ${ }^{78}$

Die Handlungsfreiheit des Galerius werde durch Konstantin eingeschränkt. Laktanz verweist aber darauf, dass die Pläne des Galerius vorsahen, alterum extra numerum zu ernennen, sich also nicht an die Vorgaben der tetrarchischen Ordnung zu halten, wie sie von Diokletian eingeführt wurde. Mit dem Verweis darauf, dass Galerius vom vorgesehenen System abweiche, unterstreicht er die Tyrannei des Galerius. Konstantin, der Anti-Galerius, der von Gott gesandte, durchkreuzt die Pläne des Galerius, des Tyrannen, der den gesamten römischen Staat in den Untergang stürzen möchte.

In den nachfolgenden Passagen versuche Galerius, seine Macht zu stärken, indem er Severus zum Augustus ernennen und Konstantin mit Maximinus als Caesaren ansprechen lasse. ${ }^{79}$ Dieser Ordnungsversuch werde durch den Putsch des Maxentius durchkreuzt, der sich in Rom zum Imperator hat ausrufen lassen. ${ }^{80}$ Laktanz gibt Galerius die Schuld für diesen Putsch, weil dieser die Besteuerung Roms eingeführt habe, um seine Gier zu stillen, und so den Zorn des stadtrömischen Volkes auf sich gezogen habe, das sich durch die Ernennung des Maxentius zum Imperator zu befreien versuche. ${ }^{81}$ Unterstützt wird der Putsch des Maxentius dadurch, dass er selbst bei der Nachfolgeregelung unter Diokletian übergangen worden sei und eigentlich rechtmäßig genauso Anrecht auf die Nachfolge habe wie Konstantin. ${ }^{82}$ Beide

78 Iam turbatae rationes eius fuerant nec poterat alterum extra numerum nuncupare, ut voluerat. Lact. mort. pers. 25,4 (Brandt/Laubmann 1897, 201,18-20).

79 Vgl. sed illud excogitavit, ut Severum, qui erat aetate maturior, Augustum nuncuparet, Constantinum vero non imperatorem, sicut erat factus, sed Caesarem cum Maximino appellari iuberet, ut eum de secundo loco reiceret in quartum. Lact. mort. pers. 25,5 (Brandt/Laubmann 1897, 201,20-24): „Aber jener überlegte sich, dass er Severus, der älter war, zum Augustus ernennen würde, Konstantin aber nicht zum Feldherrn, wie er ernannt worden war, sondern befahl, dass er zusammen mit Maximinus Caesar genannt würde, damit er vom zweiten auf den vierten Platz zurückgesetzt würde“.

$80 \mathrm{Vgl}$. Compositae ei res quodam modo iam videbantur, cum subito illi alius terror adlatus est, generum ipsius Maxentium Romae factum imperatorem. Lact. mort. pers. 26,1 (Brandt/Laubmann 1897, 201,25 - 27): „Es schien ihm, dass die Umstände nun gewissermaßen geregelt seien, als ihm plötzlich eine andere Schreckensnachricht zugetragen wurde, dass nämlich sein Schwiegervater Maxentius in Rom zum Feldherrn ausgerufen worden sei“".

$81 \mathrm{Vgl}$. cum statuisset censibus instituis orbem terrae devorare, ad hanc usque prosiluit insaniam, ut ab hac captivitate ne populum quidem Romanum fieri vellet inmunem [...]. milites pauci [...] Maxentium purpuram induerant. Lact. mort. pers. 26,2-3 (Brandt/Laubmann 1897, 201,28-202,7): „Als er [sc. Galerius] beschlossen hatte mit den eingeführten Steuern den Erdkreis zu verschlingen, stürmte er bis zu diesem Wahnsinn, dass er von dieser Knechtschaft nicht einmal das Volk Roms ausnehmen wollte [...]. Einige Soldaten [...] hatten Maxentius das Purpurgewand verliehen“.

82 Vgl. Constantio quoque filius erat Constantinus, sanctissimus adulescens et illo fastigi dignissimus, qui insigni et decoro habitu corporis et industria militari et probis moribus et comitate singulari a militibus amaretur, a privatis et optaretur. eratque tunc praesens iam pridem a Diocletiano factus tribunus ordinis primi Lact. mort. pers. 18,10 (Brandt/Laubmann 1897, 19-24): „Konstantius hatte auch einen Sohn: Konstantin, der ein überaus ehrwürdiger junger Mann und seinem Charakter nach der Würdigste 
übergangenen Nachfolger sind so zu Imperatoren ausgerufen worden und haben ihre rechtmäßige Stellung entgegen den Plänen des Galerius angetreten. Es scheint, als würde Gott schrittweise die richtige Ordnung wiederherstellen, indem er zuerst die von Galerius übergangenen Caesaren wieder in die tetrarchische Herrschaftskonstellation einbringt. Mit Blick auf das Ende von De mortibus persecutorum wird schließlich sogar das Zweimännerkollegium wieder eingeführt, wie es in republikanischer Zeit üblich war.

\subsubsection{Der Aufstieg Konstantins. Lact. mort. pers. 27 und 32}

Galerius versuche nach der Niederlage des Severus selbst, Rom zu erobern und scheitere an der unerwarteten Größe der Hauptstadt. Diesmal führt Laktanz die Niederlage aber nicht auf göttliche Intervention zurück, sondern auf das schlechte Vorwissen des Galerius. Dennoch zeigt sich, wie die Vorhaben des Galerius seit dem Herrschaftsantritt des Konstantin stetig scheitern, unabhängig davon, aus welchem Grund. Laktanz kontrastiert die Niederlage des Galerius vor Rom mit dem Bild, das Galerius bei Herrschaftsantritt von sich selbst gezeichnet haben soll:

Einst hatte jener freilich, als er den Namen Imperator angenommen hatte, gestanden, dass er ein Feind des Namens „römisch“ sei, von dessen Bezeichnung er wollte, dass sie verändert wird, damit es nicht mehr römisches Reich, sondern dakisches Reich genannt werde. ${ }^{83}$

Die tyrannischen Ambitionen des Galerius werden seit dem Wendepunkt stückweise widerlegt, sodass Galerius sehe, wie seine Pläne sich vor seinen Augen ins Gegenteil verkehren. Er schaffe es nicht, das römische Reich in dakisches Reich umzubenennen, er schaffe es nicht einmal, seine Herrschaft zu konsolidieren. Sein Gegenspieler Konstantin gewinnt an Macht, während er selbst sie verliert. Zum stetigen Verlust seiner Macht gehört, dass Galerius auch von den nachfolgenden Tetrarchen nicht mehr als höchste Instanz akzeptiert wird. Maximinus, der von Diokletian auf Drängen des Galerius hin zum Tetrarchen ernannt worden sei, widersetze sich dem Vorgehen des Galerius. ${ }^{84}$ Hatte Galerius als Caesar selbst noch Macht über Diokletian, den

war, der wegen seiner ausgezeichneten und anmutiger Körperhaltung und seinem Auftreten eines Militärangehörigen und wegen seiner rechtschaffenen Sitten und einzigartiger Kameradschaft von den Soldaten geliebt wurde und von der Bevölkerung gewünscht wurde. Damals war er auch anwesend, weil er am Vortag von Diokletian zum Tribun des ersten Ranges gemacht worden war“.

83 Olim quidem ille ut nomen imperatoris acceperat, hostem se Romani nominis erat professus, cuius titulum immutari volebat, ut non Romanum imperium, sed Dacisum cognominaretur. Lact. mort. pers. 27,8 (Brandt/Laubmann 1897, 205,2-5).

84 Vgl. Nuncupato igitur Licinio imperatore Maximinus iratus nec Caesarem se nec tertio loco nominari volebat [...] sese priorem esse debere, qui prior sumpserit purpuram; Lact. mort. pers. 32,1-3 (Brandt) Laubmann 1897, 209,16-21): „Als Maximinus darüber benachrichtig wurde, dass Licinius zum Feld- 
Augustus, verliere er nun als Augustus seine Macht über die Caesaren, die sich seiner Herrschaftsstruktur widersetzen.

Sein Ziel, durch die Ernennung vermeintlich treuer Caesaren seine eigene Regierungszeit und seinen Ruhestand zu sichern, ${ }^{85}$ scheitere:

Es schmerzt das wilde Tier und es muht, weil gegen seinen Willen und seine Bitten, obwohl er einen unbekannten Mann zum Caesaren gemacht hat, damit der ihm gehorchte, dieser dennoch in so großer Pflichtvergessenheit unehrerbietig ankämpfte. ${ }^{86}$

Erstmals empfindet Galerius Schmerz über das Verhalten eines anderen Tetrarchen. War Galerius noch invitus, als er Konstantin als Kaiser anerkannte, ${ }^{87}$ komme jetzt seine Natur wieder zum Vorschein und Laktanz beschreibt ihn als bestia. Passend zum bestia-Begriff wählt Laktanz das Verb mugire und rekurriert auf die Charakterisierung des Galerius zu Beginn des Werkes. Das Tiersein ist der Inbegriff der religio-Ferne für Laktanz ${ }^{88}$ und indem er nach nur zwei kurzen Beschreibungen der Gewalt an Christen den eigentlichen Vorwurf an die Tyrannen, nämlich die Christenverfolgung, wieder in den Fokus rückt, verknüpft Laktanz das Leid des Galerius mit seinen Vergehen gegen Gott. Dessen Ablehnung des christlichen Gottes drückt sich in seiner Tierhaftigkeit aus, die die Ernennung des Nachfolgers Maximinus Daia nach sich zieht. Dass Daia sich nun gegen Galerius wendet, ist die Konsequenz aus dem schlechten Urteilsvermögen des Galerius. Er hat unter großem Druck auf Diokletian darauf bestanden, Daia zum Caesaren zu ernennen und damit genau das herbeigeführt, was er zu vermeiden suchte.

\subsubsection{Der Krankheitsbeginn. Lact. mort. pers. 33}

Der Endpunkt des Abstiegs Galerius' findet sich in den körperlichen Qualen einer Krankheit:

Schon wurde das achtzehnte Jahr gefeiert, als ihn Gott mit einer unheilbaren Krankheit erschütterte. Ihm entstand ein übles Geschwür am unteren Teil der Genitalien und breitete sich

herrn ernannt worden war, erzürnte er und wollte selbst weder Caesar noch an dritter Stelle genannt werden [...] Er, der zuerst das Purpurgewand erhalten hätte, müsse früher genannt werden“.

85 Vgl. Lact. mort. pers. 18,11: ita fiet, ut ego non possim facere quae velim. eos igitur oportet nuncupari qui sint in mea potestate, qui timeant, qui nihil faciant nisi meo iussu (Brandt/Laubmann 1897, 193,27194,3) „So wird es dazu kommen, dass ich nicht machen kann, was ich will. Es ist nötig, dass diejenigen erwählt werden, die unter meiner Gewalt stehen, die sich fürchten, die nichts ohne meinen Befehl tun werden".

86 Dolet bestia et mugit, quod cum ideo ignobilem fecisset Caesarem, ut sibi obsequens esset, is tamen tanti beneficii sui oblitus voluntati ac precibus suis impie repugnaret. Lact. mort. pers. 32,4 (Brandt) Laubmann 1897, 209,23-210,1).

87 Lact. mort. pers. 25,3 (Brandt/Laubmann 1897, 201,17).

88 Siehe hierzu Seite 84 in dieser Arbeit. 
weiter aus. Die Ärzte schneiden heraus und heilen. Aber als sich schon eine Narbe gebildet hat, wird die Wunde aufgerissen und es fließt Blut aus der gebarstenen Ader bis hin zur Todesgefahr, kaum wird dennoch das Blut gestoppt. Ganz von vorne beginnt eine neue Behandlung. Endlich wird sie bis zur Narbe durchgeführt. Wiederum wird sie durch eine leichte Körperbewegung verletzt; Mehr Blut als vorher läuft hervor. Er selbst erbleicht und wird schwach vor schwindenden Kräften, und dann freilich wird der Fluss an Blut gestoppt. Es beginnt die Wunde die Medizin nicht zu spüren; Der Krebs dringt in jedwedes umliegendes Gewebe ein und umso mehr er herausgeschnitten wird, umso weiter wütet er. So oft er geheilt wird, wächst er nach. ${ }^{89}$

Galerius erkranke an Krebs, der durch gängige medizinische Vorgänge nicht geheilt werden könne, sondern streue. Laktanz macht bereits im ersten Satz des Abschnitts deutlich, dass Gott der Urheber dieser Krankheit sei. Der Rezipient kann den Krebs als unmittelbare Folge des Fehlhandelns des Galerius begreifen und die Ausgestaltung der Strafe auf sich wirken lassen. Das Geschwür entsteht laut Laktanz an den Genitalien des Galerius. Der Penis war auch in der Antike ein Zeichen für Männlichkeit und Macht und eine Funktionsstörung oder Krankheit ein Makel. ${ }^{90}$ Dass nun gerade ein Kaiser an seinen Genitalien erkrankt, muss als Machtverlust verstanden werden. Laktanz bedient sich auch bei diesem Bild keiner neuen Idee, sondern knüpft an Beschreibungen wie beispielsweise die des Satyrus von Heraclea an, der während seiner grausamen Herrschaft an einem unheilbaren Geschwür zwischen Leistenbeuge und Skrotum erkranke, das nässe und schließlich zu seinem Tod führe. ${ }^{91}$ Laktanz „entmannt“ und „entmachtet“ Galerius in dieser Szene schließlich, nachdem dieser bereits seit der Machtergreifung Konstantins immer mehr an Einfluss und Macht im Reich verloren hat.

Zum metaphorischen Machtverlust tritt auch noch die Unannehmlichkeit der Krankheit im Allgemeinen: Die Behandlung sei langwierig und biete geringe Erfolgsaussichten. Laktanz beschreibt mehrfach, wie die Wunde wieder aufbreche und nur unter großem Blutverlust wieder geschlossen werden könne. Beim ersten Mal beschreibt Laktanz, dass Galerius viel Blut ad periculum mortis verliert und beim zweiten Mal plus sanguinis quam ante. Wenn Galerius beim ersten Blutverlust schon in Todesgefahr schwebte, ist er beim zweiten Blutverlust in noch größerer Gefahr, wenn nicht sogar nahezu tot. Laktanz beschreibt einen rivus cruoris und macht den Blutstrom zu einer Naturgewalt, die nicht aufzuhalten sei. Das Bild eines Flusses aus Blut

89 Iam decimus et octavus annus agebatur, cum percussit eum deus insanabili plaga. nascitur ei ulcus malum in inferiori parte genitalium serpitque latius. medici secant curant. sed inducta iam cicatrice scinditur vulnus et rupta vena fluit sanguis usque ad periculum mortis. vix tamen cruor sistitur. nova ex integro cura. tandem perducitur ad cicatricem. rursus levi corporis motu vulneratur: plus sanguinis quam ante decurrit. albescit ipse atque absumptis viribus tenuatur, et tunc quidem rivus cruoris inhibetur. incipit vulnus non sentire medicinam: proxima quaeque cancer invadit et quanto magis circumsecatur, latius saevit, quanto curatur, increscit. Lact. mort. pers. 33,1-4 (Brandt/Laubmann 1897, 210,7-18).

90 Vgl. Kimmel/Milrod/Kennedy (2014), 53.

91 Vgl. hierzu auch Africa, (1982), 5. Weitere Beispiele finden sich in 2 Chr 16,12; 2 Kön 20,1-7; Jes 38,1-21. Plutarch führt als Todesursache Sullas Geschwüre an, die schließlich aufbrechen und Wurmbefall auslösen: Plut. Sulla 36,2; Ios. ant. lud. 17,168-169. 
erinnert an die Erzählung des Marsyas, wie sie beispielsweise in den Metamorphosen Ovids beschrieben wird. ${ }^{92}$

Marsyas tritt aus Hochmut gegen den Gott Apollo im musikalischen Wettstreit an. Weil Marsyas beinah gewinnen konnte, zieht Apollo ihm bei lebendigem Leib die Haut ab und aus dem Blutstrom entsteht der Fluss Marsyas, der Inbegriff eines blutigen Flusses. Wenn Laktanz sich desselben Bildes bedient, um das Leiden des Galerius zu beschreiben, evoziert er eine Parallele zu einer anderen Figur, die von einem Gott für ihren Hochmut bestraft wurde. Der Verstoß gegen göttliches Recht (nefas), die Arroganz, sich einem Gott überlegen zu fühlen oder diesen nicht anzuerkennen, und der Leichtsinn, gegen diesen Gott vorzugehen, respektive mit ihm in einen Wettkampf zu treten, kann nur dazu führen, dass man zu einem reißenden Fluss voller Blut wird metaphorisch oder tatsächlich.

Der Anklang an den paganen Mythos kann auch dazu dienen, den Gewaltakt in einen historischen Kontext zu setzen. Götter bestrafen diejenigen, die sich an ihnen vergehen, auf grausame Weise. Gleichzeitig legitimiert Laktanz seine Erzählung als historisch akkurat, weil sie sich mit den Erzählungen aus einer mythischen Vorzeit verschränken lässt. Gerade der Verweis auf die Metamorphosen, die laut lyrischem Ich geschrieben wurden, um den Anfang der Welt bis in die Zeit des Dichters zu beschreiben und ewig fortwährende Erinnerung hervorzurufen, bietet eine starke Selbstdarstellung des Laktanz. Er knüpft an Ovid an, einen Dichter, der tatsächlich auch über seinen Tod hinaus bekannt geblieben ist. Einen Dichter, der die Realität beschreibt und zeigt, wie es zu existierenden Phänomenen gekommen sei, die in der Gegenwart der Bevölkerung des römischen Reichs alltäglich sind. Laktanz möchte

92 Vgl. Sic ubi nescioquis Lycia de gente virorum rettulit exitium, Satyri reminiscitur alter, quem Tritoniaca Letous harundine victum adfecit poena. 'quid me mihi detrahis?' inquit; 'a! piget, a! non est' clamabat 'tibia tanti.' clamanti cutis est summos derepta per artus, nec quidquam nisi vulnus erat; cruor undique manat detectique patent nerui trepidaeque sine ulla pelle micant venae; salientia viscera possis et perlucentes numerare in pectore fibras. illum ruricolae, silvarum numina, Fauni et Satyri fratres et tum quoque carus Olympus et nymphae flerunt et quisquis montibus illis lanigerosque greges armentaque bucera pavit. fertilis immaduit madefactaque terra caducas concepit lacrimas ac venibus perbibit imis; quas ubi fecit aquam, vacuas emisit in auras. inde petens rapidum ripis declivibus aequor Marsya nomen habet, Phrygiae liquidissimus amnis. Ov. Met. 6,382-400 (Tarrant 2004, 166,10-167,2): „Sobald so irgendeiner aus dem lykischen Volk vom Untergang der Männer berichtet hat, erinnert ein anderer an den Satyr, den Latonas Sohn, nachdem er mit einem Pfeil siegreich gewesen war, eine Wunde zufügte. ,Warum ziehst du mich von mir weg?“ sagt er: „Oh! Es tut mir leid!“ rief er. Die Flöte ist mir nicht so wichtig“. Dem Schreienden wird die Haut von den Gliederspitzen gezogen, und nichts war er als eine einzige Wunde; Das Blut fließt überall hin und die aufgedeckten Nerven liegen frei und die zitternden Venen glänzen ohne jegliche Haut; Die springenden Eingeweide und die in der Brust leuchtenden Fasern könntest du zählen. Die Landbewohner, Waldgottheiten, Faune und Satyren und dann auch der geliebte Olymp und die Nymphen weinen und wer auch immer an jenen Bergen die wolletragenden Herden und das Rinderhörner habende Großvieh weidet. Die fruchtbare Erde wurde feucht und befeuchtet nimmt sie die fallenden Tränen auf und saugt sie bis in ihr Innerstes; Sobald sie diese zu Wasser gemacht hat, entlässt sie es in die leeren Lüfte. Von da an hat der reißende Fluss mit den abschüssigen Ufern den Namen Marsyas, der wasserreichste Fluss Phrygiens“. 
ebenfalls beschreiben, wie es zur Herrschaft unter Konstantin und Licinius gekommen sei, welche Genese dem Staatswesen vorangegangen sei und wie das Eingreifen Gottes die Welt dahingehend verändert habe. Der Selbstanspruch des Laktanz, seine Beschreibungen für die Nachwelt zu konservieren, ist ebenso ausgeprägt wie der Wunsch des Ovid. Ovid möchte sich durch sein Werk ewigen Ruhm sichern, Laktanz hingegen möchte die wahren Geschehnisse erzählen, vertritt aber auch den Anspruch, von der Nachwelt als historisch akkurater Zeuge wahrgenommen zu werden. $\mathrm{Zu}$ den wahren Geschehnissen, die Laktanz der Nachwelt überliefern möchte, gehört auch, dass der Krebs des Galerius auf die gängigen Behandlungen nur bedingt anspricht. Zwar komme es anfänglich zur Narbenbildung, diese könne aber nicht vollständig verheilen. Als Kaiser hat Galerius Zugang zu den besten Ärzten:

Es zögern die Lehrer,

Chiron, der Sohn des Phillyrides und Melampus, der Sohn des Amythaonius. ${ }^{93}$

Von überall her werden bedeutende Heiler herbeigezogen, nichts bewegen die menschlichen Hände. Man flieht zu Götzenbildern: Apollo und Asclepius werden angebetet, ein Heilmittel gefordert. Apollo gibt ein Heilmittel; das Übel wird umso schlimmer vergrößert. ${ }^{94}$

Laktanz zieht ein Zitat aus den Georgica des Vergil heran, um die Ausweglosigkeit der Situation für Galerius zu beschreiben. Die Szene, die er auswählt, ist charakteristisch für das Ende des dritten Buches der Georgica: Beschrieben werden Tierkrankheiten, Pest und Seuchen, die nicht abwendbar sind. In den Georgica breitet sich die Krankheit über alle Tierarten hinweg aus, wie sich der Hass gegen die Christen von Galerius aus erst in der Tetrarchie, dann in Teilen des Volkes ausgebreitet habe. Das massenhafte Sterben der Tiere in den Georgica kann mit der Auslöschung der Bestien wie Galerius durch Gott gleichgesetzt werden. Die Szene wird allerdings ins Gegenteil verkehrt, sodass die Krankheit des Tieres nicht wie in den Georgica negativ besetzt ist, sondern vielmehr positiv, weil sie ein Befreiungsakt ist. Der Staat wird von der kranken Bestie befreit und auch die paganen Gottheiten können nicht verhindern, dass der Christenhass in Person des Galerius ausgelöscht wird, wenn der christliche Gott ihn für seine Vergehen bestraft. Dass nach der Marsyas-Anspielung gerade Apollo angerufen wird, um Galerius zu heilen, gibt der Krankheit eine neue Wendung. Apollo ist in der Lage, unendliche Schmerzen durch einen Fluss aus Blut zu verursachen, ist aber nicht in der Lage, diese Schmerzen zu heilen, wenn sie vom christlichen Gott zugefügt werden. Seine Macht, obwohl sie in mancher Hinsicht ähnlich anmute, sei der des

93 Cessere magistri, Phillyrides Chrion Amythaoniusque Melampus. Verg. Georg. 3,549b-550 (Hirtzel 1963).

94 Undique medici nobiles trahuntur: nihil humanae manus promovent. confugitur ad idola: Apollo et Asclepius orantur, remedium flagitatur. dat Apollo curam: malum multo peius augetur. Lact. mort. pers. 33,4-5 (Brandt/Laubmann 1897, 211,1-6). 
christlichen Gottes deutlich unterlegen. Apollo, obwohl er eigentlich mit Asclepius für die Heilung zuständig ist, versage. ${ }^{95}$

Laktanz zeigt so, dass es sich bei den paganen Gottheiten um unvollkommene und in sich schwächliche Wesen handeln muss, die dem christlichen Gott zweifelsfrei unterlegen sein müssen. ${ }^{96}$ Die Anrufung dieser Gottheiten bringe keine Linderung, sondern verschlimmere das Leid noch. Die paganen Gottheiten können also für Leid und Qual, auch für Bestrafung herangezogen werden, das Gute, die Heilung und den Schutz biete aber nur der christliche Gott. Erst nachdem alle anderen Mittel gescheitert sind, wenden sich die Ärzte an die Götter. Möglicherweise liegt hier eine subtile Kritik des Laktanz daran versteckt, dass religio keine tragende Rolle im Alltagsleben der paganen Bevölkerung gespielt hat, während er selbst darlegt, dass religio eine Grundkonstante im menschlichen Leben sei, die das gesamte Handeln auf Gott ausrichte. ${ }^{97}$ Laktanz bezeichnet die paganen Götter als idola und verweist auf das alttestamentliche Bilderverbot ${ }^{98}$.

Galerius ist während der Heiligungsversuche lediglich Objekt des Geschehens und wird vom zweiten Satz an nicht mehr genannt - weder namentlich noch über ein Pronomen. Er scheint völlig aus der Szenerie entrückt, während Laktanz seine Beschreibung auf die Krankheit und die missglückten Heilungsversuche fokussiert. Die Strafe kann so abstrahiert und allgemeingültig auf die Feinde Gottes interpretiert werden: Jeder, der sich in solch schwerem Maß an Gott vergehe oder dies versuche, müsse mit einer schweren Krankheit rechnen und jeder Versuch, dem Willen Gottes zuwider zu handeln und dessen Strafe zu mildern oder zu heilen scheitere - selbst unter Anbetung der paganen Gottheiten. Der Autor unterstreicht so sein Vorhaben, die Tetrarchen als Exempla ${ }^{99}$ der Macht Gottes für die Nachwelt zu nutzen. Natürlich vergisst der Rezipient nicht, wer hier gerade von Würmern zerfressen wird, aber es wäre leicht, den Tetrarchen auszublenden.

Der Krebs greife schließlich auf die inneren Körperpartien über:

Das Verderben war nicht mehr weit entfernt und hatte alle unteren Körperteile hinweggerissen. Die Eingeweide verfaulten von außen her völlig und zu Eiter zerfloss das gesamte Gesäß. Nicht

95 Tamás Adamik sieht vornehmlich das Versagen der Ärzte im Vordergrund. Vgl. Adamik (1984), 89. Viel eher ist aber doch das Versagen der paganen Gottheiten für Laktanz von Bedeutung. Die Ärzte versagen gerade deshalb, weil sie sich den falschen göttlichen Beistand erbitten.

$96 \mathrm{Zu}$ Daemones bei Laktanz siehe Seite 67 und 215 in dieser Arbeit.

$97 \mathrm{Vgl}$. nam si divinitas, quae gubernat hunc mundum, incredibili beneficentia genus hominum sustentat et quasi paterna indulgentia fovet, vult profecto gratiam sibi referri et honorem dari, nec constare homini ratio pietatis potest, si caelestibus benefeciis extiterit ingratus, quod non est utique sapientis. Lact. inst. 4,3,3 (Heck/Wlosok 2007, 316,8-12): „Denn wenn eine Gottheit, die diese Welt lenkt, mit unglaublicher Wohltätigkeit das menschliche Geschlecht erhält und gleichsam mit väterlicher Zärtlichkeit brennt, will sie in der Tat, dass ihr Dank abgestattet und Ehre erwiesen wird und nicht vermag das Nachdenken über pietas für den Menschen dies, was, wenn er sich für die himmlischen Wohltaten undankbar zeigt, überhaupt kein Zeichen von Weisheit ist". Vergleiche in dieser Arbeit Seite $84 \mathrm{f}$.

98 Vgl. Ex 20,1-6.

$99 \mathrm{Zu}$ Exempla in der lateinischen Literatur siehe beispielsweise Langlands (2011). 
aber hörten die unglückbringenden Ärzte auf ohne Hoffnung das Übel zu besiegen zu glühen und zu heilen. Als das Übel ins Mark zurückgedrängt worden war, zog es sich nach innen zurück und ergriff die inneren Körperteile, Würmer wurden im Inneren geschaffen. Der Gestank drang nicht nur durch den Palast, sondern die gesamte Stadt. Und es ist kein Wunder, weil schon die Ausgänge des Kots und Urins durcheinandergebracht worden waren. Aufgefressen wurde er von Würmern, und der Körper wurde mit unerträglichen Schmerzen zu Fäulnis aufgelöst. ${ }^{100}$

Der Krebs wird als so aggressiv dargestellt, dass er den Körper immer weiter auffrisst. Während Genitalkrebs durch Amputation geheilt werden konnte, führen die Heilungsversuche bei Galerius dazu, dass sein Körperinneres angegriffen werde. Auch Celsus beschreibt Geschwüre, die durch medizinische Behandlung nicht geheilt werden können, an deren Darstellung sich Laktanz zu orientieren scheint. ${ }^{101}$ Der scheinbare Erfolg durch das Zurückdrängen verschlimmere die Krankheit so sehr, dass Würmer in den Eingeweiden entstünden. Die Qualen seien groß:

Grauenerregende Klagerufe erhebt er zugleich zu den Sternen, so wie ein Muhen, als verwundet vom Altar flieht der Stier. ${ }^{102}$

Galerius wird mit einem Stier verglichen, der dem Tod nahe ist, weil er an einem Altar den Göttern geopfert werden soll. Das Geschrei sei grauenerregend und einem Tier entsprechend. Da Galerius im Verlauf des Werkes immer wieder als bestia bezeichnet wird, erinnert Laktanz seine Leser daran, dass Galerius kein bemitleidenswerter Mensch sei, der an einer schweren Krankheit leide, sondern ein wildes Tier, das den Tod verdiene. Wenn er das Geschrei an die Sterne richtet, richtet er es gleichsam an Gott im Himmel. Wieder greift Laktanz die Erklärungen zur Mensch-Gott-Interaktion auf, wie er es bereits bei der Beschreibung des Galerius als bestia andeutet. Der Mensch, der sich vom Tier nicht durch die Sprache oder Körperhaltung unterscheidet, sondern durch die Fähigkeit, Gott zu erkennen und ebenfalls (an-)erkannt zu werden. Der letzte Ausweg, den Galerius in seinen Schmerzen sehe, sei, sich an Gott zu wenden und um Hilfe zu rufen, diesmal in Gestalt eines Tieres.

Laktanz zitiert erneut Vergils Aeneis. Im zweiten Buch der Aeneis, aus dem diese Szene übernommen ist, erzählt Aeneas der Königin Dido vom Untergang Trojas. Sinon, der sich als Überläufer ausgibt, wird von den Trojanern empfangen und

100 Iam non longe pernicies aberat et inferiora omnia corripuerat. conputescunt forinsecus viscera et in tabem sedes tota dilabitur. non desinunt tamen infelices medici vel sine spe vincendi mali fovere curare. repercussum medellis malum recidit introrsus et interna comprehendit, vermes intus creantur. odor it non modo per palatium, sed totam civitatem pervadit. nec mirum, cum iam confusi essent exitus stercoris et urinae. comestur a vermibus, et in putredinem corpus cum intolerandis doloribus solvitur. Lact. mort. pers. 33,6-8 (Brandt/Laubmann 1897, 2116-14).

101 Vgl. Cels. V 28,3 A-B. Hierzu auch Adams, (1988), 522-527. Ganz recht verweist Arand darauf, dass die Fülle der Beschreibungen vermuten lässt, dass Galerius nicht einmal an Krebs erkrankt war. Vgl. Arand (2002), 173.

102 Clamores simul horrendos ad sidera tollit, quales mugitus, fugit cum saucius aram taurus. Lact. mort. pers. 33,8 (Brandt/Laubmann 1897, 211,15-17); Vgl. Verg. Aen. 2,222-224a. 
schildert ihnen die vermeintlichen Geschehnisse im gegnerischen Lager und von deren Rückzug. Währenddessen bereitet der Neptunpriester Laokoon, der als einziger vor dem Geschenk der Griechen - dem trojanischen Pferd - warnte, ein Stieropfer vor und wird dabei von zwei Seeschlangen angegriffen und qualvoll getötet. Die Verse stammen aus eben dieser Todesszene. Durch den Tod des Laokoon kann der Hinterhalt der Griechen gelingen und Troja fällt. Nur wenige Verse später berichtet die Aeneis, dass Laokoon seinen Tod verdient zu haben scheint:

[...] und man sagte, dass Laokoon

das Verbrechen gebüßt habe, wie er verdient. ${ }^{103}$

Die unmittelbare Verknüpfung der Laokoon-Passage mit dem Todeskampf des Galerius verweist zuerst darauf, dass die Qualen des Galerius damit vergleichbar seien, von zwei riesigen Schlangen getötet zu werden. Die Schlangen sind ein Werk Athenas, die den Untergang der Trojaner möchte und daher den einzigen Widerstand in Gestalt Laokoons vernichtet. Die Szene scheint ambivalent, da Rom ohne diese Szene niemals gegründet worden wäre und Laokoon als einziger der Trojaner die Wahrheit erkannt hatte, sie also für den Verlauf einer römischen Geschichtsschreibung positiv besetzt sein müsste. Für den Aufstieg Roms zur Weltmacht ist jedoch essentiell, dass die Trojaner Laokoon keinen Glauben schenken und er stattdessen stirbt. So ist auch für Laktanz der Verlauf der Weltgeschichte und die Vormachtstellung Roms in der Welt davon abhängig, dass Galerius stirbt. Er ist derjenige, der dem Imperium Romanum den größten Schaden zuzufügen scheint und durch seine Steuererhöhungen und konstanten Grausamkeiten das römische Weltreich in seiner Blüte behindere, wie die Erkenntnis Laokoons die Entstehung des Reiches hätte verhindern können. Der Todeskampf Laokoons wird auf Galerius übertragen, der durch seine Christenverfolgung beweist, dass er keine Erkenntnis über göttliches Handeln haben könne - egal ob pagan oder christlich. Der Tod Laokoons wird erst aus der Rückschau verständlich und so kann Laktanz implizieren, dass auch er aus der Rückschau das Handeln Gottes im Leid des Galerius erkannt habe und es nun seinen Rezipienten zu erklären versucht. Die Passagen werden also doch miteinander vergleichbar: Sowohl Galerius als auch Laokoon haben einen, respektive den höchsten Gott beleidigt. ${ }^{104}$ Wenn Laokoon nicht von einer Göttin niedergestreckt worden wäre, wäre das römische Reich niemals entstanden und wenn Galerius nicht vom christlichen Gott in diesen Todeskampf verwickelt worden wäre, könnte das römische Reich niemals gerettet werden.

Der Gestank, der vom verwesenden Galerius ausgehe, steht diametral den Beschreibungen von Märtyrern gegenüber, bei deren Beschreibung stets Wert gelegt wird

103 Et scelus expendisse merentem Laocoonta fuerunt Verg. Aen. 2,229b-230a (Hirtzel 1963).

104 Vgl. auch Adamik (1984), 89-90. 
auf ihren überaus wohlriechenden Leichnam. ${ }^{105}$ Nicht-christlich betrachtet steht der Geruch beim Sterben in engem Zusammenhang mit der Verbrennung von Opferfleisch. Der Geruch des Opfers ist die Verbindung zwischen Gott und den Menschen. Gleichermaßen stellt der Geruch der Märtyrer in der christlichen Tradition eine Verbindung zu Gott her. Evans erklärt:

A prime function of a martyr's tale is to create an image so compelling that others will want to follow. The martyrology is designed to spread a message about the character, worthiness and truth of both the divine being who inspired such a sacrifice and the one who gave his or her life. Fragrance can be seen as functioning similarly to a martyrology. ${ }^{106}$

Die Darstellung eines Martyriums müsse zum Nachahmen anregen. Die Komposition der Märtyrerfigur müsse zur Verbreitung der Erzählung beitragen. Beides sei besonders durch die Verknüpfung mit Wohlgeruch möglich gewesen. Im Gegensatz zu Märtyrern verbreitet Galerius in der Darstellung keinen Wohlgeruch, sondern Gestank. Adaptiert man das christliche Verständnis von Geruch, wird deutlich, dass sowohl Galerius selbst von schlechtem Charakter und Gottes unwürdig sein muss. Er kann nicht in Verbindung zum christlichen Gott stehen oder ein gutes Leben geführt haben, weil seine Vita und sein Geruch sonst zur Nachahmung anleiten würden. Diese Lesart impliziert, dass auch der Gott, dem sich Galerius zuordnet - also Jupiter - kein Gott ist, dem nachzufolgen ratsam ist. Während Anhänger Gottes wohlriechend in den Tod gehen, stirbt Galerius, der sich familiär mit Jupiter verknüpft sieht, stinkend. Aber auch ohne christliche Martyriumsvorstellung ist für den paganen Rezipienten klar, dass der abstoßende Gestank ein Ausdruck des Tyrannendaseins des Kaisers ist. Auch für sie war der würdevolle Tod mit Wohlgeruch verknüpft, der durch Kräuter, Räucherwerk oder Balsam herbeigeführt wurde. Laktanz knüpft einen Heilungsversuch und schließlich die Hinwendung Galerius' zu Gott an und rückt so die Zusammenhänge von Geruch und gewählter Gottheit näher zusammen.

Um Galerius vor dem Tod zu retten, versuchen seine Ärzte, die Würmer mit Fleisch aus der Wunde zu locken:

Man legte auf seinen zerfließenden Schoß gekochte und warme Tiere, damit die Hitze die Würmchen herauslockte. Nachdem diese weggenommen worden waren, wimmelte ein unzählbarer Schwarm hervor und dennoch erschuf das fruchtbare Verderben eine umso größere Fülle an verfaulenden Eingeweiden. Schon hatten Teile der Eingeweide ihr Aussehen durch die verschiedenen Übel verloren. ${ }^{107}$

105 Vgl. S. Evans (2002). Vergleiche auch Eus. HE 15,10. Euseb referiert den Märtyrertod Polykarps und beschreibt, dass die Anwesenden einen süßen Duft wahrgenommen hätten, der vom Scheiterhaufen her kam.

106 S. Evans (2002), 195.

107 Adponebantur ad sedem fluentem cocta et calida animalia, ut vermiculos eliceret calor. quis resolutis inaestimabile scatebat examen et tamen multo maiorem copiam tabescendorum viscerum pernicies fecunda generaverat. iam diverso malo partes corporis amiserant speciem. Lact. mort. pers. 33,9-10 (Brandt/Laubmann 1897, 211,18-212,2). 
Erwärmtes Fleisch werde auf die vom Krebs zerstörten Körperpartien gelegt, um die im Inneren befindlichen Würmer herauszuziehen. Erfolgreich werde eine große Anzahl Würmer so hervorgelockt, doch könne die Krankheit so nicht gelindert werden. Der Körper spiegele die innere Destruktion wider. Laktanz legt großen Wert darauf, die versuchten Heilungsprozesse bildlich darzustellen. Der Schoß zerfließt, er spricht nicht von Fleisch, sondern konkret von gekochten und warmen Tieren und benutzt das Diminutiv für die krankhaften Würmer. Es handelt sich um einen Schwarm an Würmern und der Körper des Galerius verliert seine menschliche Gestalt. Fecunda pernicies ist ein Oxymoron, das unterstreicht, dass die Qualen, die Galerius zu Grunde richten, gleichzeitig der Nährboden für die Würmer sind, die aus ihm entstehen. Auch hier zeigt sich, dass der Untergang des Galerius für eine andere Lebensform das (Über-)Leben bedeutet - für die Würmer, aber auch für das römische Reich, das so niemals zum dakischen Reich werden wird. Während Valerianus nach seinem Tod zum Futter für wilde Tiere wurde, ${ }^{108}$ dient Galerius noch zu seinen Lebzeiten als Nahrung für eine andere Spezies. Es war unüblich, dass der Mensch von Tieren verspeist wurde, vielmehr war es die Aufgabe des Menschen, Tiere zu verspeisen. Diese Inversion deutet bereits an, dass Galerius seine Menschlichkeit verliert und damit einhergehend auch die Gottesebenbildlichkeit.

Der Oberkörper war er bis zur Wunde hin ausgetrocknet und mit elender Magerkeit hatte die blasse Haut weithin zwischen die Knochen gelegt, der Unterleib schien ohne irgendeine Gestalt der Füße, aufgeblasen auf beide Seiten, das Gewebe. Und dies geschah durch das gesamte Jahr hindurch, bis endlich der von den Übeln besiegt gezwungen war, sich zu Gott zu bekennen. Er schrie vor neuen drängenden Schmerzen während der Unterbrechungen, dass er den Tempel Gottes wiederherstellen lassen werde und für sein Verbrechen Genüge tun werde. Und schon veröffentlichte er im Dahinscheiden ein derartiges Edikt: ${ }^{109}$

Laktanz beschreibt, wie die Haut des Galerius am oberen Teil des Körpers schlaff über seinen Knochen sitze, sich an seinen Füßen aber spanne. Laktanz nimmt die Beschreibung des Aussehens des Galerius wieder auf ${ }^{110}$ und kehrt sie um. Galerius sei kein fetter aufgedunsener Fleischberg mehr, sondern werde durch seine Frevel zu einer ähnlich unansehnlichen, aber völlig gegenteilig zu charakterisierenden Gestalt. Bei der Einführung des Tetrarchen im Werk sei er angsteinflößend gewesen, schaurig und sein Aussehen habe seinen grausamen Charakter gestützt. Am Ende seines

108 Vergleiche zum Tod Valerianus' Seite 247-249 in dieser Arbeit.

109 Superior usque ad vulnus aruerat et miserabili macie cutis lurida longe inter ossa consederat, inferior sine ulla pedum forma in utrium modum inflata discreverat. et haec facta sunt per annum perpetem, cum tandem malis domitus deum coactus est confiteri. novi doloris urgentis per intervalla exclamat se restituturum dei templum satisque pro scelere facturum. et iam deficiens edictum misit huiusmodi: Lact. mort. pers. 33,10 (Brandt/Laubmann 1897, 212,2-9).

$110 \mathrm{Vgl}$. status celsus, caro ingens et in horrendam magnitudinem diffusa et inflata. Lact. mort. pers. 9,3 (Brandt/Laubmann 1897, 183,3-4) ,seine hochgewachsene Statur, das massige Fleisch war sowohl in erschreckende Größe zerflossen als auch aufgeblasen“. Siehe in dieser Arbeit Seite 86. 
Lebens sei Galerius ein Schatten seiner selbst. Er habe an Umfang, an Gewicht, an gravitas verloren. Er sei durch die langen Qualen nicht mehr angsteinflößend und Gott habe dafür gesorgt, dass er sein Aussehen zusammen mit seiner Bedeutung für den Staat ablegen müsse.

Für das Bild des von „Gewürm“ befallenen Frevlers finden sich zahlreiche literarische Vorbilder, sowohl biblisch als auch pagan: ${ }^{111}$ Herodot beschreibt, wie Pheretime für ihre Rache an den Einwohnern Barkas von den Göttern zur Rechenschaft gezogen wird. Sie wird bei lebendigem Leib von Würmern von innen heraus aufgefressen. ${ }^{112}$ In der Antiken Literatur finden sich noch andere Persönlichkeiten, die durch Läuse zu Tode gekommen sind, weil sie sich gegen einen Gott vergangen haben: „Der thessalische Heros Akastos, der Lyriker Alkman, der Prophet und Mythograph des 6. Jh. v.Chr. Pherekydes von Syros, Kallisthene von Olynth, der Jurist Quintus Mucius Scaevola und Eunu der Anführer des ersten sizilischen Sklavenaufstands 136 132 v. Chr. “113

Biblisch findet sich eine Bestrafung durch Würmer, die den Körper auffressen im Buch Judith als Androhung ${ }^{114}$ und wird im zweiten Makkabäerbuch umgesetzt. De

111 An dieser Stelle sollen nur einige wenige Beispiele verhandelt werden. Genannt seien aber noch Tert. Scap. 3-4; Oros. 7, 8,12 und Apg 12,23, wobei sich bei letzterer die Erzählung auf lediglich einen einzigen Vers beschränkt und damit die kürzeste Darstellung bietet, die ohne den Topos, der in den früheren Werken etabliert wurde, nicht hätte verstanden werden können. Auch Plin. nat. 7,136 verweist in Anknüpfung an Plut. Sulla 36-38 auf den grausamen Tod des Sulla, dessen Körper sich selbst aufzehrte. In Plin. nat. 11,116 verweist Plinius bei der Beschreibung von Würmern, die im lebenden Menschen entstehen, auf Sulla und den griechischen Dichter Alkman. Tobias Arand zeigt außerdem auf, inwiefern Krankheit ein typischer Topos ist, mit dem ein schlechter Kaiser gekennzeichnet werden soll. Vgl. Arand (2002), 208-209 und allgemeiner 171.

112 Vgl. Hdt. 4,205. Es stellt sich die Frage, ob Galerius tatsächlich an Wurmbefall gestorben sei. Diese Fragestellung sollte idealerweise auf einer vorausgehenden literarischen Analyse des Werkes basieren. Eine literarische Detailanalyse müsste den Topos des Wurmbefalls über verschiedene Epochen hinweg untersuchen, Gemeinsamkeiten und Unterschiede herausarbeiten und dabei nicht versuchen, den historischen Wahrheitsgehalt dieser (meist Erzähl-)Texte herauszustellen. Africa, der eine breite Darstellung des Topos unternimmt, kommt zu dem Schluss: „What is common to all accounts is a fatal corruption of tissue in the lower abdomen, swarming with worms or 'lice' and emitting a terrible stench. An object of loathing, the victim of phthiriasis dies horribly and painfully. While Heaven bestows this affliction on the just and unjust alike, the disease is an appropriate punishment for cruel tyrants and enemies of God. The temptation for moralistic historians to inflict phthiriasis on hated rulers is obvious, and each episode must be judged on its own merits“. Africa (1982), 2. An dieser Erkenntnis ließen sich weitere Studien anschließen. Auch anderen literarischen Darstellungen wurde der Wahrheitsgehalt abgesprochen mit der Konsequenz, dass der Autor als nicht vertrauenswürdig eingestuft wurde. Vgl. Forschungsüberblick. Besonders häufig thematisiert wird die persönliche Unterhaltung zwischen Galerius und Diokletian, bei dem Laktanz nicht persönlich anwesend gewesen sein kann, diese aber in Dialogform wiedergibt. Verwiesen sei hier auf die Arbeit Wolfgang Kuhoffs, der auch die unkritischen Übernahmen der Gesprächsinhalte aufzählt. Kuhoff (2002), 180 - 181. Vgl. Lact. mort. pers. 18. Roland Steinacher untersuchte verschiedene Darstellungen des Wurmbefalls als literarische Topoi. Er zeigt, dass die Darstellung des Laktanz keine genuin neuen Aspekte erhält.

113 Steinacher (2003), 149.

114 Vgl. Jdt 16,17. 
mortibus persecutorum bietet in der Beschreibung des Wurmbefalls große Parallelen zum zweiten Makkabäerbuch. Der König Antiochos versucht, das Judentum zu unterdrücken. Auf dem Höhepunkt seiner Judenverfolgung wird er von Gott wegen seines Frevels bestraft und mit Würmern geschlagen: ${ }^{115}$

Es wuchsen auch Maden aus dem Leibe des Gottlosen, und er verfaulte mit großen Schmerzen, daß ganze Stücke von seinem Leibe fielen, und stank so übel, daß niemand vor dem Gestank bleiben konnte. ${ }^{116}$

Der Vorwurf in 2 Makkabäer ist auch, dass Antiochos sich für gottgleich gehalten habe. ${ }^{117}$ Galerius wird von Laktanz nicht explizit dieses Vergehens bezichtigt, stellt sich aber in die Nachfolgerschaft Diokletians und Maximianus', die ihre Gottgleichheit durch ihre Namenswahl zur Schau stellen.

Die Würmer sind in De mortibus persecutorum keine Krankheitsdämonen ${ }^{118}$, sie sind aber das Resultat der Dämonenanbetung des Galerius. Die Nähe zu den paganen Gottheiten, die mit der Ferne zum Christengott einhergeht, ist eben auch die Nähe zu Dämonen. War dem Rezipientenkreis also die Interpretation der Würmer als Krankheitsdämonen geläufig und erinnert sich der Leser daran, dass es sich bei den paganen Gottheiten um daemones handle, kommt er kaum umhin, den Schluss zu ziehen, dass derjenige, der sich mit Dämonen abgibt, zerfressen werden wird.

Da aber auch pagane Mythen von Wurmbefall als Strafe eines Gottes berichten, können auch nicht-christliche Rezipienten das Geschehene in ihren Erfahrungshorizont einordnen und das Handeln als wahrhaft göttlich verstehen. ${ }^{119}$ Laktanz legt seinen Fokus auf die moralischen Verfehlungen des Galerius, scheint aber auch mit den naturwissenschaftlichen Untersuchungen vertraut. ${ }^{120}$ Unter dem Stichwort aemulatio betrachtet, ist die Textpassage mit ihrer Nähe zum Makkabäerbuch als Hommage zu verstehen aber auch als Versuch, die Erzählung noch zu übertreffen. Die Elemente der Episode sind dieselben: Der verfolgende Herrscher, die Strafe Gottes, die Umkehr des Herrschers, das Edikt. Der Unterschied besteht jedoch darin, dass Laktanz den Text mit einer Vielzahl paganer Referenzen anreichert und ihn so aus seinem jüdisch-christlichen Verständnis in einen nicht-christlichen Verständniskontext überführt. Diese Loslösung erhöht nicht nur den Wiedererkennungswert bei nicht-

115 Vgl. 2 Makk 7-9.

116 Makk 9,9.

117 Vgl. 2 Makk. 7,37 und 9,12. Zur Tyrannentopik in Makk: Friedrich (1973), 99-100.

118 „Würmer sah man häufig als Krankheitsdämonen, die im menschlichen Körper sitzen und durch spezifische Beschwörungen auszutreiben seien“ Steinacher (2003), 145.

119 Steinacher unterstreicht, dass es in den paganen Textfunden sowohl eine „Rationalisierung des Motivs“ gibt - besonders bei den naturwissenschaftlichen Untersuchungen - als auch eine moralische Ausdeutung der Krankheit. Vgl. Steinacher (2003), 160.

120 Wie bereits gezeigt, hat ihm mit hoher Wahrscheinlichkeit Celsus vorgelegen. Vgl. in dieser Arbeit Seite 210, Anm. 101. Außerdem zitiert Laktanz selbst Plinius nat. 7,156-159 in den Divinae Institutiones $2,12,23$. 
christlichen Rezipienten, sondern zeigt, dass das Christentum eine eigenständige Instanz sei, die über den anderen Religionen stehe und sie übertreffe. Gott - und das kann nur der christliche Gott sein - sei in allen Religionen wahrnehmbar. Die Bestrafung durch Wurmbefall trägt „seine Handschrift“, auch wenn die Darstellungen ihm zuvor nicht zugeordnet worden sind.

Folgt man der plausiblen These, dass es sich um eine Selbstentstehung von Tierarten handelt, ${ }^{121}$ liegt die Frage nahe, ob Laktanz neben dem Topos des Wurmbefalls auch noch andere literarische Vorbilder $\mathrm{zu}$ Rate gezogen hat. Aristoteles postuliert, dass bestimmte Tiere wie Läuse, Flöhe oder Maden in Autogenese aus dem Fleisch oder dem Fell des Wirtes entstehen. ${ }^{122}$ Vergil führt die Entstehung von Bienen auf die Bugonie zurück, eine Autogenese aus einem Kuhkörper. ${ }^{123}$ Die Bugonie im dritten Buch der Georgica Vergils beschreibt, wie man aus einem jungen Stierkörper, der im Inneren zerstoßen wird, einen Bienenschwarm ziehen kann und stellt den Zusammenhang von Werden und Vergehen dar. Ein Tier wird geopfert, damit eine andere Tierart entstehen kann. Aus dem positiv besetzten Nutztier Stier können die ebenfalls positiv besetzten Bienen entstehen, die dem Imker seinen Lebensunterhalt garantieren. Aus der Bestie Galerius hingegen entstehen Würmer. Sicherlich ist das vorherrschende Motiv des Laktanz klar die Parallelisierung des Galerius mit den anderen Tyrannen, die wegen ihres Frevels von Gott durch ihre Verwesung und den Wurmbefall bestraft werden. Die Tatsache, dass aus den Tyrannen aber eben keine positiv besetzten Tiere entstehen, kann durchaus mit dem schlechten Nährboden zusammenhängen, den sie für die generatio spontanea bieten. Laktanz hat sicherlich die paganen und christlichen Prätexte gekannt und diese bewusst miteinander verwoben.

121 Im Forschungsdiskurs fokussiert sich Africa auf den „Wahrheitsgehalt“ der Passage und kommt zu dem Schluss: „At best, the accounts of Lactantius and Eusebius are too hyperbolic to be taken literally, and neither witnessed the awful scene. Both writers were pedants, familiar with the wormy agonies that religious bias had inflicted on Antiochus IV, Herod the Great, Judas, and Agrippa I. Their hatred is too great, their exaggerations too obvious, to warrant listing Galerius as a victim of phthiriasis“. Africa (1982), 14. Africa beruft sich auf die Beschreibung in Eus. HE 8,16,4-5 (Schwartz) Mommsen 1903-1909, 790). Die Beschreibung gleicht der des Laktanz in kürzerem Umfang. Dass die Betrachtung der Textstelle unter der Fragestellung „war es so?“" wenig ergiebig ist, zeigt er somit selbst. Bei einer solchen Herangehensweise kann das Fazit nur lauten, dass die literarische Darstellung in Frage gestellt werden muss und so das gesamte Werk seine Rechtfertigung verliert, weil es „offensichtlich“ nicht die „Wahrheit“ wiedergibt. Steinacher hingegen diskutiert die Historizität des Wurm-, beziehungsweise Läusebefalls und kommt zu dem Schluss, dass die Krankheit als generatio spontanea, dem unabhängigen Entstehen von Tieren, im literarischen Kontext gesehen werden muss. Er setzt diese Erkenntnis jedoch nicht in einen größeren literarischen Kontext. Vgl. Steinacher (2003).

122 Vgl. Aristot. hist. an. 5,1;31.

123 Vgl. Verg. Georg. 4,312ff. 


\subsubsection{Todesqualen. Lact. mort. pers. 35}

Gott, das heißt der christliche, sei der Gott des Alten Testaments, der Gott des Neuen Testaments, aber auch die eigentliche Instanz, die hinter den vermeintlichen paganen Gottheiten stehe und über Strafe und Vergebung entscheide.

Und dennoch empfing er für diese Tat keine Vergebung für sein Verbrechen von Gott, sondern wurde, wenige Tage nachdem seine Ehefrau und sein Sohn dem Licinius übergeben wurden, als ihm schon die Glieder des ganzen Körpers zerflossen, von grauenhaftem Eiter verzehrt. ${ }^{124}$

Galerius sterbe, indem sich seine Krankheit noch weiter ausbreite und ihn schließlich vollends verschlinge. Gleichzeitig erfährt der Leser, dass Sohn und Ehefrau des Galerius an Licinius übergeben worden seien. In seinem Sterbemoment ist Galerius völlig verlassen. Er hat seine Macht verloren, seine Frau und sein Sohn - Familienmitglieder, die erst einen Haushalt entstehen lassen - wurden seinem Feind übergeben, er hat ein Edikt verfasst, das seinem größten Bestreben als Herrscher zuwiderlief und verschwindet letztendlich vollständig. Consumere verweist darauf, dass nach dem Tod nichts mehr vom Tyrannen übrigbleibe. Es gebe keine Überreste, die begraben werden könnten, von einer Bestattung schreibt Laktanz nicht. Die fehlende Bestattung spiegelt die Strafe wider, die er den Christen habe angedeihen lassen, indem er sie nach dem Scheiterhaufen habe im Meer verstreuen lassen. Gleichzeitig gibt es auch nichts mehr, woran man sich erinnern könnte, wie einen Grabstein.

Diffluere verbildlicht die Todesqualen des Galerius. Obwohl das Edikt recht umfangreich Raum einnimmt, knüpft die Todesszene an die vorige Krankheitsbeschreibung an, bei der der Unterleib bereits völlig aufgelöst war. Noch während er das Edikt verfasst habe, müssen seine Gliedmaßen vom Eiter zerfressen worden sein. Es ergibt sich das Bild eines Mannes, der am Oberkörper verdorrt und ausgetrocknet ist und nun bereits keine Beine und keinen Unterleib mehr besitzt. Der grauenhafte Eiter wandere nun ähnlich wie Würmer oder Maden über den Rest des Körpers, bis keine Überreste mehr übrig sind.

\subsubsection{Zusammenfassung}

Während Galerius zu Beginn strategisch seinen Machtbereich vergrößert hat, verliert er sukzessive an Macht im Staat, sobald Konstantin beginnt politisch zu agieren. Das ganze Handeln des Galerius ist darauf ausgelegt, seinen Einfluss zu vergrößern und seinen Willen auch gegen den ranghöheren Diokletian durchzusetzen. Er wünscht immer grausamere Verfolgungen und bedroht seine Mitherrscher, bis sie zustimmen.

124 Nec tamen ille hoc facto veniam sceleris accepit a deo, sed post dies paucos commendatis Licinio coniuge sua et filio atque in manum traditis, cum iam totius corporis membra diffluerent, horrenda tabe consumptus est. Lact. mort. pers. 35,3 (Brandt/Laubmann 1897, 214,5-8). 
Schließlich muss er allerdings ertragen, dass seine Mitherrscher - sogar der von ihm eingesetzte Daia - sich gegen ihn wenden. In dieser bereits machtlosen Position wird er von Gott mit einer unheilbaren Krankheit geschlagen. Ausführlich beschreibt Laktanz den Krebs und die anschließenden Leiden des Galerius. Diesem kann nicht geholfen werden und die Versuche, pagane Götter um Hilfe zu bitten, verschlimmern die Situation. ${ }^{125}$ Erst als er schon beinahe tot ist, bittet er um Vergebung. Er erlässt eine Verlautbarung, die die Christenverfolgung stoppen soll. In der Darstellung des Schreibens erkennt Galerius Gott aber nicht an, sondern entscheidet rein aus Milde und Kalkül, dass es besser sei, dass die Christen ihren Gott anbeteten, als dass sie gar keinen Gott anbeten. ${ }^{126}$

Zwei Gründe sind möglich, aus denen Galerius trotz seines Eingeständnisses stirbt. Obwohl Galerius Gott erkennt, ist er durch seinen schlechten Charakter nicht in der Lage, religio auszuüben. Er besitzt nicht die Größe, seinen Fehler einzugestehen und offiziell seine Gotteserkenntnis zu bekennen. Für Laktanz besteht jedoch gerade im Bekenntnis zu Gott und dem Willen, negative Konsequenzen für seinen Glauben auf sich zu nehmen, die Aufgabe eines Menschen, der religio hat. Auch wenn Galerius einen Teil seiner bestialischen Natur abgelegt hat, ist er trotzdem nicht in der Lage, seiner anthropologischen Ausrichtung gerecht zu werden. Sein Charakter hindert ihn daran. Der Tyrann hat zwar erkannt, dass Gott die lenkende Instanz und der einzig wahre Gott ist, ist aber nicht bereit, dies als Herrscher einzugestehen, weil damit klar würde, dass er sich in seinem Vorgehen und seiner gesamten Verfolgungspolitik geirrt hat. Letztlich erfährt er keine Vergebung, sondern stirbt bereits völlig in Eiter aufgelöst. Der grausamste aller Tyrannen stirbt seinen Gräueltaten entsprechend. Zusammenfassend ist die Gewalt, die an Galerius verübt wird, unzweifelhaft grausam.

Gott, der ihn mit einem Geschwür geschlagen hat, ist die einzige Instanz, die Galerius retten könnte. Dadurch, dass er sich an pagane Gottheiten und Ärzte wende, bleibe ihm jegliche Linderung verwehrt. Der Krankheitsverlauf ist dem Topos eines von Würmern zu Grunde gerichteten Tyrannen entsprechend aufgebaut. Laktanz folgt deutlich 2 Makk, bezieht aber auch oder gerade pagane Darstellungen mit ein. ${ }^{127}$ Letztendlich ist der Topos ausschlaggebend für die Todesart: Immer wieder finden sich Beschreibungen eines Tyrannen, der von den Göttern wegen seiner Tyrannei durch Wurmbefall niedergestreckt wird. Der Umfang der Passage übersteigt die

125 Immer wieder wird in der Forschung erklärt, dass Laktanz Galerius auf Grund seiner Krankheit zum Hauptverantwortlichen der Christenverfolgungen gemacht habe. Vgl. Gelzer (1935), 35-44; Davies (1989).

126 Sebastian Schmidt-Hofner sieht in der Formulierung des Edikts einen Fokus auf die disciplina der Christen, die sich am Erhalt der pax deorum beteiligen müssten. Es gehe darum, „der nicht-christlichen Reichsbevölkerung eine Kehrtwende in der Religionspolitik, nämlich das Ende der Verfolgungen, plausibel zu machen, die mit den traditionellen Legitimationsgrundlagen des Kaisers unvereinbar waren und erheblichen Rechtfertigungsdruck erzeugten“ Schmidt-Hofner (2016), 178-179. Diese These wurde bereits von Jochen Bleicken vertreten: Bleicken (1992), 7.

127 Vgl. Hdt. 4,205; Plut. Sulla 36-38; Plin. nat. 11,116. Vgl. Seite 214, besonders Anm. 112 in dieser Arbeit. 
anderen Todesszenen bei Weitem. Auffällig ist auch, dass das Edikt des Galerius von seinen Todesqualen und seinem endgültigen Tod gerahmt wird. Durch diese Rahmung bekommt die Krankheitsbeschreibung eine Legitimation, da das wörtliche Edikt ${ }^{128}$ ein Beweis für die Historizität des Werkes darstellen möchte. Wenn ein solches oder so ähnliches Edikt bekannt war und der Wortlaut dem üblichen Wortlaut eines solchen Edikt entsprochen hat, wirkt es glaubhaft, dass auch der Krankheitsverlauf und die Todesart der Schilderung des Laktanz entsprochen haben.

\subsection{Maximinus Daia}

\subsubsection{Der Machtverlust. Lact. mort. pers. 43-44}

Maximinus Daia, der sich besonders gegen Galerius aufgelehnt habe, soll als letzter Gegner Gottes sein Leben verlieren:

Ein einziger war übrig von den Widersachern Gottes, dessen Niedergang und Sturz ich nun beschreiben werde. ${ }^{129}$

Laktanz beschreibt, wie Maximinus Daia einen Hinterhalt gegen Licinius plane, indem er eine Allianz mit Maxentius eingehe, der seinerseits gegen Konstantin vorzugehen versuche. ${ }^{130}$ Nach dem Sieg Konstantins über Maxentius wende sich das Schicksal für Maximinus Daia. Ihm werde der Ehrentitel des Augustus aberkannt und auf Konstantin selbst übertragen:

Der Senat beschloss für Konstantin wegen dessen virtus den Titel des höchsten Namens, den Maximinus für sich in Anspruch nahm. Als ihm der Sieg der befreiten Stadt berichtet worden war, nahm er ihn nicht anders auf, als wenn er selbst besiegt worden wäre. Als er schließlich über den Senatsbeschluss in Kenntnis gesetzt worden war, entbrannte er so sehr vor Schmerz, dass er seine Feindschaft öffentlich bekannte und Schmähungen mit Scherzen vermischt gegen den größten Feldherrn aussprach. ${ }^{131}$

Anmerkung zu 4.4: In diesem Kapitel behandelte Textabschnitte: Lact. mort. pers. 43,1; 44,11-12; 45,$3 ; 46,8-9 ; 47,4-6 ; 49,1-2 ; 49,3-4 ; 49,4-5 ; 49,5-7$.

$128 \mathrm{Ob}$ es sich hier um eine tatsächlich wörtliche Widergabe handelt, ist für die Bedeutung der Passage nicht relevant. Es soll an dieser Stelle keine Entscheidung getroffen werden, ob es sich bei dem von Laktanz beschriebenen Edikt um ein „sogenanntes Edikt“, ein „Reskript“, eine „Dienstanweisung“, einen Brief oder etwas völlig anders Geartetes handelt. Zur Diskussion um den Begriff des „Mailänder Toleranzedikts“ siehe ausführlicher Seeck (1981), 381-386 als Auslöser der Diskussion, Rist (2001), 217-223 und Zecchini (2016).

129 Unus iam supererat de adversariis dei Maximianus: cuius nunc exitum ruinamque subnectam. Lact. mort. pers. 43,1 (Brandt/Laubmann 1897, 222,9-10).

130 Vgl. Lact. mort. pers. 43,2-4.

131 Senatus Constantino virtutis gratia primi nominis titulum decrevit, quem sibi Maximinus vindicabat: ad quem victoria liberatae urbis cum fuisset adlata, non aliter accepit, quam si ipse victus esset. cognito 
Er ist der letzte Tyrann, der durch den Abgesandten Gottes besiegt werden muss und gerade in dem Moment, in dem sich Konstantin vor der Schlacht an der Milvischen Brücke offiziell auf die Seite des Christengottes stelle, ist das Schicksal des Widersachers besiegelt. Konstantin, unter dem Schutz Gottes, steigt im Staat weiter auf und bekommt den Titel zugesprochen, den Daia trägt. Gott hat die Macht, den Sieg einer Partei zu evozieren und entscheidet sich für Konstantin, der sich für den Christengott entschieden hat. ${ }^{132}$ Der Schritt vorwärts des christlichen Konstantin ist der erste Schritt rückwärts für den antichristlichen Daia. Diese Wende zeigt sich unter anderem darin, dass der Senat beschließe, Konstantin zum Augustus zu ernennen und nicht etwa er selbst, wie es bei Galerius der Fall gewesen war. Mit dem Fall des Daia, des letzten Tyrannen, geht auch die Wiederherstellung der rechten Staatsgewalt, der Res Publica einher. Die Macht, die Staatsführung zu ernennen, werde wieder auf den Senat übertragen, die dynastische Herrschaft, wie sie besonders in der Tetrarchie zu gipfeln scheint, bei der ein Herrscher all seine Mitherrscher ernennt, wird wieder abgeschafft. Der Titel werde virtutis gratia verliehen, nicht um die Macht eines Tyrannen zu stärken, um eine Dynastie zu bedienen oder aus Gefälligkeit. ${ }^{133}$ Die Wiederherstellung der staatlichen Ordnung gehe mit der Wiederherstellung der kirchlichen Freiheit einher, die unter den Tetrarchen zerstört worden war. Die Freiheiten und der Titel, die Daia unrechtmäßig besessen habe, gehen zurück in das rechtmäßige System. Besonders deutlich wird hierdurch, dass der Sieg des Christentums - oder in diesem Fall, die Anerkennung eines christlich agierenden Kaisers - gleichbedeutend ist mit der Befreiung des gesamten Staates von der Tyrannei. Dieser Prozess muss schrittweise voranschreiten, wie auch der Tod des Daia sich schrittweise vollzieht. Der Verlust des Titels ist der Anfang seines Untergangs.

Auch die Nachricht über den Sieg Konstantins an der Milvischen Brücke ist für Daia ein Schlag, der ihn treffe, als sei er selbst besiegt worden. Die Allianz, die er mit Maxentius trifft, war für keinen der beiden hilfreich. Gesteigert wird das Leid des Daia,

deinde senatus decreto sic exarsit dolore, ut inimicitias aperte profiteretur, convicia iocis mixta adversus imperatorem maximum diceret. Lact. mort. pers. 44,11-12 (Brandt/Laubmann 1897, 224,18-23).

132 Tamás Adamik verweist darauf, dass das Vergilzitat diesen Umstand unterstütz. Vgl. Adamik (1984), 90.

133 Konstantin wird so in die unmittelbare Nachfolge des Augustus gestellt, der im Kontext christlicher Geschichtsschreiber zumeist eine herausragende Rolle einnimmt, da in seiner Regierungszeit Jesus geboren ist. Die Parallelisierung des Konstantin mit Augustus, die sich noch durch zahlreiche Punkte ergänzen ließe, bietet teleologisch die Möglichkeit, Christus mit der Ecclesia gleichzusetzen: Unter Augustus ist Christus geboren, unter Konstantin ist die Ecclesia wiedergeboren. Ein neues Zeitalter setzt mit beiden Kaisern ein, die Abwege der Vergangenheit werden überwunden, sei es die Bürgerkriegszeit der ausgehenden Republik, sei es die Leiden und Wirrungen unter den Tetrarchen. Auch die Ausrufung der Kaiser durch die Soldaten beschreibt Laktanz hier nicht. Hat er wenige Kapitel zuvor noch die Ausrufung Konstantins als Nachfolger seines Vaters legitimiert, bekräftigt er die Herrschaft als Augustus durch den Senat. Konstantin ist somit sowohl im tetrarchischen System und dessen inhärenten Logik ein legitimer Herrscher, da er dynastisch auf den guten Herrscher Constantius folgt und in der eigentlichen Dynastie aus niederen Beweggründen übergangen würde, als auch aus Sicht der Res Publica, die an dieser Stelle sicherlich als restituta zu verstehen ist. 
indem er vom Senatsbeschluss zu Ehren Konstantins erfährt. Während der Rezipient bei Diokletian erfährt, dass dieser sich selbst für einen guten Herrscher halte, der den Staat zu schützen versuche, überliefert uns Laktanz keine solche Einschätzung zu Daia. Der Tyrann sei von seiner Wesensart her in vielerlei Hinsicht untugendhaft. ${ }^{134} \mathrm{Er}$ raube und vergewaltige. Konstantin hingegen zeichne sich durch virtus aus, die dem Verhalten des Daia diametral entgegensteht. Es bleibt unklar, ob Daia zu irgendeiner Form von Selbsterkenntnis komme, wahrscheinlich ist aber, dass ihn schlichtweg der Verlust seiner Ehrentitulatur und seiner Machtstellung im Reich erschüttert. Laktanz beschreibt die Gefühlsregung, die Daia empfindet als dolor.

Sein Leid beginnt durch psychische Belastung, die ihm Schmerzen verursache. Die Dinge, die mit anderen Herrschern geschehen, hätten unmittelbar Einfluss auf die Gefühlswelt des Daia, der durch die psychische Belastung, die der Titel- und somit auch Machtverlust mit sich bringt, Leid empfindet, das als körperlicher Schmerz in Erscheinung tritt. Die Reaktion des nun Caesaren ist eine Form von Gegengewalt. Er mache Witze und verbreite Schmähungen gegen Konstantin. Er richtet seinen Fokus auf Konstantin, der diese Ehren nicht selbst an sich gerissen, sondern sie auf legitimem Staatsweg angetragen bekommen hat. Die Scherze und Schmähungen stehen der virtus des Konstantin deutlich entgegen, sollen sie doch eben diese virtus in Frage stellen oder relativieren. Laktanz erklärt nicht, um welche Art von Beleidigungen es sich handelt, aber ein Blick in die gängigen Invektiven der Antike macht deutlich, welches Ausmaß die Schmähungen für gewöhnlich annahmen. Durch die Auslassung von Details ermöglicht Laktanz den Rezipienten, diese Leerstelle eigenständig zu füllen. Manche haben möglicherweise über die Beleidigungen Daias gehört, andere kennen die Gattung der Invektive und projizieren ihre Vorkenntnisse auf die geschilderte Situation. Das öffentliche Bekenntnis zur Feindschaft ist der Zeitpunkt, an dem auch die Beleidigungen als Angriffe aufgefasst werden müssen.

Laktanz lässt den Kaiser von einer persönlichen, zwischenmenschlichen Feindschaft sprechen, als ob zwei gleichgestellte Anhänger unterschiedlicher politischer Strömungen miteinander uneins wären. Indem er den Begriff inimicitia wählt, forciert er die Reflexion über die Frage, wessen Feind Daia letztendlich sei. Obwohl Daia sich als persönlichen Widersacher Konstantins zu verstehen gibt, weiß die Leserschaft, dass er für Laktanz der Feind des ganzen Staates, des Staatswesens und des Christentums ist. Gleichzeitig kommt somit zum Ausdruck, dass Daia nicht ernstgenommen werden könne, besonders weil er diese negativen Aussagen gegen den maximus imperator, den größten Feldherrn, richte.

134 Siehe in dieser Arbeit ab Seite 103. 


\subsubsection{Die Schlacht und Niederlage gegen Licinius. Lact. mort. pers. 45-47}

Als Reaktion auf die familiäre Verbindung zwischen Konstantin und Licinius, die durch die Ehe des Licinius mit der Schwester Konstantins bekräftigt wurde, beschließe Maximinus Daia, Licinius anzugreifen. Beim Marsch nach Perinth fordere Daia seine Truppen so stark, dass sie, durch die Wetterverhältnisse und langen Marschetappen geschwächt, Mühe haben, sich gegen die kleinen Außenposten des Licinius durchzusetzen. Die Strapazen des Weges beschreibt Laktanz als Omen für die Unternehmung des Daia:

Denn durch immense Regenfälle und Schnee und Schlamm und Kälte und Strapazen wurde Vieh jeder Art verloren, dessen elender Verlust auf dem Weg den Soldaten schon den Anblick des künftigen Krieges und eine ähnliche Niederlage berichtete. ${ }^{135}$

Durch sein rücksichtsloses Vordringen nimmt Daia den Verlust seiner Lasttiere in Kauf. Wenn die Tiere bereits durch die Anstrengungen sterben, hat das zum einen die Folge, dass die Lasten nicht mehr transportiert werden können und auch Lebensmittel knapp werden, zum anderen, dass auch die Soldaten ausgezehrt sind. Die Wetterphänomene, die den Soldaten und Tieren zusetzen, beschreibt Laktanz polysyndetisch und gibt so jedem einzelnen Umstand bildlich Raum, die Tiere zu schwächen. Bereits starke Regenfälle allein, Schnee allein, schlammige Wege, Kälte oder harte Anstrengung allein wären genug gewesen, die Truppen zu schwächen. Die Kombination all dieser Umstände mache es den Soldaten nahezu unmöglich, ans Ziel zu gelangen. Hinzu kommt die Demoralisierung der Truppen durch den Verlust ihres Viehs. Den Soldaten sei bewusst, dass es ihnen bald genauso ergehen werde wie den Tieren. Laktanz lokalisiert das Leid der Soldaten erst im Krieg, den sie seiner Meinung nach unter großen Verlusten verlieren werden, aber auch die körperlichen Konsequenzen des Marschs dürften sich bei den Truppen bemerkbar gemacht haben. Der Anblick der verendeten Tiere steht proleptisch für den Ausgang einer Schlacht, bei der die Soldaten ausgezehrt und vom Marsch erschöpft keine Chance mehr gegen Truppen haben, die im Besitz ihrer vollen Kräfte sind. Nuntiare als Verb der Berichterstattung unterstreicht die Unumgänglichkeit der Niederlage und der hohen Verluste. Die Truppen selbst werden nicht für ihr Leid und ihren folgenden Tod verantwortlich gemacht. Vielmehr setze Daia den Sieg und das Leben seiner Kämpfer aufs Spiel, weil er aus persönlicher Ablehnung heraus das Glück der beiden anderen Herrscher ausnutzen möchte, um seine Vorrangstellung wiederherzustellen und seine Macht zu sichern. Gleichzeitig provoziere er seinen eigenen Untergang.

Kurz bevor es zum Kampf kommt, stünden sich Licinius und Daia mit ihren Truppen gegenüber, wobei die Truppengröße des Daia mehr als doppelt so groß sei

135 Nam maximis imbribus et nivibus et luto et frigore et labore iumenta omnis generis amissa sunt, quorum miserabilis per viam strages speciem iam futuri belli et similem cladem militibus nuntiabat. Lact. mort. pers. 45,3 (Brandt/Laubmann 1897, 225,6-9). 
wie die des Licinius. ${ }^{136}$ Daia opfere Jupiter mit dem Gelöbnis, die Christen vollständig zu vernichten, wenn er den Sieg erringe. ${ }^{137}$

Als es zur Schlacht komme, sei nach Laktanz die Niederlage des Maximinus bereits vorbestimmt:

Der Feldherr [sc. Licinius] setzte die Schlacht am Tag der Kalenden des Mai fest, die das achte Jahr der Ernennung dessen [sc. Daia] vollendeten, sodass er am ehesten an seinem Geburtstag besiegt werde, so wie jener [sc. Maxentius] in Rom besiegt wurde. Maximinus wollte früher vorrücken; Am Vortag stellte er in der Frühe seine Schlachtreihe auf, damit er seinen Geburtstag am Folgetag als Sieger feiern könnte. ${ }^{138}$

Wenn Licinius den Schlachttag auf den Ernennungstag des Maximinus Daia legt, zeigt dies proleptisch den Ausgang der Schlacht an; Daia soll so besiegt werden, wie Maxentius besiegt worden ist, mit dem er zuvor eine Allianz eingegangen war. Der Sieg am dies nuncupationis, der mit dem dies natalis gleichgesetzt wird, verweist auf die Unrechtmäßigkeit der Herrschaft Daias. Am selben Tag, an dem er die Kaiserwürde innerhalb des tetrarchischen Systems verliehen bekommen habe, werde sie ihm aufgrund seiner Tyrannenherrschaft wieder aberkannt. Der Verlust der Kaiserwürde an ebendiesem Tag zeigt gleichzeitig die Kritik an der persönlichen Herrschaft des Daia als auch am System der Tetrarchie, die durch die Überwindung Daias nun von einer republikanisch anmutenden Zweierherrschaft abgelöst wird, und zuletzt am Vertrauen auf pagane Gottheiten, die in der Auseinandersetzung mit einem christlich agierenden Widersacher das Nachsehen haben müssen. Die Niederlage am eigentlichen Feiertag käme aus der Perspektive des Maximinus Daia einer Inversion des Tages gleich. Aus Perspektive des Volkes betrachtet wäre die Abschaffung eines Tyrannen an einem eigentlichen Feiertag ein noch viel größerer Grund zur Freude und ersetzt so die Feierlichkeiten durch das Wiedergewinnen der Freiheit.

Laktanz berichtet, dass Daia genau die gegenteiligen Überlegungen angestellt habe bei der Wahl des Schlachtzeitraums: Wenn er die Schlacht siegreich beende, gäbe es mehr Gründe zum Feiern, neben den Jubiläumsfeierlichkeiten könnte ein Triumphzug gehalten werden, seine Herrschaft wäre bestätigt worden und er wäre zum Alleinherrscher über den Westen erhoben worden, was mit einer erneuten Krönung gleichzusetzen wäre. Nach vollbrachter Arbeit könnte er seine Feier doppelt genießen. Beide Positionen gehen also von einem unausweichlichen Sieg aus und planen die Siegesfeierlichkeiten in Übereinstimmung mit den Jubiläumsfeierlichkeiten. Daia übernimmt so die Machtposition, da er Licinius dazu nötigt, entgegen seiner Pläne zu handeln, was neben topographischen Gegebenheiten die Kriegsführung und

136 Vgl. Lact. mort. pers. 45,7.

137 Vgl. Lact. mort. pers. 46,2.

138 Statuit imperator proelium diei Kalendarum Maiarum, quae octavum annum nuncupationis eius implebant, ut suo potissimum natali vinceretur, sicut ille victus est Romae. Maximinus voluit praeire maturius: pridie mane aciem composuit, ut natalem suum postridie victor celebraret. Lact. mort. pers. 46,8-9 (Brandt/Laubmann 1897, 226,27-227,4). 
-taktik der anderen Partei massiv beeinflussen kann. Immerhin geht Licinius ein Tag „verloren“, an dem er seine Truppe vorbereiten, Vorräte sammeln, Schlachtpläne strukturieren und durchdenken kann. Es handelt sich gewissermaßen um eine Hierarchisierung unter den Gegnern: Licinius setze einen Termin an, den Daia nach vorne verschiebe und nicht nur die Entscheidung zur Schlacht treffe, sondern auch noch signalisiere, dass er trotz schwerem Marsch früher bereit sei zu kämpfen als sein Gegner. Durch diese Zurschaustellung der Siegesgewissheit kann auch von einer Art psychologischen Kriegsführung gesprochen werden. Licinius bereite sich unter dem Beistand des christlichen Gottes auf die Schlacht vor. Seine Truppen seien den Truppen des Daia überlegen, woraufhin Daia vergeblich versuche, die gegnerischen Truppen durch Bestechung zum Überlaufen zu überreden. ${ }^{139}$ Als Daia erkenne, dass seine Truppen niedergestreckt werden, entscheide er sich zur Flucht:

\begin{abstract}
Maximinus sieht, dass die Situation anders verläuft, als er dachte. Er schmeißt sein Purpurgewand fort und flieht, nachdem er ein Sklavengewand angelegt hatte, und schmeißt sich ins Meer. Aber im Heer war die eine Hälfte dahingestreckt worden, der andere Teil aber hatte sich entweder ergeben oder war in die Flucht geschlagen worden; Es hatte der Überläufer-Feldherr die Schmach eines Überläufers angenommen. Aber jener gelangte an den Kalenden des Mai, das heißt eine Nacht und einen Tag später, in der nächsten Nacht nach Nikomedien, [und] als das Schlachtfeld 160 Meilen weit entfernt war und nachdem er seine Söhne, seine Gattin und wenige Palastangestellte geraubt hatte, brach er zum Orient auf. Aber in Kappadokien blieb er, nachdem er seine Soldaten nach der Flucht und aus dem Orient versammelt hatte. So legte er sein Gewand wieder an. ${ }^{140}$
\end{abstract}

Statt sich mit samt seiner Truppen zurückzuziehen und zu kapitulieren, lasse Maximinus Daia seine Truppen im Stich. Er werfe sein Purpurgewand, das Zeichen seines Standes, von sich und tausche es gegen ein Sklavengewand ein. So vollzieht Daia äußerlich den Statusverlust, den er durch die Niederlage gegen Licinius ganzheitlich zu erwarten habe. Die Strafe des Statusverlusts spiegelt auch die Vergehen des Daia wider, der selbst für den Statusverlust vieler Untergebener gesorgt habe, indem er sie zu einem gottlosen Krieg gezwungen und sie durch Bestechung zu Überläufern gemacht habe. Der Rezipient erfährt nur, dass die Schlacht anders verlaufen sei, als Maximinus Daia sich dies erhofft habe. Theoretisch wäre es noch möglich, dass die Schlacht zu seinen Gunsten ausgeht, durch seine Flucht räumt er diese Option jedoch aus der Welt. Sein Handeln ist gänzlich unangebracht für einen Kaiser und Kommandanten, der seine Truppen während einer Schlacht keinesfalls im Stich lassen sollte. Nicht einmal der im Werk zu Beginn beschriebene Valerianus habe seine

139 Vgl. Lact. mort. pers. 46,10-47,3.

140 Videt Maximinus aliter rem geri, quam putabat. proiecit purpuram et sumpta veste servili fugit ac fretum traiecit. at in exercitu pars dimidia prostrata est, pars autem vel dedita vel in fugam versa est: ademerat enim pudorem deserendi desertor imperator. at ille Kalendis Mais id est una nocte atque una die, Nicomediam alia nocte pervenit, cum locus proelii abesset milia centum sexaginta, raptisque filiis et uxore et paucis ex palatio comitibus petivit Orientem. sed in Cappadocia collectis ex fuga et ab Oriente militibus substitit. ita vestem resumpsit. Lact. mort. pers. 47,4-6 (Brandt/Laubmann 1897, 227,27-228,8). 
Truppen im Stich gelassen, obwohl er als Konsequenz grausam versklavt und schließlich hingerichtet worden war. ${ }^{141}$

Wie ich bereits für Frauenkleidung gezeigt habe, ${ }^{142}$ ist es ein Zeichen von fehlender virtus, standesunangemessene Kleidung zu tragen. Mit der Beschreibung, dass der Kaiser sich ins Meer stürze, greift Laktanz gedanklich die Todesszene des Diokletian wieder auf, die das wogende Meer mit der emotionalen Problematik des Augustus verknüpft hatte. Die Rezipienten können erwarten, besonders da hier die Beschreibung des Daia vom Blick auf sein Heer unterbrochen wird, dass dieser im Meer zu Tode kommt. Auch wenn dies nicht geschieht, wird sein Tod durch diese Anspielung bereits antizipiert. Mit dem sozialen Sturz des Tyrannen und seinem wörtlichen Sprung ins Meer ist sein endgültiger Sturz unvermeidbar.

Im Zeitraffer vergehen anderthalb Tage und der Tetrarch sei in Nikomedien angekommen. Die zwischenzeitlich geschehenen Aktionen drückt Laktanz in Partizipialkonstruktionen aus und rafft so die Erzählzeit noch weiter. In nur einem Satz beschreibt er, dass Daia 160 Meilen in einem Tag und einer Nacht zurückgelegt habe und anschließend samt Familie und Hofstaat weiterreise. Während er äußerlich als Sklave in Erscheinung trete, habe er dennoch einen Teil seines Hofstaates bei sich. Es scheint absurd, dass niemand den Kaiser erkannt haben soll auf dessen Reise, doch Laktanz greift hier die Ernennung des Daia durch Galerius auf, bei der Diokletian selbst keine Kenntnis darüber hatte, wer dieser Halbbarbar eigentlich sein solle. ${ }^{143}$

$141 \mathrm{Vgl}$. non multo post Valerianus quoque non dissimili furore correptus impias manus in deum intentavit et multum quamvis brevi tempore iusti sanguinis fudit. at illum deus novo ac singulari poenae genere adfecit, ut esset posteris documentum adversarios dei semper dignam scelere suo recipere mercedem. hic captus a Persis non modo imperium, quo fuerat insolenter usus, sed etiam libertatem, quam ceteris ademerat, perdidit vixitque in servitude turpissime. nam rex Persarum Sapor, is qui eum ceperat, si quando libuerat aut vehiculum ascendere aut equum, inclinare sibi Romanum iubat ac terga praebere et imposito pede super dorsum eius illud esse verum dicebat exprobrans ei cum risu, non quod in talibus aut parietibus Romani pingeret. ita ille dignissime triumphatus aliquamdiu vixit, ut diu barbaris Romanum nomen ludibrio ac derisu esset. Lact. mort. pers. 4,1-6 (Brandt/Laubmann 1897, 178,10 - 179,6): „Nicht viel später wurde auch Valerian von nicht unähnlichem Wahnsinn hinfortgerissen und streckte seine gottlosen Hände gegen Gott aus und vergoß, wenn auch nur kurze Zeit, viel gerechtes Blut. Aber jenem ließ Gott eine neue und ungehörte Art von Strafe angedeihen, damit er der Nachwelt zum Beweis dafür diene, dass die Gegner Gottes stets die gerechte Strafe für ihre Verbrechen erhalten. Dieser wurde von den Persern gefangengenommen und verlor nicht nur seine Herrschaft, die er unverschämt ausgeübt hatte, sondern verlor auch die Freiheit, die er den übrigen genommen hatte. Er lebte in schändlichstem Sklavendienst. Der Perserkönig Sapor nämlich, der Mann, der ihn gefangengenommen hatte, befahl, dass der Römer sich vor ihm niederknien und den Rücken hinhalten müsse, wenn es ihm beliebte seinen Wagen oder sein Pferd zu besteigen. Und während er den Fuß auf seinen Rücken setzte, sagte er ihm vorwurfsvoll und unter Gelächter, dass dies die Wirklichkeit sei, und nicht, was die Römer auf Bilder oder Wände malten. So lebte jener, der am ehesten würdig war, besiegt zu werden, eine ganze Zeit lang, so dass lange den Barbaren die Bezeichnung Römer Anlass zu Spott und Hohn gab“. Diese Todesart ist für Valerianus vorher nicht belegt. Möglicherweise handelt es sich um eine Anspielung auf den persischen Gnostiker Mani. Vgl. auch Arand (2002), 169, besonders Anm. 905.

142 Zur Frauenkleidung siehe Seite 197 in dieser Arbeit, besonders Anm. 57.

143 Siehe hierzu Seite 110 in dieser Arbeit. 
Auch nach seiner Amtszeit ist er offensichtlich immer noch unbekannt - sogar dem eigenen Volk. Im Orient ziehe er seine Truppen wieder zusammen und kombiniere die dort stationierten Soldaten mit denjenigen, die nach der Schlacht geflohen sind. Mit der Stärke seiner Truppen bewaffnet, lege er sein kaiserliches Gewand wieder an und trete erneut ins öffentliche Leben.

\subsubsection{Die Todesqualen. Lact. mort. pers. 49}

Nach einer Passage über litterae ${ }^{144}$ des Licinius und des Konstantin zur Wiederherstellung der Kirchen, beschreibt der Autor die zeitlich anschließende Verfolgung des Daia:

Der Flüchtige entwich dem Licinius, der den Tyrannen mit seinem Heer verfolgte, und er kehrte zurück in die Enge des Taurusgebirges. Er versuchte mit Bauten von Befestigungen und Türmen den Weg zu versperren und hinabgedrängt von den Siegern, die alles überrannten, floh er letztlich nach Tarsus. Als er dort schon von Land und Meer aus bedrängt wurde und keine Zuflucht mehr hoffen konnte, floh er sich aus Enge des Herzens und Furcht in den Tod wie in ein Heilmittel der Übel, die Gott in dessen Haupt eingegeben habe. ${ }^{145}$

Licinius verfolgte mit seinem Heer Daia, der sich flüchte und durch Schutzwälle zu schützen suche. Nach intensiver Verfolgung begehe Daia Selbstmord. Die gesamte Verfolgung über bleibt er Subjekt der Handlungen, die zwölf Verbalhandlungen umfasst, von denen sequens, profugus, concedere, petere, confugere (2x) und premere aus dem Wortfeld „verfolgen-fliehen“ stammen. Die hohe Anzahl der Verbalhandlungen und die Verknüpfung mehrerer Handlungen in kurzer Abfolge verleiht der Passage eine größere Dynamik. Die Flucht läuft rasend schnell. In jedem Satz findet sich sowohl eine Flucht- als auch eine Verfolgungshandlung, die das Nachsetzen des Licinius verbildlicht. Die Kombination von Prädikaten und Partizipien wirkt wie eine Art Zeitraffer. Selbst der Bau von Befestigungsanlagen ist in einer Partizipialkonstruktion dargestellt.

Daias Plan, sich im Gebirge zu verschanzen, setze Licinius schon durch die schiere Masse an Soldaten außer Kraft, die über den Rückzugsort hereinfallen. Durch perrumpentibus omnia victoribus greift Laktanz einerseits zurück auf den Ausgang der Schlacht, bei der Licinius bereits siegreich war und seine Truppen die Truppen Daias entweder in die Flucht geschlagen oder getötet hatten. Andererseits ist victores pro-

144 Zur Diskussion um den Begriff des „Mailänder Toleranzedikts“ siehe Seite 219, Anm. 128 in dieser Arbeit.

145 Sequenti autem Licinio cum exercitu tyrannum profugus concessit et rursus Tauri montis angustias petiit. munimentis ibidem ac turribus fabricatis iter obstruere conatus est et inde detrusus perrumpentibus omnia victoribus Tarsum postremo confugit. ibi cum iam terra marique premeretur nec ullum speraret refugium, angore animi ac metu confugit ad mortem quasi ad remedium malorum, quae deus in caput eius ingessit. Lact. mort. pers. 49,1-2 (Brandt/Laubmann 1897, 233,21-234,5). 
leptisch zu lesen, da die Truppen auch in dieser Schlacht siegreich sein werden und bereits in dieser Szene der Sieg errungen wird. Der Kampf ist bereits entschieden. Auch in dieser scheinbar ausweglosen Situation erkenne der Unterlegene seine Niederlage nicht an und verzögere den Ausgang noch weiter. Die stetig neuen Hindernisse, die Daia seinem Gegner entgegen zu bringen versucht, stehen im diametralen Gegensatz zur raffenden Erzählweise des Abschnitts. So kommt zum Ausdruck, dass alle Versuche, sich der Strafe Gottes zu entziehen, nur kurzweilig sein können. Der Rezipient weiß, dass Daia unterliegen wird und er hat im Verlauf des Werks bereits gelernt, dass Gottes Strafe immer Erfüllung findet, selbst wenn sie nicht als solche erkennbar ist. Somit kann das „Zeitschinden“ des Kaisers nicht lange währen.

Daia könne weder zu Land noch zu Meer auf einen sicheren Zufluchtsort hoffen. Licinius und seine Truppen, vermutlich aber auch die Unterstützung Konstantins, haben alle Gebiete unter Kontrolle. Zum einen ist Tarsus lokal gesehen von den Truppen umstellt, übertragen gesehen haben Licinius und Konstantin, respektive der christliche Gott, aber bereits ihre Herrschaft über den gesamten Erdkreis ausgebreitet. Stand Licinius anfangs noch cum exercitu im Singular der Verbalhandlung, sind die victores nun im Plural angeführt. ${ }^{146}$ Auch die Gefühlswelt Daias, die durch die Flucht im Meer bereits eine Reminiszenz an die wogenden Gefühle des Diokletian erfahren hat, tritt nun in den Vordergrund. Er sei pleonastisch angora animi ac metu von Furcht erfüllt und der Tod sei das Heilmittel für die überwältigende Situation. Der Pleonasmus greift die Angstbeschreibung des Diokletian in 9,6 wieder auf. Während der Rezipient Diokletian von Beginn des Werkes als in omni tumultu meticulosus animique deiectus $^{147}$ kennenlernt, ist Daia erst in seiner Todesszene von Angst erfüllt. Die Alliteration von angora animi bildet eine Parallele zur Alliteration in der Todesbeschreibung des Diokletian, der aestuante animi per dolorem ${ }^{148}$ den Tod findet. Während Diokletians animus so sehr ins Wogen gerate, dass er sterbe, finde bei Daia wieder eine Verkehrung der Beschreibung statt. Der animus des Daia wird „zusammengedrückt“, „,beklemmt“, geradezu massiv verkleinert und steht so im unmittelbaren Gegensatz zum sonst so ausschweifenden, extrovertierten, aktiv handelnden Daia.

Das Heilmittel für Daia sei von Gott verordnet. Der Rezipient erfährt, dass Gott als Initiator der nachfolgenden Handlung gesehen werden muss und Daia dazu anleite, den Tod zu suchen. Die Umsetzung dieses Befehls greift die charakterliche Schwäche der libido des Kaisers wieder auf: Er ergebe sich der Völlerei, bevor er sich mit Gift umbringen möchte:

146 Das Konstantinbild in De mortibus persecutorum ist nicht Inhalt dieser Arbeit, hier sei aber kurz angemerkt, dass Konstantin so, ohne an der Verfolgung teilgenommen zu haben, in den Handlungsstrang integriert wird.

147 Lact. mort. pers. 9,6 (Brandt/Laubmann 1897, 183,9-10).

148 Lact. mort. pers. 42,2 (Brandt/Laubmann 1897, 222,3-4). 


\begin{abstract}
Aber zuvor stopfte er sich mit Essen voll und soff sich mit Wein voll, wie es diejenigen zu tun pflegen, die glauben, dass sie es im letzten Moment tun, und so schöpfte er das Gift. Dessen Kraft konnte, durch den vollgestopften Magen zurückgewiesen, sich gegenwärtig nicht entfalten, sondern ist in eine schlimme Ermattung umgeschlagen ähnlich einer Krankheit, sodass er das Foltermittel länger in seinem gezwungenen Geist fühlte. Schon hatte das Gift in ihm zu wüten begonnen. ${ }^{149}$
\end{abstract}

Daia nimmt ein letztes Mahl ein, bevor er sich mit Gift zu töten versucht. Er kenne kein Maß und ist sich sicher, dass diese Mahlzeit seine letzte sein werde. Infercire und ingurgitare zeigen deutlich, dass es sich nicht um normales Essen handelt, sondern ein über das Nötige herausgehende Stopfen und Schütten. Durch eben dieses maßlose Fressen kann das Gift seine Wirkung nicht vollständig entfalten und wird stattdessen zum Foltermittel, zur cruciamenta, die Schmerzen und Leid im Akt des Sterbens über mehrere Tage verlängere. Eine weitere Konsequenz vor dem erwarteten Einsetzen des Todes ist der Wahnsinn, dem Daia anheimfällt. Dieser verleitet ihn dazu, Erde zu essen und seinen Kopf derartig gegen eine Wand zu schlagen, dass seine Augen aus ihren Höhlen springen. Die Darstellung des Laktanz greift die Motive der Selbstmordbeschreibungen des Sokrates ${ }^{150}$ und Senecas ${ }^{151}$ auf, die beide als weise Philosophen lieber den Schierlingsbecher zu sich nahmen, als unfrei, fremdbestimmt weiter zu leben. Diese beiden Philosophen sind invertierte Vorbilder für die Todesbeschreibung des Daia. Daia habe ebenfalls keinen Ausweg aus einer bedrohlichen Situation. Die Inversion wird deutlich bei der Lebensführung, die Sokrates, Seneca und Daia in diese Situation gebracht haben. Die Philosophen haben ein vorbildliches Leben geführt, sich um das Wohl des Staates bemüht und schließlich gegen einen Tyrannen aufgelehnt. Den Freitod wählen sie, um sich vor ungerechter Strafe zu schützen.

Maximinus Daia ist selbst der Tyrann, der im Verlauf seines Lebens Unrecht getan habe und sich mit dem Freitod einer gerechten Strafe entziehen wolle. Wie schon in der Charakterisierung des Daia herausgearbeitet wurde, karikiert der Kaiser den stereotypischen Epikureer, der sein Leben nur unter Genussaspekten betrachtet und keine Mäßigung kenne. Ebenso sehe er den Tod als einzigen Ausweg aus einem Leben, das keinen Genuss mehr verspricht, sondern Leid androhe. Die beiden Philosophen sind in ihrer Stunde des Todes ruhig und verlassen freiwillig das Leben, wohingegen

149 Sed prius cibo se infersit ac vino ingurgitavit, ut solent ii qui hoc ultimo se facere arbitrantur, et sic hausit venenum. cuius vis referto stomacho repercussa valere non potuit in praesens, sed in languorem malum versum est pestilentiae similem, ut diutius protracto spiritu cruciamenta sentiret. iam saevire in eum coeperat virus. Lact. mort. pers. 49,3-4 (Brandt/Laubmann 1897, 234,5-10).

150 Vgl. Plat. Phaid. 117a-118a.

151 Vgl. Tac. ann. 15,60,2-65. Vgl. Brinkmann (2002). Zahlreiche Gelehrte haben sich mit Senecas Tod bei Tacitus befaßt. Verwiesen sei hier lediglich auf die jüngeren Arbeiten: Billerbeck (1991), 2765; Schmal (2008), bes. 116-120. Miriam Griffin zeigt auf, dass „Seneca’s death was a re-enactment of the death of Socrates for which Plato, in his dialogue the Phaedo, had provided the script“ Griffin (1986), 66. 
der Tetrarch wie ein in die Enge gedrängtes Tier zu diesem Ausweg greife und sich in höchster Agitation befinde:

Als durch dessen Gewalt seine Eingeweide rasten, wurde er fortgerissen vom unaushaltbaren Schmerz bis zur Raserei des Geistes, so sehr, dass er über vier Tage hinweg von Wahnsinn angestachelt mit den Händen geschöpfte Erde essen wollte. Schließlich nach vielen schweren Foltern, als er seinen Kopf gegen die Wand schlug, sprangen seine Augen aus den Augenhöhlen. ${ }^{152}$

Die Einnahme des Gifts treibt Daia in den Wahnsinn ${ }^{153}$. Unter enormen Schmerzen in den Eingeweiden versuche er Erde zu essen. Als der Wahn sich weiter steigert, schlage er seinen Kopf gegen die Wand, bis die Augen herausspringen, um als Blinder Gott zu sehen. Er bitte um Gnade und sterbe schließlich. Laktanz verwendet den Begriff dolor auch für die Todesqualen des Diokletian, der durch den Schmerz in so heftige Gefühlsregungen versetzt wird, dass er letztlich stirbt. Daia werde durch dolor nicht nur von Gram und Kummer ergriffen, sondern verliere regelrecht den Verstand. Neben einer Fülle an Begriffen, die zum Wortfeld „Wahnsinn“ gehören (furere, dolor, rabies, insania) fällt die Verwendung von rabies ins Auge. Zumeist findet rabies im medizinischen Kontext Verwendung, kann hier jedoch synonym zu insania verstanden werden ${ }^{154}$ und scheint hier keine Anspielung auf die bestia-Motivik des Galerius ${ }^{155} \mathrm{zu}$ bieten. Vielmehr steht die allumfassende Vielschichtigkeit der Verrücktheit im Vordergrund, die sich auch in der Blindheit des Daia widerspiegelt: Er sei orientierungslos und könne sich in seiner Umwelt nicht mehr zurechtfinden. Der Sehverlust ist bei Daia unmittelbare Auswirkung seines von Gott initiierten Wahnsinns, der ihn dazu veranlasse, sich selbst Leid zuzufügen. ${ }^{156}$ Neben der Blindheit als Wahnsinnssymptom und der Inversion des „Blindseins für Gott“157 greift Laktanz auf die Charakterbeschreibung des Maximianus zurück. ${ }^{158}$ Dieser habe den Senat geblendet, um seine Gier zu stillen und dabei trotz seiner Sehkraft das rechte Verhalten aus den Augen verloren. Nun sei es gerade die Blindheit, die durch den Wahn hervorgerufen wird, die ihn zur Gotteserkenntnis befähige:

Dann endlich begann er, nachdem er die Sehkraft verloren hatte, Gott zu sehen, der mit weiß gekleideten Dienern über ihn richtete. Er rief also aus wie diejenigen, die gefoltert werden, es zu

152 Cuius vi cum praecordia eius furerent, insustentabili dolore usque ad rabiem mentis elatus est, adeo ut per dies quattuor insania percitus haustam manibus terram velut esuriens devoraret. deinde post multos gravesque cruciatus cum caput suum parietibus infligeret, exilierunt oculi eius de caveis. Lact. mort. pers. 49,4-5 (Brandt/Laubmann 1897, 234,10-15).

153 Vgl. Ausführungen zum Wahnsinn auf Seite 50, Anm. 30 in dieser Arbeit.

154 Ähnlich Sittig (2018), 75.

155 Zum bestia-Begriff siehe in dieser Arbeit Seite 84.

156 Dieses Motiv findet sich auch bei Oedipus (Sen. Oed.960 - 967), Io (Ov. Met. 1,724-733) und Orest (Eur. El.), die durch ihre Blindheit rastlos werden und ihre seelische Disposition durch lokale Unsicherheit zum Ausdruck bringen. Vgl. hierzu Sittig (2018), 77.

157 Vergleiche beispielsweise Röm 3,18.

158 Vergleiche hierzu Seite 142 in dieser Arbeit. 
tun pflegen, und er sagte, dass nicht er, sondern andere es getan hätten. Dann bekannte er sich, gezwungen von den Qualen, schließlich zu Christus, diesen um Gnade anflehend und bittend, dass er sich seiner erbarmen möge. So hauchte er zwischen den Seufzern, die er, als ob er verbrannt werde, herausbrachte, den schädlichen Geist in der verabscheuungswürdigen Todesart aus. ${ }^{159}$

Als er gerichtet werde, weise er jegliche Schuld von sich und bekenne sich zu Christus. Die Vision des Daia kann mit den Träumen Licinius' und Konstantins' verglichen werden: In einer Schlüsselszene des Werkes initiiert Gott aktiv die Kommunikation zu einem Menschen. Während Licinius und Konstantin den Weg zum Sieg über ihre Widersacher gezeigt bekommen, sehe Daia die Konsequenzen seines Handelns. Noch während der Vision versuche der Kaiser die Schuld von sich zu weisen und seinen Mitregenten die Verantwortung zu übertragen, gestehe jedoch anschließend. Einerseits kann fateri rückbezüglich gelesen werden. Dann gesteht Daia seine Taten, die er unmittelbar vorher noch geleugnet hat, andererseits kann fateri Christus als Objekt nach sich ziehen, was bedeutet, dass er sich zu Christus bekennt. Der Christenverfolger suche nun bei Christus Gnade und Rettung vor seinem Leid. Als er sich Gottes bewusst werde, empfinde er Schmerzen, die denen gleichkommen, die gegen die Christen verhängt worden sind. Das Bekenntnis der Märtyrer, die im Werk durch Feuer zu Tode kamen, wird im Tyrannen gespiegelt: Erkennen die Märtyrer Gott und müssen deshalb Feuerqualen erleiden, erleide der Kaiser Qualen wie beim Verbrennen, um anschließend Gott zu erkennen. Es wird kein Gnadenakt Christi geschildert, Daia hauche seinen nocens spiritus aus. Der Tod wird als detestabilis bezeichnet, also vom philosophischen Ideal weit entfernt. Laktanz unterstreicht so die enge Verbindung von Charakter, Taten und Todesart des Tyrannen.

Während der Giftmord in Anlehnung an Sokrates und Seneca gelegentlich als „Philosophenselbstmord“ charakterisiert wird, ${ }^{160}$ teilt Laktanz ganz genau mit, welche Interpretation der Todesart er vom Rezipienten erwartet: Daia begeht einen verabscheuungswürdigen Tod. Im Vergleich zur Flucht des Tetrarchen vor Licinius ist die Todesszene ausführlich ausgestaltet. Die Imperfekta überwiegen im deutlichen Gegensatz zur partizipgedrängten Raffung der Flucht. Das Leid, die Qualen und schließlich das Bekenntnis werden literarisch in die Länge gezogen. ${ }^{161}$

159 Tunc demum, amisso visu, deum videre coepit candidatis ministris de se iudicantem. exclamabat ergo sicut ii qui torquentur solent, et non se, sed alios fecisse dicebat. deinde quasi tormentis adactus fatebatur Christum subinde deprecans et implorans, ut suimet misereretur. sic inter gemitus quos tamquam cremaretur edebat, nocentem spiritum detestabili genere mortis efflavit. Lact. mort. pers. 49,5-7 (Brandt/Laubmann 1897, 234,15-21).

160 Vgl. Plat. Phaid. 117a-118a; Tac. ann. 15,60,2-65;

161 Vgl. hierzu auch Friedrich (1973). Friedrich bietet mehrere antike Beispiele, die die Qualen der Tyrannen literarisch deutlich in die Länge ziehen. Besonders Herodot sei für dieses Vorgehen bekannt. Vgl. Arand (2002), 209-213. Tobias Arand fasst zusammen: ,... ist die Position der christlichen Autoren eindeutig. Hier dient der Suizid eindeutig als krönende Darstellung eines verpfuschten Lebens“. (211) Zudem verweist er darauf, dass die Überlieferung anderer Autoren mit Ausnahme des Anonymus der 


\subsubsection{Zusammenfassung}

Laktanz zeigt, dass die Niederlage des Tetrarchen endgültig und verdient war. Es scheint passend, im Wahnsinn des Kaisers und seinem anschließenden Selbstmord auch eine Art Indikator für die Umwelt zu vermuten. Wie bereits an anderer Stelle gezeigt, ${ }^{162}$ wurde der Selbstmord im Kontext einer Anklage häufig als Schuldeingeständnis verstanden. Ebenso lässt sich auch der Wahnsinn, der allseits bekannt entweder die personifizierten Gewissensbisse oder eine Strafe Gottes darstellt, deuten: „Indem der Kaiser wahnsinnig wird, legt er ein Geständnis über seine Untaten ab und ist letztlich eher als Verbrecher denn als Kranker überführt" ${ }^{\text {163 }}$

\subsection{Zusammenfassung}

Die Christenverfolger finden ihr Ende auf recht unterschiedliche Arten, es lassen sich dennoch vier übereinstimmende Grundelemente erkennen. (1) Die Todesszenen sind alle gekennzeichnet von Schmerzen und Leid, das die Tyrannen erfahren. (2) Alle Tetrarchen sind an ihrem Untergang beteiligt und Laktanz unterstreicht die Eigenverantwortlichkeit im Kontext ihres Dahinscheidens. (3) Die Todesart ist immer dem Leben und den Vergehen angepasst. (4) Gleichzeitig macht er deutlich, dass ihr Leiden und letztlich ihr Tod gottgewollt und ausgelöst ist. Dies geschieht oft nur durch die Kontextualisierung im Werk.

1. Diokletian stirbt an inedia, ausgelöst durch die Trauer, die die Damnatio Memoriae des Konstantin an Maximianus in ihm auslöst. Die Stunden vor seinem Tod werden detailliert beschrieben und Laktanz unterstreicht, dass Diokletian vor dolor wahnsinnig wird und stirbt. Maximianus wird beim Versuch Konstantin zu töten ertappt und sukzessive in eine Frau verwandelt, bis er schließlich durch die selbstgewählte Todesart des Erhängens einen „grässlichen“ Tod stirbt. Galerius leidet unter einer langen Krankheit, die ihn von Innen heraus verzehrt, um dann trotz seines Edikts, das die Christenverfolgung aufhebt, und seines Bekenntnisses zu Gott qualvoll zu sterben. Der grausamste Tyrann löst sich körperlich auf und büßt geradezu seine Existenz ein. Daia schließlich trinkt Gift, um sich vor den Konsequenzen seiner Niederlage gegen Licinius zu retten. Durch seine Völlerei werden die Qualen des Gifts

Epitome de Caesaribus den Tod Daias als Selbstmord wiedergibt. Arand führt dies darauf zurück, dass die „damit [dem Selbstmord] verbundenen Wertungskategorien“ außer Mode gekommen seien und somit „auch nicht mehr als Gegenstand der literarisch codierten Diskussion über Herrscher- oder Lebenstugenden dienen“ (212). Diese Vermutung scheint nur bedingt zu greifen. Laktanz orientiert sich zumeist ja gerade an älteren Topoi, um seine Aussagen in eine lange Tradition von Argumentationen einzuflechten wie auch Arand an konstatiert (213). Vgl. hierzu die Ausführungen zur Gattung in dieser Untersuchung.

162 Zum Suizid in der Antike siehe Seite 186, Anm. 14 Hofmann (2007).

163 Sittig (2018), 85. 
in die Länge gezogen und er mit Wahnsinn geschlagen. Er reißt sich die Augen aus, was ihn schließlich dazu befähigt, Gott zu erkennen. Schließlich wirkt das Gift doch.

2. Die Tyrannen tragen die Schuld an ihrem Leid selbst. Wie bereits in den vorangehenden Kapiteln gezeigt werden konnte, gibt Laktanz gerade Galerius, dem einzigen, der nicht durch Selbstmord stirbt, den größten Anteil der Schuld an den Christenverfolgungen. Galerius ist derjenige, der für den Beginn der Christenverfolgungen verantwortlich ist, der Diokletian unter Vorspiegelung falscher Tatsachen und durch ein Attentat überhaupt erst zu drastischen Maßnahmen bewegt. Er ist der „schlimmste“ aller Kaiser. Dass Galerius als einzigem ein Tod zuteilwird, der nicht als Selbstmord charakterisiert werden kann, liegt meines Erachtens daran, dass ihm ein noch schlimmerer Tod widerfährt: Der Befall durch Würmer. Hier lässt sich auch die Gewichtung der Quellennutzung des Laktanz ansatzweise erkennen. Die Strafbeschreibung, die unmittelbar parallel zu einer biblischen Strafbeschreibung gestaltet ist, ist die grausamste, umfangreichste und für den schlimmsten Kaiser angemessene Todesbeschreibung. Während die Suizidbeschreibungen der Kaiser Diokletian, Maximianus und Maximinus Daia grausam und den Taten der Herrscher angemessen sind, sind sie trotzdem nicht die grausamste Strafe, die Gott gegen seine Verfolger verhängt hat. Die Selbsttötung im Kontext innerrömischer Machtkämpfe ist ein häufiges literarisches Mittel, um die Überlegenheit des Siegers über die Usurpatoren zu konsolidieren. ${ }^{164}$

Auch in De mortibus persecutorum findet sich die Beschreibung von Suiziden als Ausdruck der Machtkonsolidierung. Explizit verbalisiert wird das Machtverhältnis beim befohlenen Selbstmord des Maximianus, bei dem Konstantin den Tod anordnet und Maximianus die Todesart wählt. Beim Selbstmord durch Gift des Maximinus Daia ist der Zusammenhang zwischen dem pudor des Daia und dem Sieg des Licinius evident. Der Selbstmord ist das Zeichen dafür, dass Daia seine Niederlage anerkennt im letzten Moment seines Todes erkennt er auch den Sieg Gottes an. Implizit ist der Wandel der Machtkonstruktion zumindest für Diokletian nachzuweisen: Der Ex-Augustus stirbt ebenfalls aus pudor. Anders als bei Daia ist er aber nicht explizit Opfer einer Niederlage, sondern von der Niederlage des Maximianus „mit-“betroffen. Er muss sich in seiner Position jedoch der Verfügungsgewalt des Konstantin unterwerfen, der Errungenschaften des Diokletian irreversibel zerstört. In all diesen Fällen ist die Überlegenheit Konstantins oder Licinius', die sich in der Verfügungsgewalt über Leben und Tod auszeichnet, evident und muss von den Tyrannen akzeptiert werden. Gleichermaßen könnte die Selbsttötung des Daia auch als Aufbegehren gewertet werden, da er sich einer möglicherweise noch schlimmeren Strafe entzieht. Da sie allerdings die einzige von Gott wörtlich befohlene Selbsttötung ist, wird auch dieses Mittel des Widerstandes ausgeschlossen.

Als weitere Sichtweise der Selbsttötung steht die Frage nach dem philosophischen Mehrwert und der Bewertung eines solchen Todes im soziokulturellen Kontext des 
Werkes und durch den Autor selbst. Das Hauptcharakteristikum der durch Gift dahinscheidenden Beispiele aus der Geschichte ist die Ruhe und Bedachtheit der Philosophen. ${ }^{165}$ Sie gehen ausgeglichen und mit ruhigem Gemüt in den Tod, unabhängig davon, aus welchen Gründen sie diesen wählen. ${ }^{166}$ Diese durchdachte, ruhige Darstellung des Selbstmordes steht in unmittelbarem Kontrast zu den Szenen, die Laktanz beschreibt. Diokletian und Daia werden von starken Gefühlsregungen ergriffen, die sie letztlich in den Tod treiben. Maximianus werden keine emotionalen Regungen zugeschrieben, er wird jedoch durch eine Szene zum Tode verurteilt, die alles andere als affektlos ist.

3. Auf verschiedene Weise verknüpft Laktanz die Todesszenen der Verfolger mit ihrem Charakter und ihren tyrannischen Taten. Diokletian, der hauptsächlich als ängstlich und auf seine Außenwirksamkeit bedacht dargestellt wird, erfährt die Vernichtung seiner Monumente noch zu Lebzeiten. Diese öffentliche Verunglimpfung seiner Person, wenn auch nicht in erster Linie gegen ihn gerichtet, treibt ihn in Kummer und den Tod durch Verhungern. Die Todesart ist nicht als schändlich oder erniedrigend gekennzeichnet und in der Antike mit einem großen Geltungsbedürfnis des Dahinscheidenden verknüpft. Diokletian war charakterlich nicht der schlimmste Tyrann, hat aber aus seiner Angst heraus die Christenverfolgung von Galerius vorantreiben lassen. In jeder Szene, in der eine Entscheidung gegen Gott gefallen ist, war Diokletian von Angst und Unsicherheit geleitet, die ihn schließlich auch in den Tod treiben.

Maximianus wird im Verlauf des Werkes als hypermaskuliner, seinen Begierden erlegener Vergewaltiger dargestellt, der die soziale Stellung seiner Opfer und den mos maiorum nicht achte. Ihm wiederfährt die völlige Invertierung seiner Machtposition, indem er zur Frau verwandelt in einer sozial geächteten Todesart stirbt. Galerius wird als grausamster und blutrünstigster Tyrann beschrieben, der seinen Genuss aus dem vornehmlich körperlichen Leid der Untertanen ziehe und Angst und Schrecken verbreite, wie schon durch sein Aussehen deutlich wird. Deshalb stirbt Galerius auf die grausamste und langwierigste Art. Der Würmerbefall zeichnet sich neben Grausamkeit und Dauer auch durch die völlige Zerstörung seines Körpers aus. Während er als massiger Fleischberg in das Werk eingeführt wird, stirbt er als zerflossener, ausgemergelter Schatten seiner selbst.

Bei Daia steht seine Habgier im Vordergrund des Werkes. Er häuft alle möglichen Güter an, gibt sich seinen Gelüsten hin und fungiert als Anti-Philosoph. Besonders seine Völlerei wird ihm im Tod zum Verhängnis: Aus Habgier und Machtlust getrieben versucht der Tyrann, Licinius zu besiegen und scheitert, weil dieser die Unterstützung Gottes vor der Schlacht bekommt, während Daia selbst Jupiter um Hilfe anruft. Seine fortwährende Verfolgung endet damit, dass er als einziger der Tyrannen den Richtspruch Gottes zu Lebzeiten über sich ergehen sieht.

165 Vgl. Plat. Phaid. 117a-118a; Tac. ann. 15,60,2-65.

166 Vgl. Griffin (1986), 66. 
4. Die Beteiligung Gottes an den Toden der Tyrannen ist bei Laktanz explizit, im Verlauf der Todesbeschreibung aber nur diffizil dargestellt. Diokletians Vorgehen gegen die Christen hat ihn zum Untergang gebracht. In nur einem einzigen Satz verknüpft Laktanz Diokletian mit seinen Taten und der Strafe Gottes:

Nachdem er zwanzig Jahre lang der glücklichste Kaiser gewesen war, ist er nun von Gott zur Niedrigkeit herabgestürzt und durch seine Untaten zerstampft und zum Hass auf das Leben herabgeleitet worden und schließlich vor Hunger und Beklemmung gestorben. ${ }^{167}$

Nach dem Tod Maximianus' teilt Laktanz dem Leser in wieder einem einzigen Satz mit, dass Gott für das Schicksal des Tetrarchen verantwortlich war:

Von ihm weg richtete Gott, der Rächer seiner Religion und seines Volkes, die Augen auf den anderen Maximianus, den Urheber der gottlosen Verfolgung, damit er an ihm auch ein Exempel seiner Macht statuierte. ${ }^{168}$

Der Rezipient erfährt nach dem Tod des Maximianus gleichzeitig, dass Gott für dessen Tod verantwortlich ist und für die folgenden Geschehnisse ebenfalls als lenkende Instanz verstanden werden muss. Der andere Maximianus, Galerius, wird im darauffolgenden Abschnitt von einer schweren Krankheit befallen, deren Auslöser offensichtlich Gott ist. Daia, der als letzter Tyrann stirbt, bekommt von Gott den Befehl zum Selbstmord:

Als er dort schon von Land und Meer aus bedrängt wurde und keine Zuflucht mehr hoffen konnte, floh er sich aus Enge des Herzens und Furcht in den Tod wie in ein Heilmittel der Übel, die ein Gott in dessen Haupt eingegeben habe. ${ }^{169}$

Bei jedem der Tyrannen lässt sich also die Urheberschaft Gottes für die Gewalt, die sie erleiden, nachweisen. Es ist also nun schlüssig, Gott als Akteur in den Blick zu nehmen, nachdem die Objekte seiner Handlungen betrachtet wurden.

167 Ita viginti annorum felicissimus imperator ad humilem vitam deiectus a deo et proculatus iniuriis atque in odium vitae deductus postremo fame atque angore confectus est. Lact. mort. pers. 42,3 (Brandt/ Laubmann 1897, 222,6-8) und in dieser Arbeit 187.

$168 \mathrm{Ab}$ hoc deus religionis ac populi sui vindex oculos ad Maximianum alterum transtulit, nefandae persecutionis auctorem, ut in eo et iam suae vim maiestatis ostenderet. Lact. mort. pers. 31,1 (Brandt/ Laubmann 1897, 208,6-8).

169 Ibi cum iam terra marique premeretur nec ullum speraret refugium, angore animi ac metu confugit ad mortem quasi ad remedium malorum, quae deus in caput eius ingessit. Lact. mort. pers. 49,2 (Brandt) Laubmann 1897, 234,2-5). 